\title{
ipen
}

Autarquia associada à Universidade de São Paulo

\section{PROPOSTA DE PROCEDIMENTOS PARA EVITAR ERROS EM RADIOTERAPIA BASEADOS EM LIÇÕES APRENDIDAS DE EXPOSIÇÕES ACIDENTAIS.}

\author{
GISELLE OLIVEIRA VIEIRA BUENO
}

Dissertação apresentada como parte dos requisitos para obtenção do Grau de Mestre em Ciências na Área de Tecnologia Nuclear - Aplicações.

Orientadora:

Dra. Laura Natal Rodrigues 
INSTITUTO DE PESQUISAS ENERGÉTICAS E NUCLEARES Autarquia associada à Universidade de São Paulo

PROPOSTA DE PROCEDIMENTOS PARA EVITAR ERROS EM RADIOTERAPIA BASEADOS EM LIÇÕES APRENDIDAS DE EXPOSIÇÕES ACIDENTAIS

GISELLE OLIVEIRA VIEIRA BUENO

Dissertação apresentada como parte dos requisitos para obtenção do Grau de Mestre em Ciências na Área de Tecnologia Nuclear - Aplicações.

Orientadora:

Dra. Laura Natal Rodrigues 
Dedico este trabalho às pessoas importantes de minha vida. Meus pais Odonias e Regina, aos meus padrinhos João Batista e Dalva, ao meu esposo Dênio e aos meus filhos Paulo e 


\section{AGRADECIMENTOS}

A Deus e Nossa Senhora Auxiliadora, por todos os momentos maravilhosos que me proporcionam de luz e superação.

À Dra. Laura Natal Rodrigues, minha orientadora, pela orientação dedicada, pelo inestimável apoio e incentivo, conhecimento transmitido, pela compreensão, atenção e paciência no decorrer da realização deste trabalho.

A todos da Divisão de Ensino e da Comissão de Pós-Graduação do IPEN, por todo o auxílio.

Ao Instituto de Pesquisas Energéticas e Nucleares (IPEN), pela infra-estrutura e por possibilitar o desenvolvimento desse trabalho.

À Dra. Linda Caldas, ao Dr. Orlando Rodrigues, ao Dr. Alberto Todo pela contribuição dada a este trabalho.

Ao Departamento de Radioterapia e Física Médica do Hospital das Clinicas (HCFMUSP) e toda equipe de funcionários pela oportunidade de aprendizagem.

Aos físicos: Anderson Pássaro, Camila Pessoa Sales, Cristiane Barsanelli pela atenção, incentivo e por estarem sempre disponíveis para esclarecer minhas dúvidas.

Aos físicos, Laura Furnari, Maria Esmeralda Poli, Gisela Menegussi, Marco Antonio da Silva, Rodrigo Rubo, pelo carinho, atenção e a oportunidade de acompanhar os procedimentos da rotina hospitalar.

À Patrícia M., Priscilla S., André V., Maíra G., Maíra T., Ana Carolina B., pelo apoio desde o início do curso.

À Doralice Xavier pela amizade, carinho e apoio durante os momentos difíceis.

Ao Calil F.do departamento de informática pela atenção e conhecimento transmitido sobre banco de dados.

A Todos que de alguma forma contribuíram para a realização deste trabalho meus mais 


\title{
PROPOSTA DE PROCEDIMENTOS PARA EVITAR ERROS EM RADIOTERAPIA BASEADOS EM LIÇÕES APRENDIDAS DE EXPOSIÇÕES ACIDENTAIS.
}

\author{
Giselle Oliveira Vieira Bueno
}

\begin{abstract}
RESUMO
A fim de propor alguns procedimentos para evitar erros em radioterapia baseados em lições aprendidas de exposições acidentais e de acordo com informações contidas em relatórios internacionais elaborados pela International Atomic Energy Agency (IAEA) e do banco de dados disponibilizado pelo grupo europeu Radiation Oncology Safety Information System (ROSIS) sobre os eventos, realizou-se uma investigação dos erros ocorridos. Para a avaliação dos incidentes foi criado um banco de dados baseado no ROSIS e acrescentado mais um parâmetro "tipo de erro". Todos os dados armazenados possibilitaram a avaliação dos 839 incidentes em termos de freqüência do tipo de erro, o processo de detecção, o número de pacientes atingidos e o grau de severidade. Dos 50 tipos de erros encontrados, o tipo de erro que apresentou maior freqüência foi "coordenadas de tratamento incorreto", confirmado com os dados da literatura e correspondendo a $28,96 \%$ do total dos incidentes. Os resultados mostraram que $44,44 \%$ são descobertos no momento do tratamento e que o processo de verificação da ficha ou revisão clínica do paciente é uma verificação mais segura e ocorrida em $43,33 \%$ dos eventos pesquisados. Os resultados indicaram que mais de $50 \%$ dos incidentes o grau de severidade é nulo e em aproximadamente $62 \%$ um paciente é afetado durante a realização do tratamento de radioterapia. Este trabalho mostrou que analisar o banco de dados segundo a metodologia proposta por Klein et al.; por Reason, e Dunscombe et al. é interessante inserir características mais detalhadas no banco de dados tais como: o número de frações por paciente afetado, número de campos de tratamento por fração que foi afetado, desvio da dose prescrita e desvio do volume prescrito em todos os eventos cadastrados. Existem várias causas que podem conduzir a erros quando pacientes são submetidos à irradiação em radioterapia. Algumas medidas podem ser tomadas para que esses erros não ocorram tais como: realizar dosimetria in vivo "off-axis" com diodo para reduzir o uso da direção incorreta da cunha; utilizar valores da distância vertical com indicador de distância óptica (SSD) para evitar erro de distância de tratamento; empregar o sistema de transferência de dados DICOMRT entre as estações de trabalho do planejamento de tratamento e a simulação, aumentando a eficiência e acurácia no tratamento; considerar a redundância nas verificações dos cálculos realizados por computador ou manualmente; empregar um sistema computadorizado de registro e verificação do tratamento; evitando-se erros nos tratamentos diários devidos à seleção incorreta dos parâmetros de tratamento; implantar um cartão magnético de identificação do paciente com foto, número de identificação, nome da instituição, nome do departamento, a data da primeira emissão e médico responsável para se evitar erros de identificação e registro e poderá ser utilizado em todo o processo do tratamento. Desta forma, esses procedimentos podem evitar mais incidentes em radioterapia e enfatizar a cultura de segurança.
\end{abstract}




\title{
PROPOSAL OF PROCEDURES TO PREVENT ERRORS IN RADIOTHERAPY BASED IN LEARNED LESSONS OF ACCIDENTAL EXPOSITIONS.
}

\author{
Giselle Oliveira Vieira Bueno
}

\begin{abstract}
In order to consider some procedures to prevent errors in radiotherapy based in learned lessons of accidental expositions and in accordance with information contained in international reports elaborated by International Atomic Energy Agency (IAEA) and of the data base availability by the European group Radiation Oncology Safety Information System (ROSIS) on the events, a research of the occurred errors was performed. For the evaluation of the incidents a data base based in the ROSIS and added plus a parameter was created "type of error". All the stored data make possible the evaluation of the 839 incidents in terms of frequency of the type of error, the process of detention, the number of reached patients and the degree of severity. Of the 50 types of found errors, the type of error more frequently was "incorrect treatment coordinate ", confirmed with the data of literature and representing $28,96 \%$ of the total of the incidents. The results showed $44,44 \%$ are discovered at the moment of the treatment and that the process of verification of the fiche or clinical revision of the patient is a verification more occurred insurance and in $43,33 \%$ of the searched events. The results indicated that more than $50 \%$ of the incidents the severity degree are void and approximately $62 \%$ a patient are affected during the accomplishment of the radiotherapy. This work showed that to analyze the data base according to methodology proposal for Klein et al.; for Reason, and Dunscombe et al. is interesting to insert more characteristic detailed in the data base such as: the number of fractions for affected patient, number of fields of treatment for fraction that was affected, shunting line of the prescribed dose and shunting line of the volume prescribed in all the registered in cadastre events. Some causes exist that can lead the errors when patient they are submitted to the radiotherapy. Some measures can be taken so that these errors do not occur as: to carry through dosimetry in vivo "off-axis" with diode to reduce the use of the incorrect direction of the wedge; to use values of the vertical distance with pointer of optic distance (SSD) to prevent error of distance of treatment; to use the system of transference of data DICOM-RT between the stations of work of the planning of treatment and the simulation, being increased the efficiency and accuracy in the treatment; to manually consider the redundancy in the verifications of the calculations carried through for computer or; to use a computerized system of register and verification of the treatment; preventing errors in the which had daily treatments to the incorrect election of the treatment parameters; to implant a magnetic card of identification of the patient with photo, identification number, name of the institution, name of the department, the date of the first emission and responsible doctor to prevent errors of identification and register and could all be used in the process of the treatment. Of this form, these procedures can prevent incident more in radiotherapy and increase the security of the patients.
\end{abstract}




\section{SUMÁRIO}

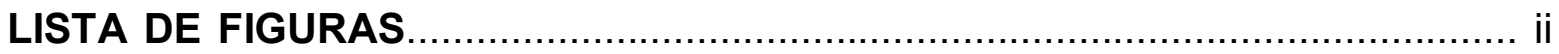

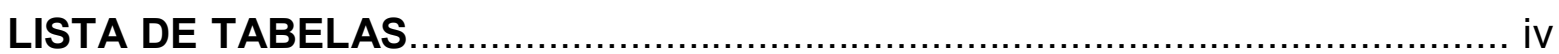

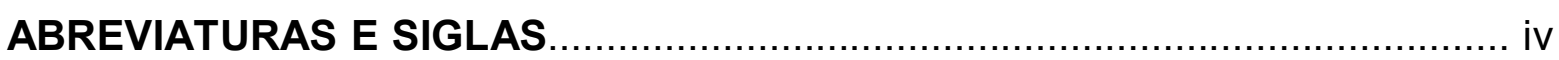

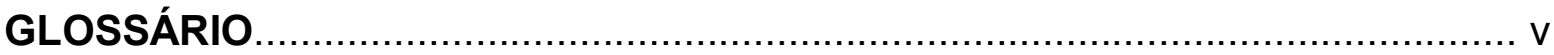

\section{CAPÍTULO 1}

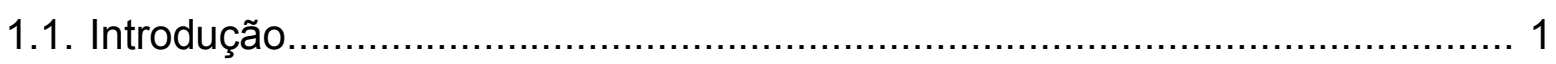

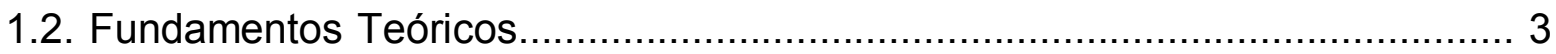

1.2.1. Garantia de Qualidade em Radioterapia............................................... 3

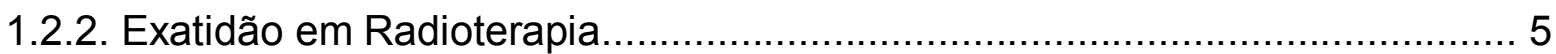

1.2.3. Grau de Severidade........................................................................ 7

1.2.4. Processo de Planejamento e Entrega de Dose do Tratamento...................... 8

1.2.5. Acidentes e Incidentes em Radioterapia......................................... 12

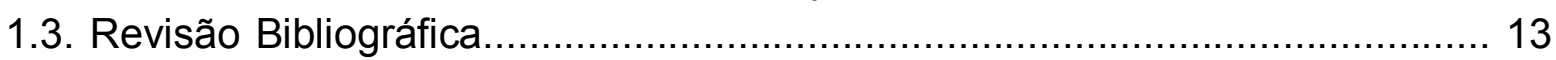

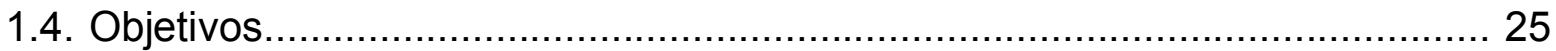

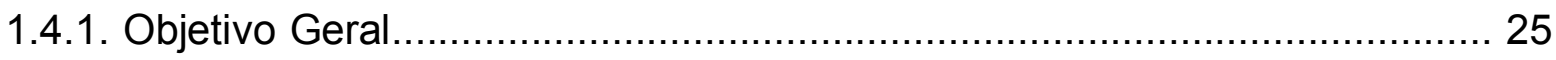

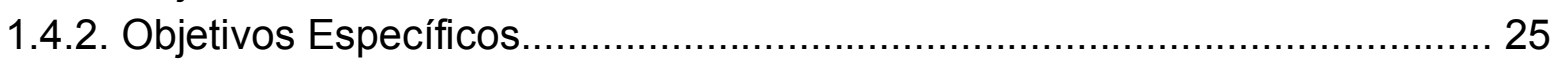

\section{CAPÍTULO 2}

2.1. Materiais e Métodos..................................................................... 26

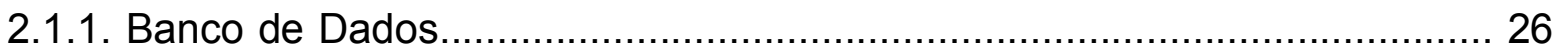

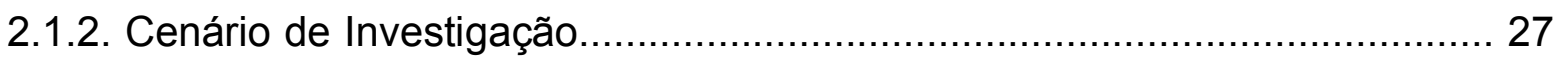

\section{CAPÍTULO 3}

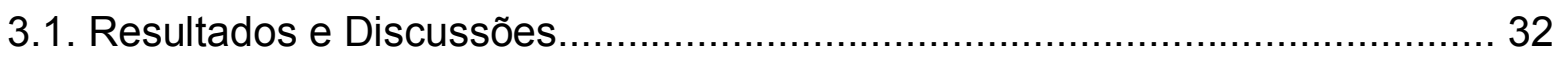

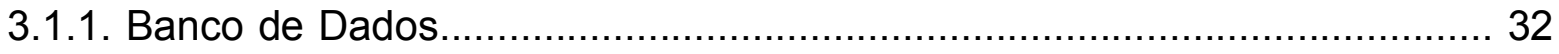

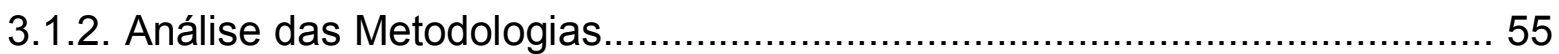

3.1.3. Medidas de Prevenção do Erro...................................................... 60

\section{CAPÍTULO 4}

4.1. Conclusões 


\section{LISTA DE FIGURAS}

FIGURA 1.1. Probabilidade de controle do tumor - Tumour Control Probability (TCP) e probabilidade de complicação no tecido normal - Normal Tissue Complications Probability (NTCP) em função da dose de radiação, em um caso hipotético.

FIGURA 1.2. Tomógrafo computadorizado utilizado para simulação do tratamento em radioterapia.

FIGURA 1.3. Localização das marcas de referência no paciente no simulador.

FIGURA 1.4. Forma esquemática do processo em "Cadeia" que consiste em várias etapas no tratamento de radioterapia após a prescrição médica.

FIGURA 1.5. Acelerador NEPTUN 10P do Białystok Oncology Centre com o cabeçote aberto quando medidas estavam sendo realizadas durante a missão da IAEA.

FIGURA 1.6. Localização geográfica do acidente ocorrido em Epinal, França apresentando os casos de vítimas levantadas até 10 de setembro de 2007 e divulgadas ao público. Disponível no site TV5 Monde.

FIGURA 3.1. Formulário do Banco de Dados referente ao primeiro evento cadastrado.

FIGURA 3.2. Formulário do Banco de Dados referente ao evento cadastrado de um acidente recente.

FIGURA 3.3. Gráfico da freqüência dos eventos cadastrados no Banco de Dados para os 50 tipos de erros identificados.

FIGURA 3.4. Gráfico da freqüência do processo de detecção para o tipo de erro "Coordenada de Tratamento Incorreta".

FIGURA 3.5. Gráfico da freqüência do processo de detecção para o tipo de erro "Dimensão do Campo Incorreta".

FIGURA 3.6. Gráfico da freqüência do processo de detecção para os tipos de erros "Cálculo Incorreto" e "Dose Incorreta".

FIGURA 3.7. Gráfico da freqüência do processo de detecção para todos os tipos de erros de todos os eventos cadastrados no Banco de Dados. 
FIGURA 3.8. Gráfico da freqüência do Grau de Severidade e No. de Pacientes Afetados para o tipo de erro "Coordenada de Tratamento Incorreta".

FIGURA 3.9. Gráfico da freqüência do Grau de Severidade e No. de Pacientes Afetados para o tipo de erro "Dose incorreta".

FIGURA 3.10. Gráfico da freqüência do Grau de Severidade e No. de Pacientes Afetados para o tipo de erro "Dose da Fração de Tratamento Incorreta".

FIGURA 3.11. Gráfico da freqüência do Grau de Severidade e No. de Pacientes Afetados para o tipo de erro "Faltando a Cunha".

FIGURA 3.12. Gráfico da freqüência do Grau de Severidade para os erros classificados no banco de dados de todos os eventos cadastrados.

FIGURA 3.13. Gráfico da freqüência do No. de Pacientes Afetados para os erros classificados no banco de dados de todos os eventos cadastrados.

FIGURA 3.14. Modelo "Queijo Suíço" aplicado por Reason ilustrando as diversas camadas (barreiras, defesas e proteções) indicando a trajetória do erro e conduzindo ao incidente.

FIGURA 3.15. Forma esquemática da taxonomia segundo Dunscombe et al. aplicada na análise dos incidentes em radioterapia. 


\section{LISTA DE TABELAS}

TABELA 1.1. Tipos de erros classificados de acordo com a freqüência, longevidade e impacto dosimétrico segundo Klein et al.

TABELA 3.1. Freqüência dos eventos cadastrados no Banco de Dados relacionados ao tipo de erro e processo de detecção como o CQ (Controle de Qualidade) do equipamento.

TABELA 3.2. Freqüência dos eventos correspondentes ao grau de severidade e No. de pacientes afetados para cada tipo de erro.

\section{ABREVIATURAS E SIGLAS ${ }^{1}$}

BEV - Beam's-eye view - Visão do feixe

BOC - Beatson Oncology Centre

CNEN - Comissão Nacional de Energia Nuclear

$\mathrm{CQ}$ - Controle de Qualidade

CT - Computed Tomography - Tomografia Computadorizada

DICOM-RT - Digital Imaging and Communications in Medicine-Radiotherapy

DRR - Digitally Reconstructed Radiograph - Radiografia reconstruída digitalmente EPID - Electronic Portal Imaging Device - Equipamento com imagem "portal" eletrônica

EUD - Equivalent Uniform Dose - Dose Uniforme Equivalente

GQ - Garantia de Qualidade

IAEA - International Atomic Energy Agency

IARC - International Agency for Research on Cancer

ICRU - International Commission on Radiation Units and Measurements

INCa - Instituto Nacional de Câncer

IPEM - Institute of Physics and Engineering in Medicine

IPEN - Instituto de Pesquisas Energéticas e Nucleares 
ISO - International Organization for Standardization

MLC - Multileaf Collimator - Colimador de Múltiplas Lâminas

NMR - Nuclear Magnetic Resonance - Ressonância Magnética Nuclear

NTCP - Normal Tissue Complications Probability - Probabilidade de Complicações no Tecido Normal

OAR - Organs at Risk - Órgão de Risco

PICR - Professional Information and Clinical Relations

PVI - Plano de Verificação do Isocentro

R\&V - Registro \& Verificação

ROSIS - Radiation Oncology Safety Information System

RPC - Radiological Physics Center

SSD - Source to Surface Distance - Distância foco-superfície

TBI - Total Body Irradiation - Irradiação de Corpo Inteiro

TCP - Tumour Control Probability - Probabilidade de Controle do Tumor

UM - Unidade Monitora

WHO - World Health Organization

\section{GLOSSÁRIO}

"Set-up" - posicionamento do paciente

Imagem "portal" - imagem obtida através de um filme radiográfico sensível

Cabeçote - componente do acelerador linear responsável pela geração de um feixe homogêneo e a produção de um campo controlado de irradiação

Colimador - componente delimitador do tamanho do campo máximo de irradiação 


\section{CAPÍTULO 1}

\subsection{Introdução}

A radiação ionizante foi empregada pela primeira vez em medicina por volta do século 19, após a descoberta dos raios-X. Nos últimos 100 anos, os tratamentos utilizando raios- $X$ vêm sendo aplicados cada vez mais na medicina não somente em diagnósticos, mas também em radioterapia. $O$ benefício evidente da administração correta dos procedimentos empregando radiação ionizante para pacientes propicia a difusão de sua utilização, embora os padrões de seu emprego variem significativamente ao redor do mundo. A radiação é utilizada de maneiras completamente diferentes em radioterapia, onde a intenção clínica é entregar níveis de dose em volumes alvos bem definidos para um tratamento eficiente no paciente. Em 2001, a Conferência Internacional de Málaga promovida pela International Atomic Energy Agency (IAEA) ${ }^{2}$ e colaboradores confirmaram que o principal modo de tratamento é a teleterapia, uma das modalidades de tratamento da radioterapia, com a possibilidade de utilizar energias de fótons e elétrons disponíveis em acelerador linear. Nos últimos 15 anos, o emprego crescente de aceleradores lineares, que fornecem feixes de fótons e elétrons de até $50 \mathrm{MeV}$, tem contribuído para o grande avanço nos tratamentos em radioterapia.

O uso médico de radiação é o único em que os pacientes são expostos intencionalmente à radiação. O objetivo na terapia de radiação é duplo: entrega de dose e distribuição de dose que seja a mais adequada para o controle do tumor, mas que também minimize complicações no tecido normal. Em aplicações terapêuticas, as doses são altas e um desvio da dose prescrita pode ter conseqüências severas ou até mesmo fatais. O sucesso ou a falha de um tratamento de radioterapia depende da dose depositada no volume alvo, e não deve variar mais que $5 \%$ da dose prescrita ${ }^{3}$. Por isso há uma grande necessidade de assegurar proteção adequada do paciente durante a aplicação da radiação e segurança na radioterapia para que as células do tecido normal sejam preservadas 
o máximo possível. Para realizar o tratamento de forma adequada é necessário que todo o pessoal envolvido seja apropriadamente treinado em suas tarefas, que o equipamento atenda às especificações nacionais e internacionais relevantes para o uso seguro da radiação, além do envolvimento da cultura de segurança nas atividades de rotina nos departamentos de radioterapia. Muitos profissionais devem interagir e trabalhar juntos nos cálculos e medidas dosimétricas, e assim podem-se evitar possíveis erros. Apesar de todos os cuidados que são tomados, muitos incidentes ou acidentes sérios ocorridos em radioterapia são relatados na literatura. Uma revisão dos acidentes e incidentes ocorridos em radioterapia demonstra que as falhas são verdadeiros erros humanos ${ }^{4}$.

Nos acidentes ocorridos em radioterapia os efeitos colaterais são usualmente menores e transientes e de maior freqüência; enquanto que complicações mais severas e de longo tempo são esperadas em menor freqüência. Acidentes resultando em doses abaixo das doses prescritas podem por em risco a probabilidade do controle do tumor. Esses acidentes são difíceis de serem descobertos e podem ser detectados após um longo período de tempo e assim envolver um grande número de pacientes. No caso de superexposições, nota-se uma rápida modificação celular, muitas vezes levando à necrose do tecido ${ }^{5}$. Para evitar esses erros de tratamento, ocasionando em doses não desejadas, são recomendados programas de garantia de qualidade específicos pelas organizações nacionais e internacionais.

Neste sentido é importante discutir os acidentes já ocorridos a fim de procurar aprender lições para evitá-los ${ }^{6}$. As lições podem ser observadas o tanto quanto possível dos acidentes, seguindo os padrões internacionais de segurança básica ${ }^{7}$. Se forem aprendidas lições também com as experiências dos outros, pode-se fazer um trabalho melhor de proteção aos pacientes. O grupo que abriu caminho nesse propósito foi o grupo europeu Radiation Oncology Safety Information System (ROSIS). ${ }^{8}$. O grupo iniciou seu trabalho em 2001, com a colaboração de Mary Coffey e Ola Holmberg, para explorar os incidentes em serviços de saúde, particularmente em radioterapia, observar seu impacto, métodos de prevenção, detecção e/ou correção e, como objetivo final, fornecer dados úteis e a devida compreensão a fim de minimizar os riscos de incidentes em radioterapia. 


\subsection{Fundamentos Teóricos}

\subsubsection{Garantia de Qualidade em Radioterapia}

O organismo World Health Organization (WHO) define e justifica Controle da Qualidade (CQ) em radioterapia por várias razões. Porém, o principal argumento para justificar um programa de Controle da Qualidade é que este é o método mais simples e eficaz de reduzir e prevenir acidentes ${ }^{9}$.

A garantia de qualidade (GQ) em radioterapia é definida como: "Todos os procedimentos que asseguram a consistência entre a prescrição clínica da dose e sua administração uniforme e exata ao paciente, com relação ao volume alvo, às limitações da dose ao tecido sadio, às exposições mínimas ao pessoal envolvido no trabalho e nas verificações das dosimetrias nos pacientes, para melhorar os resultados do tratamento e reduzir os acidentes nos centros de tratamento"10.

Um programa de $G Q$, para um centro de tratamento com radioterapia, consiste da monitoração sistemática de medidas e de procedimentos, visando à qualidade e ao cuidado apropriado ao paciente. Esse programa deve ser abrangente, incluindo os aspectos administrativos, clínicos, físicos e técnicos; logo, uma equipe multidisciplinar deve ser formada, com um representante de cada área, que definirá assim, critérios gerais ou padrões de qualidade que deverão ser seguidos pela instituição.

O controle de qualidade é definido como: "O processo regulatório através do qual o desempenho atual da qualidade é medido, comparado com padrões existentes" 11 . O controle de qualidade é uma parte da GQ e refere-se às técnicas operacionais e atividades empregadas.

Para realizar um programa de $G Q$, são realizados testes que têm como objetivo avaliar e medir o comportamento funcional dos equipamentos de teleterapia, os quais podem variar devido a defeitos eletrônicos e/ou falhas mecânicas. Portanto, as seguintes ações são necessárias: 
a) medidas de controle de qualidade (CQ), que ajudem a recuperar, manter e/ou melhorar a qualidade dos tratamentos;

b) monitoração sistemática, com o objetivo de garantir as características funcionais, tanto dos equipamentos de terapia quanto dos de medida.

Uma avaliação dos procedimentos clínicos em radioterapia indica a necessidade de um alto grau de exatidão para produzir o resultado desejado das taxas de controle do tumor tão altas quanto possível, mantendo as taxas de complicação em níveis aceitáveis. Os procedimentos de $\mathrm{GQ}$ em radioterapia podem ser caracterizados como:

- Redução de incertezas e erros em dosimetria, planejamento de tratamento, desempenho do equipamento, entrega do tratamento, etc., melhorando a dosimetria e a exatidão geométrica, e precisão da entrega de dose.

- Redução não somente da probabilidade de acidentes e ocorrência de erros, como também aumento da probabilidade de serem reconhecidos e retificados mais cedo, dessa forma reduzindo as conseqüências para o tratamento do paciente. Esse não é o caso somente de grandes acidentes, mas também de incidentes menores de maior probabilidade ${ }^{12}$.

- Possibilidade de uma intercomparação segura de resultados entre diferentes centros de tratamento em radioterapia, assegurando uma uniformidade maior, dosimetria precisa e entrega do tratamento. Isto é necessário para o processo clínico e também para compartilhar a experiência clínica em radioterapia e transferência de informações entre os centros.

- Tecnologia avançada e tratamentos mais complexos utilizados na radioterapia atual somente podem ser completamente explorados se aprovisionados com um alto nível de exatidão e consistência alcançada. 


\subsubsection{Exatidão em Radioterapia}

Várias recomendações, levando em conta a evidência dos dados clínicos, têm sido relatadas sobre a exatidão exigida na radioterapia. As imposições clínicas para exatidão são baseadas na evidência das curvas de dose-resposta para a probabilidade do controle do tumor - Tumour Control Probability (TCP) e a probabilidade de complicações no tecido normal - Normal Tissue Complications Probability (NTCP), em que são necessárias considerações cuidadosas nos tratamentos em radioterapia para uma prática adequada.

De acordo com o protocolo ICRU ${ }^{3}$ que revisou os dados sobre o TCP, recomenda uma incerteza limite de $5 \%$ na entrega de dose absorvida no volume alvo. Isto tem sido amplamente aplicado como um padrão, embora não estabelecido explicitamente.

Um exemplo simplificado dessa indicação é ilustrado em FIGURA 1.1, onde as curvas da TCP e da NTPC são apresentadas com relação à dose no volume alvo do planejamento. A probabilidade do controle local do tumor sem complicações tem um valor máximo que fornece a base para a justificação e otimização da radioterapia (dose, fracionamento de dose e distribuição de dose).

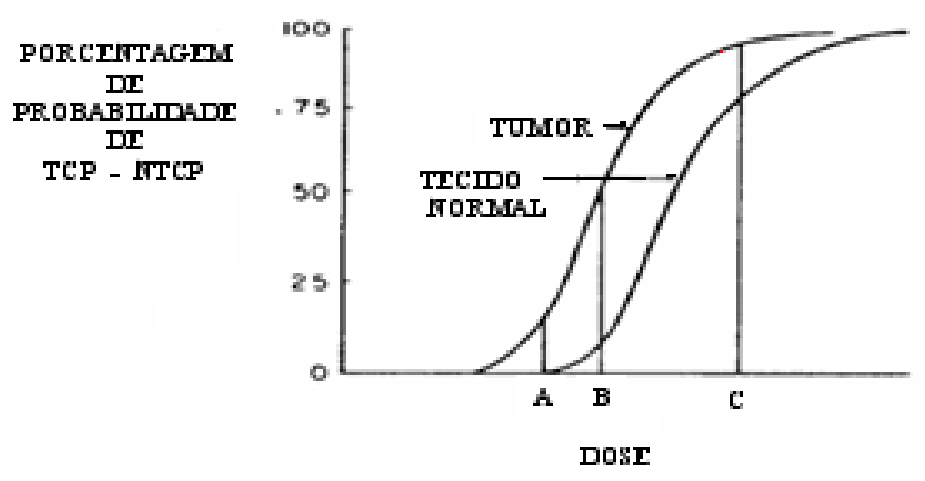

FIGURA 1.1. Probabilidade de controle do tumor - Tumour Control Probability (TCP) e probabilidade de complicação no tecido normal - Normal Tissue Complications Probability (NTCP) em função da dose de radiação, em um caso hipotético. 
A FIGURA 1.1 indica que se a complicação no tecido normal for evitada completamente, a dose de radiação não pode exceder o ponto "A"; a TCP está baixa. Aceitando uma NTPC relativamente pequena, a dose de radiação pode ser aumentada para o ponto "B", e o TCP é significativamente aperfeiçoado. Um aumento adicional da dose de radiação acima do ponto "C", resulta em um aumento na taxa de complicação com um aumento insignificante na TCP.

As exigências da exatidão para o tratamento da radioterapia devem ser basicamente derivadas do comportamento radiobiológico das células tumorais e dos tecidos normais, bem como das evidências clínicas que representam este comportamento. Nesse contexto deve ser mantido em mente que a evidência clínica obtida seja capaz de impedir incertezas na dose entregue e variações nas características das células do tumor.

No relatório recente do Institute of Physics and Engineering in Medicine $(\text { IPEM })^{13}$ foi realizada uma avaliação geral da evidência clínica sobre a importância da exatidão em radioterapia, concluindo que uma diferença na dose absorvida de $10 \%$ é detectável nos tumores e que uma diferença de $7 \%$ na dose absorvida pode provocar reações nos tecidos normais, levando a possíveis danos no tecido.

Questiona-se atualmente se um desvio padrão de $\pm 2,5 \%$ na administração da dose a um paciente é um critério muito rigoroso, e se o limite deveria ser maior; não existem, no entanto, recomendações definitivas nesse sentido. O que a radiobiologia e a radioterapia modernas confirmam é a necessidade de administrar a dose com alta exatidão, sobretudo quando se aplicam técnicas nas quais se aumenta a dose prescrita para níveis sem precedentes. Além disso, as possibilidades atuais em radioterapia usando técnicas modernas de diagnóstico para a delimitação de volumes-alvo e aceleradores avançados para a irradiação de pacientes, só podem ser aproveitadas de maneira adequada se houver um alto nível de exatidão na determinação da dose absorvida.

Há muitos passos ao longo do processo de tratamento que se relacionam com aspectos físicos, desde a calibração do feixe clínico até o cálculo do tempo de irradiação ou da unidade monitor, e todos os passos incluem erros e incertezas de maior ou menor grau. Considerando que há outras possíveis fontes de erro e incerteza nos aspectos puramente clínicos e também nos modelos radiobiológicos, 
é necessário aumentar as precauções em cada passo e minimizar seus erros e incertezas, a fim de garantir que a exatidão final do tratamento seja aceitável.

Então, a exatidão recomendada na dose entregue é geralmente de $5 \%$ a $7 \%$ dependendo dos fatores planejados para serem incluídos. Sobre a exatidão espacial, está em torno de $5 \mathrm{~mm}$ a $10 \mathrm{~mm}$, sendo usualmente determinada, dependendo dos fatores planejados que são incluídos.

\subsubsection{Grau de Severidade}

A exposição com feixes externos de radiação pode resultar em valores elevados de dose absorvida, envolvendo partes do corpo humano ou todo o corpo. Essas exposições ocorrem em situações de acidente, envolvendo fontes radioativas ou feixes de radiação intensos produzidos por geradores de radiação ionizante, como em aceleradores lineares. Como resultado dessas exposições o organismo humano desenvolve reações biológicas que podem se manifestar sob a forma de sintomas indicativos de alterações profundas provocadas pela radiação, conhecidos como Síndrome de Radiação Aguda ${ }^{14}$.

Não existe na literatura uma escala padrão indicando a severidade da irradiação relacionada aos sintomas da doença. Muito freqüentemente, são utilizados termos clínicos comuns, tais com: leve, moderado e severo para descrever o grau de severidade. Fases específicas foram desenvolvidas que descrevem os sintomas de acordo com o grau de severidade para estabelecer um grupo comum e avaliar o impacto dos sintomas.

O conjunto e a sucessão de sintomas que aparecem em vítimas de acidentes são observáveis em apenas horas, dias ou semanas após a exposição do indivíduo a uma alta dose de radiação em um pequeno intervalo de tempo. Os sistemas envolvidos são o circulatório, particularmente o hematopoiético; o gastrointestinal e o sistema nervoso central. Estudos realizados contribuíram para uma quantificação estruturada que pode expressar e avaliar a gravidade dos sintomas, formas de sintomas complexos, e assim, construir um mapa relacionando os sintomas, seqüelas e injúrias causadas aos pacientes, com dose e o tempo. Foram estabelecidos cinco níveis de severidade, de acordo com os 
sintomas, indo de nível 1 (nenhum efeito aparente) ao nível 5 (severidade máxima) dependendo da topografia do volume irradiado. O grau de severidade é definido para 6 categorias de sintomas específicos: distúrbio do sistema gastrointestinal agudo; moderado; debilidade e fadiga; hipotensão; infecção, hemorragia e febre; perda de fluidos e desequilíbrio eletrolítico ${ }^{15}$.

Respostas de incidentes recentes envolvendo radiação indicam que muitas práticas gerais são incertas sobre as conseqüências à saúde de exposições com radiação ionizante e a administração médica de pacientes expostos. As manifestações clínicas de alterações patológicas dependem da dimensão da área exposta do corpo. A severidade dos sintomas depende da dose absorvida de radiação pela área do corpo exposta ${ }^{16}$.

\subsubsection{Processo de Planejamento e Entrega de Dose do Tratamento}

O processo de planejamento do tratamento e entrega de dose envolve várias etapas; funciona como um sistema em cadeia seqüencial que se inicia com o posicionamento e imobilização do paciente na simulação do tratamento, e continua através do planejamento até a entrega de dose. A primeira etapa do planejamento é o diagnóstico e a escolha do tratamento realizada pelo médico. Realizado o diagnóstico e escolhido a terapia e a qualidade da radiação, determina-se o campo de irradiação, a área da superfície do paciente que se pretende irradiar. A escolha do tamanho do campo depende da dimensão do tumor e do volume a ser irradiado. A seguir faz-se a prescrição da dose e do fracionamento.

As etapas distintas no processo de planejamento de um tratamento, das quais deve ter seu procedimento de garantia da qualidade, podem ser classificadas da seguinte forma:

a) Posicionamento e imobilização do paciente: é importante posicionar o paciente confortavelmente e de maneira reprodutível, com a utilização de lasers e acessórios básicos utilizados na radioterapia, seja no simulador, na tomografia computadorizada, na ressonância magnética ou na unidade de tratamento. É importante garantir a 
fixação do paciente durante a aquisição de imagens durante o tratamento, permitindo que o posicionamento seja mantido com exatidão em todo o tratamento;

b) Aquisição de dados: para aquisição do contorno do paciente, assim como para a determinação do volume-alvo e dos órgãos críticos, é recomendável a utilização de equipamentos de diagnóstico como simuladores de raios- $X$ utilizados na simulação bidimensional, e imagens de tomografia computadorizada, ressonância magnética e ultra-sonografia utilizados na simulação tridimensional. A FIGURA 1.2 ilustra um Tomógrafo utilizado na simulação virtual. Devem ser desenvolvidos acessórios que, uma vez acoplados às mesas destes equipamentos de diagnósticos, se assemelhem às condições das mesas das unidades de tratamento do serviço de radioterapia;

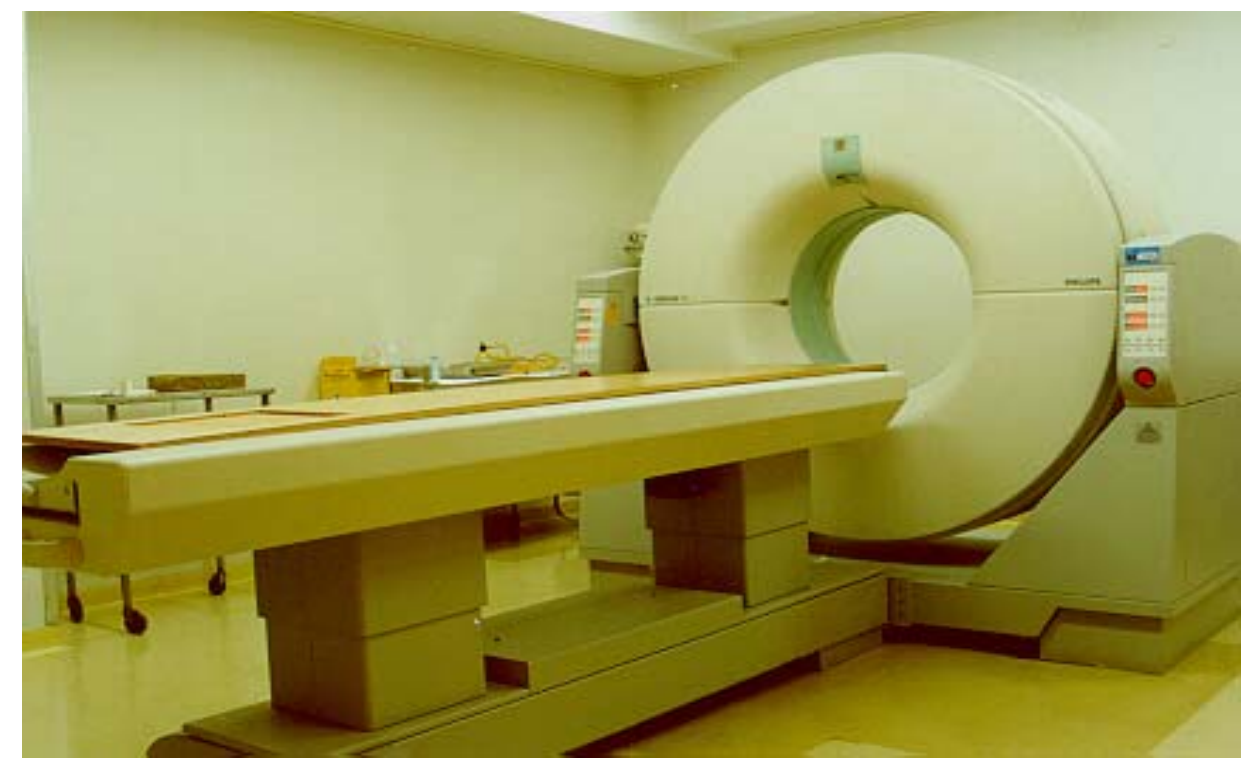

FIGURA 1.2. Tomógrafo computadorizado utilizado na simulação virtual do tratamento em radioterapia.

c) Segmentação Estruturada: após a aquisição das imagens com as marcas de referência, os dados podem ser transferidos por vias mais diretas como em fitas, discos flexíveis e/ou transferidas através de redes de computadores para outras estações de trabalho, possibilitando a transferência de parâmetros do planejamento; 
d) Planejamento do Tratamento e Avaliação: com base nas informações anatômicas adquiridas do paciente é definido o campo de tratamento, as coordenadas de tratamento, ou seja, a localização do volume alvo juntamente com as estruturas anatômicas circundantes; são criadas as curvas de isodose, da distribuição de dose que a seguir passam por uma avaliação. Quando se realiza o planejamento manual é necessário revisar se os dados foram escolhidos corretamente para o cálculo das unidades monitoras, incluindo os modificadores do feixe utilizados. No caso do planejamento computadorizado a avaliação do plano de tratamento habitualmente inclui a revisão das distribuições de dose seja no monitor do computador ou na documentação impressa;

e) Validação do Planejamento: após o cálculo de dose, o radioterapeuta responsável pelo tratamento irá validar ou não o plano de tratamento após uma avaliação de fatores importantes tais como a uniformidade da dose e os limites de dose nos órgãos críticos. Caso o plano seja aprovado passa-se à etapa seguinte, e se o plano não for aprovado ele será enviado novamente ao planejamento para ser replanejado;

f) Verificação do Posicionamento: é recomendável que o médico responsável, o radioterapeuta, esteja presente na sala de tratamento durante o primeiro posicionamento do paciente, no momento da escolha do conjunto de parâmetros do planejamento, ou quando houver variações significativas no plano de tratamento original. Geralmente é realizada imagem portal que é verificada pelo médico;

g) Entrega do Tratamento e Verificação: esta última etapa consiste na entrega de dose ao paciente propriamente dito. Durante o curso do tratamento é realizado periodicamente imagem portal e de verificação, uma vez que pode haver variações de um dia para o outro no posicionamento do paciente. Podem aparecer desvios sistemáticos significativos devido a um conjunto de fatores tais como um erro na interpretação do portal do início do tratamento, uma 
modificação no procedimento de posicionamento e/ou imobilização, troca dos técnicos em radioterapia que executam o tratamento, variações não registradas nos blocos. Também podem ocorrer alterações anatômicas do paciente devido a flutuações no peso ou no estado da enfermidade.

O sucesso ou a falha do tratamento em radioterapia depende da dose depositada no volume alvo e não é recomendável que apresente variações acima de $5 \%$ da dose prescrita.

A seguir é apresentada a FIGURA 1.3 ilustrando a simulação de tratamento de um paciente com a utilização de marcas de referência e lasers.

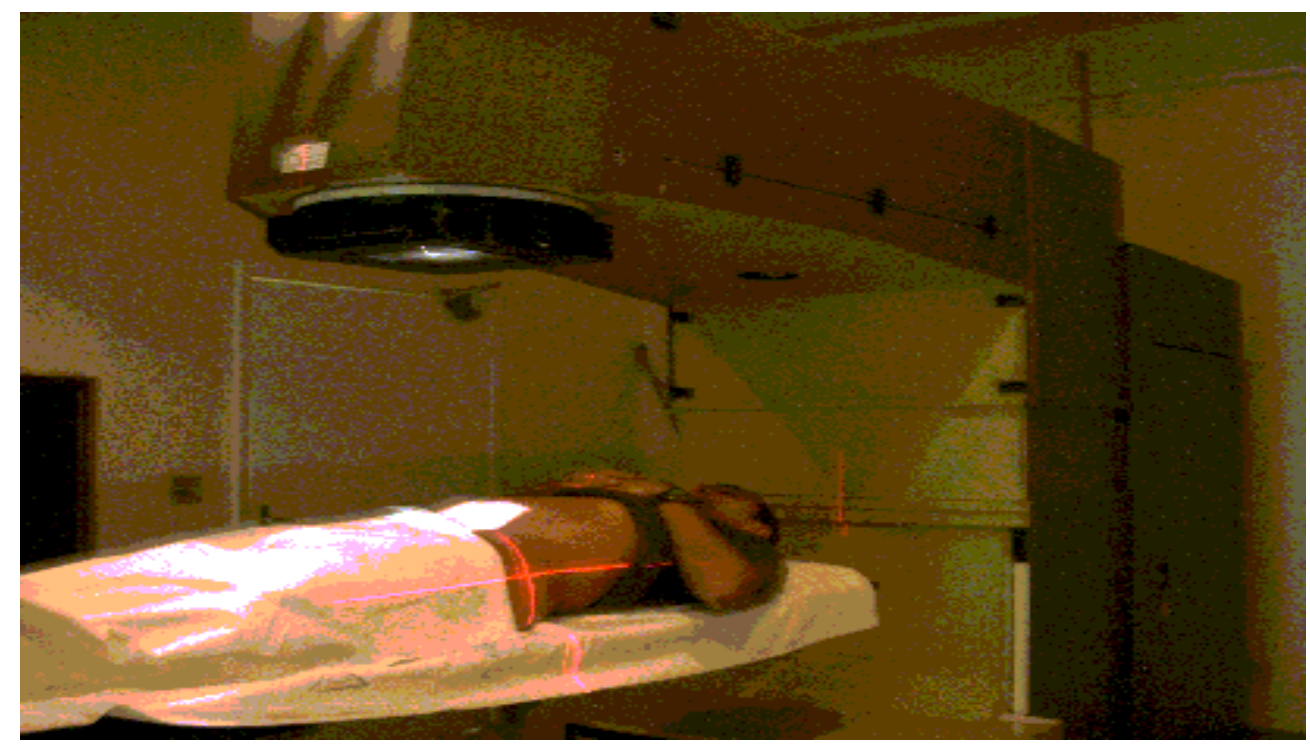

FIGURA 1.3. Localização das marcas de referência com a utilização de laser no paciente no simulador.

Um modo de observar o processo de planejamento do tratamento e entrega de dose é apresentado na FIGURA 1.4. O processo de planejamento do tratamento pode ser representado como um processo em cadeia, passando por todas as etapas do tratamento. É importante observar que nenhuma etapa pode ser omitida com riscos de comprometer o sucesso global do tratamento. 


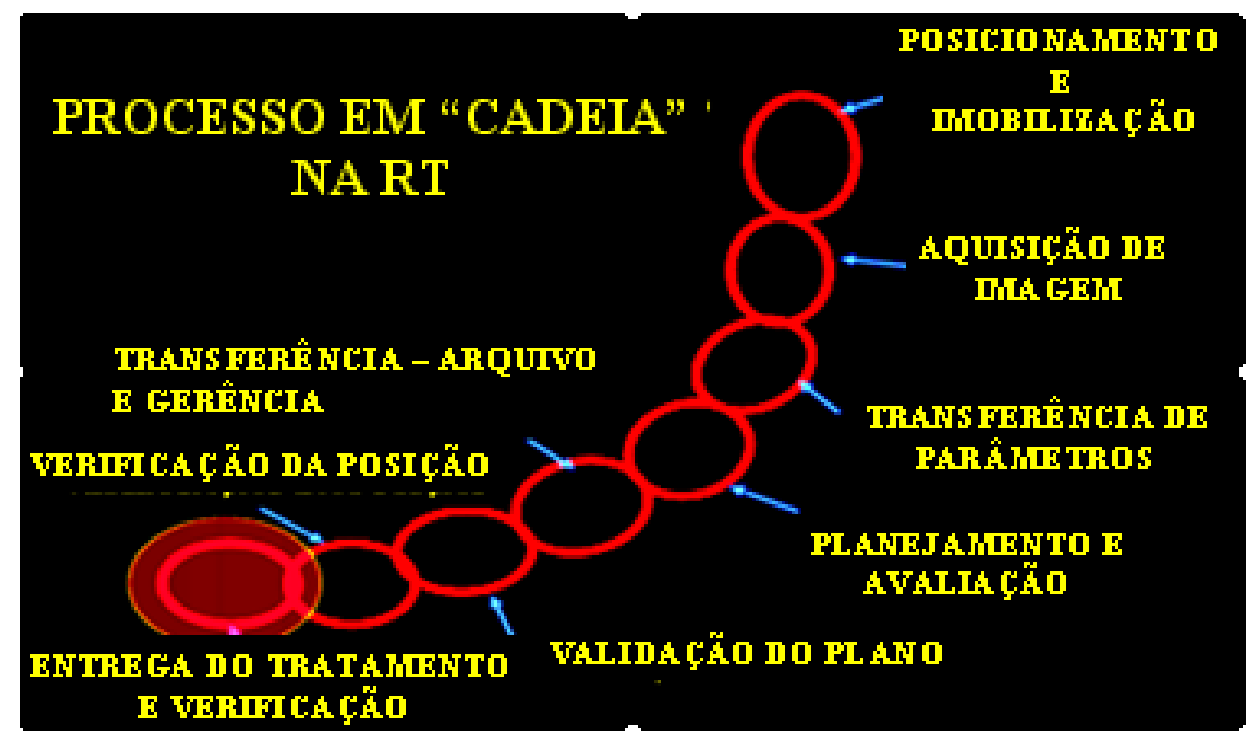

FIGURA 1.4. Forma esquemática do processo em "Cadeia" que consiste em várias etapas no tratamento de radioterapia após a prescrição médica.

\subsubsection{Acidentes e Incidentes em Radioterapia}

A terapia realizada utilizando a radiação ionizante refere-se a práticas com fontes de feixes externos, a teleterapia, realizada principalmente com feixes de fótons e elétrons produzidos em aceleradores lineares e também através de fontes de cobalto-60, fornecendo radiação gama; e a braquiterapia. Nos eventos estudados torna-se importante conhecer alguns conceitos pertinentes aos estudos realizados neste trabalho definidos de acordo com o Basic Safety Standards $(\mathrm{BSS})^{5}$.

- Exposição Potencial: é a exposição que pode resultar de um acidente devido a um evento ou a uma seqüência de eventos de natureza probabilística; a probabilidade é menor que um, quando não desprezível;

- Exposição Normal: é a exposição que se espera ter quando está se operando sob condições normais, incluindo infortúnios ou erros menores cuja probabilidade de ocorrer não é significativamente menor que um. 
As duas definições anteriores abrangem todas as exposições de uma fonte da radiação e aplicam-se à exposição ocupacional, pública e médica.

- Exposições médicas: são exposições incorridas por indivíduos durante os exames diagnósticos ou tratamento e nas exposições, à exceção da ocupacional, intencionalmente toleradas e dispostas pelos indivíduos que ajudam na sustentação e no conforto dos pacientes que se submetem ao diagnóstico e ao tratamento. A exposição médica inclui também as exposições incorridas pelos voluntários que participam dos programas da pesquisa biomédica;

- Exposição acidental: refere-se a todo evento não intencionado, incluindo os erros de operação, as falhas de equipamento ou outros infortúnios, as conseqüências ou as conseqüências em potencial que são significativas do ponto de vista da proteção ou da segurança. Em radioterapia a exposição acidental ou uma má administração do feixe externo, caracteriza-se quando a diferença entre a dose prescrita e a dose entregue é igual ou superior a $10 \%{ }^{17}$.

A exposição potencial é referida como o potencial para acidentes em radioterapia ou envolvendo fontes de radioterapia, trazendo conseqüências relevantes à segurança.

Um incidente é uma mudança na conduta normal do sistema, não desejada ou inesperada, que causa ou tem um potencial para causar um resultado adverso para pessoas ou equipamentos.

\subsection{Revisão Bibliográfica}

Atualmente, considera-se a prevenção de erros na radioterapia como uma componente da gestão de qualidade ${ }^{18}$. Princípios técnicos e administrativos precisam ser aplicados para prevenir exposições não intencionais e minimizar as conseqüências, caso elas ocorram. Esses princípios começam com uma avaliação sistemática do equipamento e procedimentos de tratamento, seguida pela 
aplicação de medidas de segurança e a integração da prescrição e entrega do tratamento em uma aproximação global.

Várias experiências têm demonstrado que, em uma situação incomum, por exemplo, após a falha de um equipamento ou quando aparecem sinais conflitantes no console do equipamento, o comportamento da equipe é freqüentemente inseguro. Suposições erradas são feitas ocasionando assim as exposições acidentais. Torna-se necessária a inclusão de situações incomuns em exercícios de treinamento da equipe e a discussão de casos históricos para ajudar a equipe a reconhecer os possíveis problemas em potencial.

A publicação do relatório da $\operatorname{IAE} A^{4}$ fornece uma revisão dos eventos que constituem incidentes ou acidentes relacionados à radiação para uso terapêutico. Esse relatório de segurança é um compêndio de um número grande de eventos que podem servir como uma lista para testar a vulnerabilidade da ocorrência de acidentes em potencial e fornecer assim dados para aperfeiçoar a segurança na utilização da radiação. A apresentação desse relatório pode permitir que um membro da equipe de tratamento em radioterapia questione a possibilidade de que aquele evento, ocorrido em outra instituição, possa ocorrer também em sua instituição. Os eventos presentes nesse relatório têm sido relatados por autoridades regulatórias e associações profissionais em que, nenhum indivíduo, instituição ou país são identificados. Esse método adotado de apresentação é com a finalidade de encorajar indivíduos e instituições a relatarem acidentes ou falhas sem causar constrangimentos profissionais. Conseqüentemente, com as lições aprendidas de exposições acidentais ocorridas, podem-se adotar medidas para prevenir acidentes ou minimizar as conseqüências se os acidentes ocorrerem.

A incidência de câncer no mundo todo vem aumentando, particularmente com relação à expectativa de vida prolongada. De acordo com estimativas recentes da Internacional Agency for Research on Cancer (IARC) e a WHO, nove milhões de novos casos de câncer estão sendo detectados por ano em todo mundo. Aproximadamente metade de todos os pacientes com câncer recebe radioterapia como parte de seu tratamento preliminar, ou em caso de reincidência, ou tratamento paliativo. Uma avaliação conservadora estima que no ano de 2015 haja a necessidade de 10.000 máquinas de teleterapia no mundo. Com esta expectativa há a necessidade de profissionais qualificados, radioterapêutas, físicos 
médicos, técnicos de radioterapia, equipe de manutenção, para operar esses novos equipamentos de radioterapia ${ }^{19}$.

Em 2001, a Conferência Internacional de Málaga promovida pela IAEA ${ }^{20,21}$ confirmou que há lacunas para reduzir os riscos radiológicos envolvidos em usos diagnósticos e terapêuticos da radiação sem reduzir os benefícios médicos. Reconheceu-se que toda pessoa da equipe envolvida no cuidado da saúde tem um papel relevante. A instrução e o treinamento da equipe de funcionários e os arranjos apropriados da garantia de qualidade foram considerados como essenciais para essa finalidade. A radioterapia é uma ferramenta extremamente importante no tratamento do câncer. Entretanto, é essencial limitar as exposições dos tecidos sadios e o risco da exposição acidental. A garantia de qualidade é essencial para a proteção do paciente assegurando o tratamento seguro e eficaz, incluindo a prevenção da exposição médica acidental.

Vários acidentes têm sido reportados pela IAEA $^{22,23,24,25,26,27,28,29,30,31,32,33,34,35,36,37,38,39,40}$ e na literatura evidenciando assim, diversos erros. Muitos acidentes ocorreram devido à falha no programa de qualidade ou negligência, conduzindo a conseqüências clínicas ${ }^{41,42,43,44,45}$. A seguir será apresentado um breve relato dos incidentes mais recentes em radioterapia relatados na literatura e muito difundidos pela imprensa.

Um acidente grave ocorreu no Instituto Oncológico Nacional Panamá ${ }^{43}$, 2000; um erro na determinação das doses emitidas entre os pacientes por uma fonte de cobalto 60 causou 28 vítimas, algumas das quais gravemente atingidas. A origem da sobre-exposição foi uma modificação no modo de digitalização dos blocos de proteção. A necessidade de introduzir cinco blocos de proteção levou o desvio do procedimento padrão para a entrada dos dados dos blocos, realizada em um único passo. A modificação do protocolo foi realizada sem o teste de verificação, como o cálculo manual do tempo de tratamento. O computador calculou o tempo de tratamento como sendo o dobro, levando a uma sobredose de 100\%. Em novembro e dezembro de 2000 apareceram os primeiros sintomas de sobre-exposição nos pacientes irradiados. Apenas em março de 2001 o erro foi detectado e os tratamentos foram interrompidos. Apesar do longo período durante o qual o erro se repetiu, o número de vítimas foi relativamente pequeno comparado com o número total de pacientes tratados, devido às regiões tratadas (cólon, 
genitais femininos e próstata). Sobre os oito falecimentos ocorridos durante 0 primeiro semestre de 2001 , três foram consecutivos ao acidente. Os sobreviventes apresentaram seqüelas graves das esferas digestivas e urinárias

Em 27 de fevereiro de 2001 no Białystok Oncology Centre ${ }^{44}$, Polônia, ocorreu um acidente devido ao mau funcionamento de um acelerador linear de modelo Neptune 10P apresentado na FIGURA 1.5. Houve falta de energia elétrica durante o tratamento de um paciente. Após a restauração da energia a máquina foi reiniciada após verificação de controle. Foi dado prosseguimento ao tratamento do paciente e foram tratados mais quatro pacientes. Foi realizada subseqüente dosimetria que revelou o rendimento da máquina significativamente mais alto do que o esperado. Um componente eletrônico do sistema de intertravamento de segurança foi danificado, verificado pelo engenheiro no dia 28 de fevereiro. Os cincos pacientes sofreram sobre-exposição durante a administração da fração de tratamento e sofreram injúrias de severidade variadas. A taxa de dose absorvida aumentou de 4,46 Gy/min para $100 \mathrm{~Gy} / \mathrm{min}$ para um feixe de elétrons de $8 \mathrm{MeV}$. Nessas condições com uma prescrição de dose equivalente a 150 unidades monitoras, a máquina poderia liberar uma dose de 100 Gy ou mais. As doses prescritas eram de 2 Gy a 2,5 Gy por fração. O paciente que continuou o tratamento após a interrupção de energia tinha uma prescrição de 50 Gy, em 25 frações com feixe de raio-X de $4 \mathrm{MV}$ com raios-X e um tratamento complementar de 2,5 Gy com feixe de elétrons de $8 \mathrm{MeV}$. Depois de poucas horas apresentou um leve eritema na área exposta. No fim do ano 2002, todos os pacientes apresentavam um estado satisfatório; o nível das doses recebidas no tórax justifica uma vigilância prolongada. 


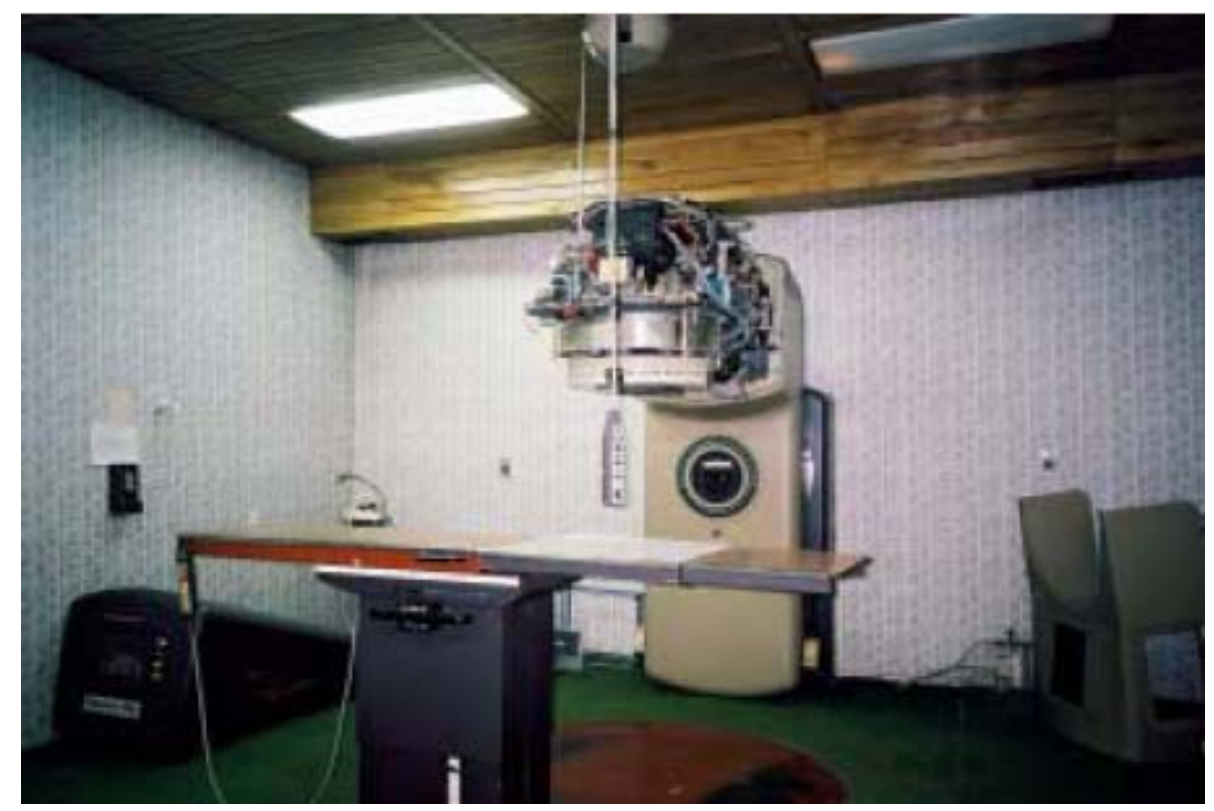

FIGURA 1.5. Acelerador NEPTUNE 10P do Białystok Oncology Centre com o cabeçote aberto quando medidas estavam sendo realizadas durante a missão da IAEA.

De acordo com o Centro Hospitalar Jean Monnet em Epinal ${ }^{45}$, França entre 6 de maio de 2004 e 1 de agosto de 2005 ocorreu um acidente envolvendo radiações ionizantes. O protocolo de radioterapia conformacional aplicado aos tumores de próstata foi alterado, a fim de servir-se mais amplamente das possibilidades do "software" de dosimetria existente desde 2000. Passou-se assim, da utilização de filtros físicos para filtros dinâmicos. Esta mudança supõe alterar igualmente o parâmetro que assegura o cálculo da intensidade de radiação, o qual não foi realizado. Os filtros físicos ou dinâmicos são utilizados para corrigir as irregularidades do contorno do paciente, diminuindo a dose recebida pelos órgãos próximos à próstata, reto e bexiga, mais ou menos sensíveis à irradiação. Durante a seleção do filtro físico de 15, 30, 45 ou 60 foi selecionado como filtro dinâmico. $O$ incidente conduziu à sobredose de 23 pacientes irradiados na região da próstata. As vítimas foram expostas a uma dose de cerca de $20 \%$ superior à inicialmente prevista. Os primeiros casos de complicações começaram a aparecer em 2005. Um dos 23 pacientes teria falecido de causa diretamente ligada à sobre-exposição, em 25 de junho de 2006, e outros três pacientes morreram sem que uma relação direta fosse estabelecida com esse acidente. Treze outros doentes tiveram 
complicações do tipo retite (inflamação do reto), e seis não manifestaram nenhum sintoma.

Recentemente descobriu-se que o número de pacientes que sofreram sobre-exposição é muito maior ${ }^{46}$. No total, são mais de 4.900 doentes tratados por radioterapia no Hospital de Epinal que receberam sobredose, entre 1989 e 2006, por conseqüência de três erros distintos. De acordo com informações mais recentes, 24 pacientes realizando tratamento para o câncer de próstata foram vítimas de uma sobredose de aproximadamente $20 \%$, entre maio de 2004 e agosto de 2005, cinco dos quais morreram. Outras 400 pessoas foram vítimas de uma sobre-exposição de aproximadamente $8 \%$ entre 2000 e novembro de 2006 . Por último, um terceiro erro, tornado conhecimento público mais recente referiu-se a 4.500 pacientes tratados entre 1989 e 2000 para diferentes tipos de câncer receberam uma sobredose de $3,5 \%$ a $5 \%$. Devido ao mau funcionamento da máquina, um erro sistemático relacionado ao parâmetro do "software", 300 pacientes dos quais sofreram a sobre-exposição de 7\% entre Julho de 1999 e Julho de 2000 e é objeto de um acompanhamento específico. A partir desse acidente foram tomadas medidas para aumentar a segurança indispensável nos tratamentos em radioterapia. Passou-se a aplicar a dosimetria in vivo, permitindo medir em tempo real a dose recebida pelos pacientes. A FIGURA 1.6 apresentada a seguir mostra a localização geográfica do acidente ocorrido em Epinal com o número de vítimas levantadas até setembro de 2007. 


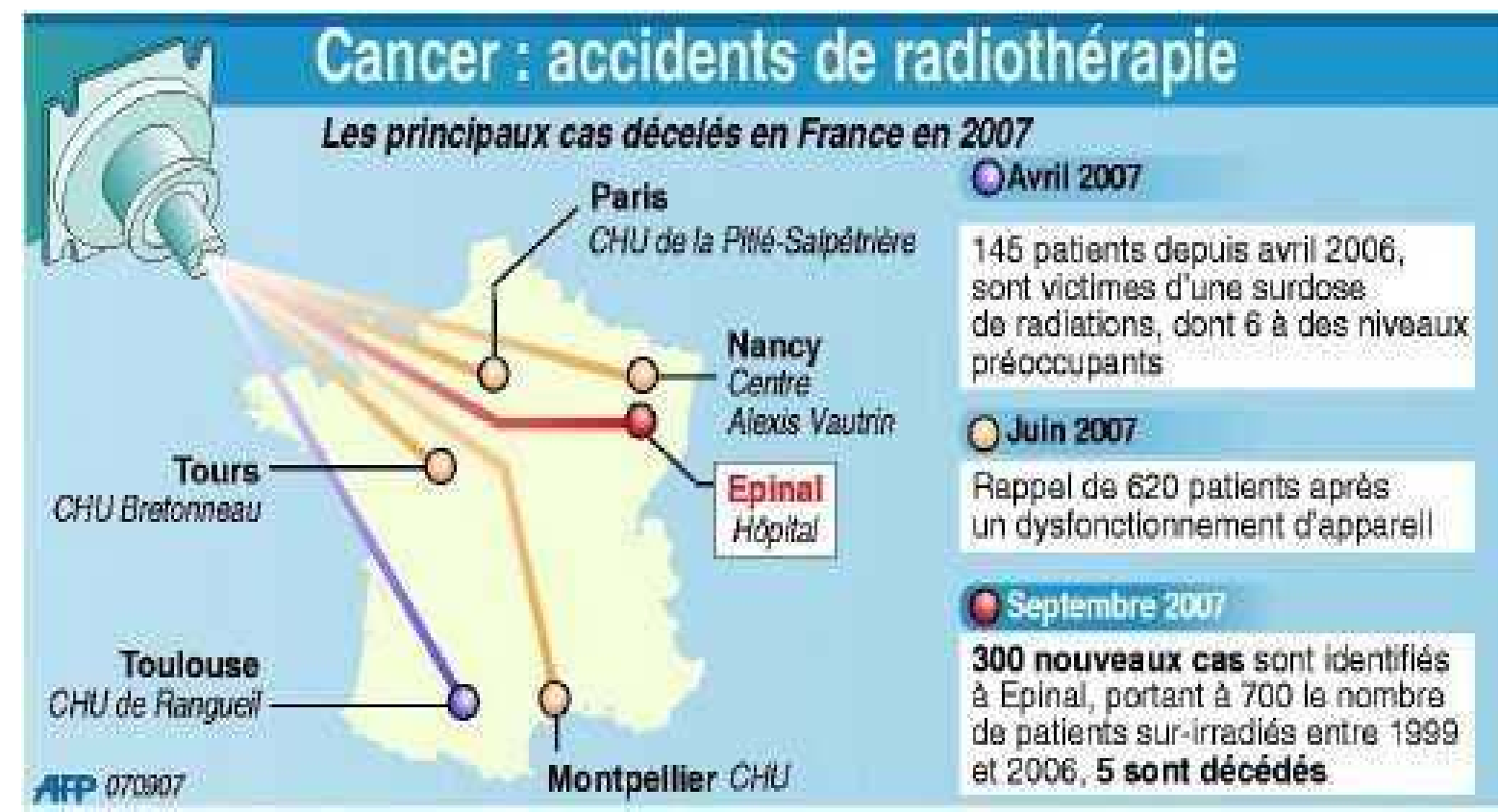

FIGURA 1.6. Localização geográfica do acidente ocorrido em Epinal, França apresentando os casos de vítimas levantadas até 10 de setembro de 2007 e divulgadas ao público ${ }^{46}$.

Entre 5 e 31 de janeiro de 2006, no Beatson Oncology Centre ${ }^{47}$, Glasgow, Escócia ocorreu um acidente grave. Um paciente com um câncer do sistema nervoso central realizando um tratamento em acelerador linear sofreu uma sobreexposição. De acordo com a prescrição clínica deveria receber uma dose de $35 \mathrm{~Gy}$ em 20 frações em todo o volume de tratamento incluindo o sistema nervoso central. Em maio de 2005 o sistema "Varis" do hospital foi atualizado para "Varis 7", sistemas de gerenciamento. Esta alteração permitiu que os parâmetros de entrega do tratamento no Relatório do Plano de Tratamento do Eclipse, fossem eletronicamente transferidos a outro módulo de "software" dentro do sistema Varis. O Eclipse é um moderno sistema computadorizado de planejamento tridimensional (3D), que recebe as imagens da simulação e realiza a distribuição da dose adequada ao caso clínico. $\mathrm{Na}$ atualização do sistema introduziram uma característica específica que, se selecionada pelo planejador do tratamento, altera a natureza dos dados no Relatório do Plano de Tratamento do Eclipse baseado em relatórios semelhantes, anteriores à atualização de maio de 2005. Essa característica foi selecionada incorretamente durante $\circ$ planejamento do tratamento, resultando em unidades monitoras inseridas no console 
significativamente mais alta do que deveriam ter sido utilizadas. O cálculo das unidades monitoras do tratamento diário ocorreu de forma incorreta, o valor de uma unidade monitora deveria equivaler a 100 cGy e passou a ser de 167 cGy, tendo como conseqüência uma dose por fração de 2,92 Gy em vez de 1,75 Gy. O erro não foi identificado no processo de verificação do plano de tratamento e planejamento. Nas 19 frações de tratamento o paciente recebeu uma sobredose de $58 \%$ da dose total prescrita, ocasionando a morte do paciente. Este acidente foi muito comentado pela imprensa, inclusive no Brasil $^{48}$.

Em 2006, um relatório de segurança ${ }^{49}$ foi elaborado e revisado por membros da IAEA, representantes da International Society of Radiation Oncology e outros órgãos regulatórios, com o objetivo de implementar o International Basic Safety Standards for Protection (BSS) para radiações ionizantes aplicados à medicina nuclear e especialmente à radioterapia. $O$ trabalho desenvolvido relata casos históricos dos maiores acidentes ocorridos mundialmente devido à perda de fontes de radiação e também de exposições impróprias de pacientes, ilustrando as conseqüências dos procedimentos recomendados e não seguidos. Os padrões de segurança requeridos são explicados em termos de condições de serviços, limitação de doses em radioterapia, classificação de áreas, monitoramento e taxa de exposição, e vigilância. O documento é um guia importante de regulamentos para procedimentos operacionais e treinamento.

Estudos realizados recentemente demonstram que a complexidade de planejamento e tratamento para pacientes utilizando radioterapia vem aumentando, e isto aumenta também o potencial de ocorrências de erros. Erros humanos são uma importante fonte de falhas em todos os passos do planejamento e da radioterapia $^{50}$. Isto é devido em parte pela introdução de novos procedimentos e técnicas de tratamento. Esse avanço não necessariamente vem acompanhado do aumento da capacidade de verificação. Embora o uso de sistemas de registro e verificação tem aumentado, alguns autores ${ }^{51,52,53,54,55}$ têm sugerido que estes dispositivos podem contribuir para propagar erros, freqüentemente são utilizados sistemas para aumentar a eficiência do sistema em vez de sistemas de garantia de qualidade. Existem vários estudos detalhados realizados sobre análises de erros $^{56,57,58}$ em tratamento com radiação em termos de como os erros ocorreram. Embora a conseqüência dosimétrica possa ser óbvia em muitos casos, não há um estudo detalhado a esse respeito. 
De janeiro de 2001 a junho de 2003 Klein et al. ${ }^{59}$ examinaram erros em potencial em termos de cenários, freqüência de ocorrência e dosimetria, com o objetivo de priorizar a prevenção de erros. Todos os erros revelados e/ou descobertos foram rastreados nos 3964 casos de terapia iniciados e sem a transferência completa eletrônica dos dados de tratamento do "set-up". Nos tratamentos com feixes de fótons, foram investigados os erros de SSD (Distância foco-superfície) incorreta, energia, omissão de filtro (físico, dinâmico, ou universal), ou filtros compensadores, filtro incorreto ou orientação do filtro físico, rotação de arcoterapia imprópria. Também foram investigados erros na geometria devido à angulação do cabeçote incorreta, colimador ou TABELA de ângulos incorretos, direção do campo invertida, e erros no "set-up" e de posicionamento do paciente. Para terapia com feixes de elétrons, os erros investigados incluíram energias incorretas, SSD incorreto, erros geométricos. Para os procedimentos especiais foram investigados erros na irradiação de corpo inteiro, (TBI, tamanho de campo incorreto, taxa de dose, distância do tratamento) e radiocirurgia em aceleradores lineares. Detalhes foram levantados para cada erro com identificação se o sistema de registro e verificação possivelmente propagou o erro, ou como em alguns casos, não foi utilizado para tratamento. A probabilidade de erros foi determinada e subseqüentemente classificada de acordo com a história de detecção para erros. Durante esse período de tempo, decisões foram tomadas para mudar o processo ou adicionar uma verificação de garantia de qualidade adicional. Estas decisões foram baseadas na freqüência e no impacto dosimétrico.

Klein et al. ${ }^{59}$ classificaram os tipos de erros durante as simulações de tratamento conforme apresentados na TABELA 1.1 de acordo com a freqüência, longevidade para 103 eventos significativos e levando em consideração também o impacto dosimétrico. Foram discriminados 14 tipos de erros mais freqüentes. 
TABELA 1.1. Tipos de erros classificados de acordo com a freqüência, longevidade e impacto dosimétrico segundo Klein et $\mathrm{al}^{59}$.

\begin{tabular}{|c|c|c|c|}
\hline Tipo de Erro & Freqüência & Longevidade & $\begin{array}{l}\text { Impacto } \\
\text { Dosimétrico }\end{array}$ \\
\hline Coordenada de tratamento incorreta. & $A$ & $\mathrm{~B}$ & $A$ \\
\hline Ângulo do cabeçote incorreto. & A & $\mathrm{B}$ & M \\
\hline $\begin{array}{l}\text { Bloco de "cerrobend" omitido ou } \\
\text { incorreto. }\end{array}$ & $A$ & B & B \\
\hline Cálculo incorreto. & $A$ & M & M \\
\hline Dimensão do campo incorreta. & M & $\mathrm{B}$ & $\mathrm{B}$ \\
\hline Ângulo do colimador incorreto. & M & B & M \\
\hline Faltando filtro compensador. & M & M & M \\
\hline Unidade Monitora incorreta. & M & $A$ & M \\
\hline Energia de fóton incorreta. & B & M & M \\
\hline Forma do MLC omitido ou incorreto. & B & B & $\mathrm{B}$ \\
\hline Direção da cunha incorreta. & B & A & $A$ \\
\hline $\begin{array}{l}\text { Número incorreto de frações para } \\
\text { determinada forma de campo. }\end{array}$ & B & M & $\mathrm{M}$ \\
\hline $\begin{array}{l}\text { Filtro compensador incorreto ou } \\
\text { ângulo incorreto. }\end{array}$ & $B$ & $\mathrm{M}$ & $\mathrm{M}$ \\
\hline $\begin{array}{l}\text { Paciente tratado de cabeça para o } \\
\text { cabeçote e digitalizado com os pés } \\
\text { para o cabeçote. }\end{array}$ & B & B & $A$ \\
\hline
\end{tabular}

$\mathrm{A}=$ Alto; $\mathrm{M}=$ Médio; $\mathrm{B}=$ Baixo. 
Freqüência: classificação do tipo de erro de acordo com o histórico da taxa de ocorrência do evento.
A: $>0,25 \%$
$M: 0,1 \%$ à $0,25 \%$
B: $<0,1 \%$

Longevidade: classificação do tipo de erro de acordo com o número de frações.

A: potencialmente > 5 frações e somente descoberto por uma cuidadosa verificação da ficha semanalmente.

M: omitido pelo filme portal, mas asseguradamente descoberto pelo diodo na $1^{\text {a }}$ verificação.

B: percebido pelo filme portal inicial.

Impacto Dosimétrico: classificação do tipo de erro de acordo com o erro da dose e/ou volume.

A: erro potencialmente $>20 \%$ por fração em termos de dose e/ou volume tratado.

M: erro entre $10 \%$ e $20 \%$ por fração em termos de dose e/ou volume tratado.

B: erro $<10 \%$ por fração em termos de dose e/ou volume tratado.

De acordo com Klein et al. ${ }^{59}$ caminho do erro pode ser detectável de três formas:

1. Um erro que é facilmente detectável antes da primeira fração pelo filme portal. Embora ocorra em maior freqüência, eles são quase sempre detectados após a segunda fração e por esta razão tem nenhuma longevidade e subseqüentemente nenhum impacto dosimétrico.

2. Um erro que não é detectável pelo filme portal, mas tem uma alta probabilidade de ser detectado pela dosimetria in vivo utilizando dosímetros de diodo e/ou revisão inicial da ficha pelo físico. Essas verificações devem ocorrer antes da segunda fração, mas têm sido realizadas até cinco frações. Em todo caso há uma longevidade 
mínima e, conseqüentemente, somente um impacto dosimétrico mínimo.

3. Um erro que não seja detectável pelo filme portal ou pela leitura do dosímetro de diodo no eixo central ou pela revisão inicial da ficha técnica do paciente pelo físico. Esses erros, embora menos freqüentes, têm a possibilidade de não serem descobertos através de muitas frações do tratamento e em muitos casos (por exemplo, um acessório incorretamente orientado) tenham impacto dosimétrico muito elevado.

Segundo Klein et al. ${ }^{59}$ os erros geométricos são os erros mais prováveis. Estes ocorrem muitas vezes devidos ao "set-up" impróprio, ou seja, erros de posicionamento, através de transferência de coordenadas ou forma do campo incorreto. O impacto dosimétrico é único para cada caso e depende da proporção de campos incorretos e volume tratado inadequadamente. Esses erros são de vida curta devido ao processo rápido de detecção através do filme portal.

A partir dos trabalhos de Klein, o Professional Information and Clinical Relations formou o Task Group 103 (TG 103) ${ }^{60}$, um grupo tarefa, com mecanismos para "revisão pareada" na física clínica da radioterapia, para assegurar que tais revisões venham a ser uma ferramenta produtiva para o clínico e o físico com a finalidade de manter o alto padrão profissional. Os encargos do Task Group são recolher informação sobre processos existentes de auditoria, tal como Radiological Physics Center (RPC), auditorias locais e programas credenciados de prática. Assim, pode-se avaliar sua relevância para auditorias, e formular uma estrutura para auditoria entre dois físicos médicos, incluindo o máximo de componentes para revisão e sugerir critérios, bem como um formato proposto de um relatório escrito resumindo a auditoria. Esse documento representa as recomendações do Task Group para um processo de auditoria voluntário entre dois físicos médicos. A auditoria é uma ferramenta eficaz e importante para melhorar o programa de física médica, realçar a segurança do paciente funcionando como um sistema de educação corporativa que compreende sistemas educacionais que privilegiam o desenvolvimento de atitudes, posturas e habilidades, visando prover oportunidades de aprendizagem ativa e contínua. Isso ajuda também no desenvolvimento 
profissional do físico médico permitindo uma troca de idéias profissionais e da crítica produtiva de todo o programa da física médica.

\subsection{Objetivos}

\subsubsection{Objetivo Geral}

Elaborar um conjunto de ações baseado nas lições aprendidas de exposições acidentais ocorridos mundialmente. Este conjunto de ações irá permitir minimizar os erros ocorridos em radioterapia, o que acarretará em uma melhoria dos serviços de radioterapia prestados ao paciente e diminuir a freqüência de acidentes/incidentes, e assim, enfatizar cada vez mais a cultura de segurança.

\subsubsection{Objetivos Específicos}

- Criar um banco de dados para armazenamento dos dados dos acidentes/incidentes relacionados à radioterapia baseado no Banco de Dados do Radiation Oncology Safety Information System (ROSIS) e acidentes relatados na literatura. A necessidade da criação desse banco de dados deve-se à necessidade de identificar com mais detalhes os parâmetros envolvidos nos acidentes/incidentes e características específicas que possam ser avaliadas em termos de freqüência.

- Identificar e analisar os parâmetros quanto à freqüência dos incidentes, processo de detecção e grau de severidade para cada tipo de erro ocorrido e Propor um conjunto de medidas a serem aplicadas na radioterapia. 


\section{CAPÍTULO 2}

\subsection{Materiais e Métodos}

\subsubsection{Banco de Dados}

Os dados referentes aos incidentes e acidentes ocorridos em teleterapia, tratamentos realizados em aceleradores lineares e também com a utilização de fonte de cobalto-60, foram selecionados para este trabalho. Estes dados foram armazenados inicialmente em planilhas eletrônicas, e posteriormente utilizados para realizar os cálculos de freqüência dos tipos de erros ocorridos, o processo de detecção e analisar o impacto dosimétrico. O aplicativo utilizado foi o Microsoft Access ${ }^{\circledR}$.

O banco de dados construído é relacional, ou seja, estabelece relações entre os dados para permitir uma consulta rápida das características específicas dos parâmetros analisados das exposições acidentais e obter os valores de cada parâmetro.

Para a construção do banco de dados, foi necessário o acesso ao arquivo disponível no site Radiation Oncology Safety Information System (ROSIS) 8 "on line" e dados dos relatórios específicos sobre exposições acidentais disponibilizados pela International Atomic Energy Agency $(\text { IAEA })^{41,42,43,44}$, publicações de órgãos

governamentais ${ }^{45,47}$ e pesquisa bibliográfica de todas as exposições acidentais ocorridas mundialmente na área de radioterapia. Após completar o banco de dados foi inserido o parâmetro "tipo de erro" em todos os eventos cadastrados como uma característica adicional com a finalidade de investigar os tipos de erros ocorridos e analisar a freqüência.

O banco de dados disponibilizado pela organização ROSIS ${ }^{8}$ periodicamente passa por atualizações com a inclusão de novas características, inserindo mais informações dos incidentes. O grupo realiza um trabalho voluntário junto às clínicas de radioterapia e preparou o banco de dados baseado em relatos voluntários dos profissionais da equipe de radioterapia sobre os incidentes 
ocorridos e ações corretivas, através da internet. Um formulário de registro é preenchido pelo participante colaborador fornecendo os detalhes de sua clínica e a pessoa de contato responsável pelo relatório receberá um número de identificação. Toda a informação submetida é anônima. Os detalhes da clínica são confidenciais e não podem ser acessados por outros usuários. O formulário de registro inclui detalhes do equipamento, da equipe de funcionários e do ambiente do seu centro. Esta informação relaciona-se à complexidade dos processos dentro dos departamentos e foi utilizada pelo grupo ROSIS com o objetivo de realizar uma análise da tendência da severidade dos incidentes com relação à complexidade da prática clínica, ao ambiente de funcionamento e à formação educacional da equipe de funcionários relacionados com os tipos de clínicas.

\subsubsection{Cenário de Investigação}

Foi construído o banco de dados a fim de armazenar as informações contidas na tabela criada posteriormente com as características dos acidentes ocorridos. A tabela assim construída apresenta, para cada evento analisado, as informações sobre os seguintes parâmetros: o número de identificação do evento; a modalidade de tratamento investigada, neste caso externa; a data da descoberta; o processo de detecção; o número de pacientes afetados; o grau de severidade; uma pequena descrição sobre o acidente,; a causa; sugestão para evitar o erro, quando disponíveis. Após inserir estas informações os eventos foram classificados de acordo com o tipo de erro.

Os eventos examinados seguiram as categorias de tratamento com feixe de fótons e elétrons de aceleradores lineares e tratamentos com cobalto, investigando-se os parâmetros pertinentes à esses tipos de tratamento. Os erros investigados foram:

A. Erros relacionados à fixação ou imobilização do paciente como:

- Procedimento com o suporte de tratamento incorreto, utilização do suporte de tratamento sem ser solicitado;

- Posição do paciente incorreta, posicionado durante o tratamento de forma invertida à da posição na simulação virtual; 
- Imobilização inadequada, como a contenção da máscara utilizada incorretamente;

- Faltando o filtro compensador, não observado na preparação do tratamento;

- Filtro compensador incorreto, como erro no planejamento;

- Fixação inadequada do acessório de tratamento, como o acessório ajustado incorretamente;

- Cunha dinâmica incorreta, como o código da cunha estava incorreto;

- Sistema de fixação do paciente inadequado; como o paciente era cego e embora fixado à mesa de tratamento, desequilibrou-se vindo a cair;

- Faltando a imobilização.

B. Erros relacionados aos modificadores do feixe como:

- Bólus incorreto, como posicionamento incorreto ou omissão;

- Faltando a cunha, ausência do acessório durante o tratamento;

- Direção da cunha incorreta, uma mudança manual da orientação da cunha no sistema de registro e verificação não foi realizada após exportar o plano;

- Faltando o filtro dinâmico;

- Cunha incorreta, número de identificação da cunha incorreta.

C. Erros relacionados ao sistema de planejamento ou equipamento como:

- Campo não tratado, registro do sistema Varis incorreto;

- Falha no equipamento, mecânica ou eletrônica;

- Fator de rendimento da máquina incorreto.

D. Erros relacionados à dose como: 
- Coordenada de tratamento incorreta, como SSD incorreta, angulação da mesa de tratamento incorreta;

- Cálculo incorreto, por exemplo, usando o fator de rendimento da máquina para a energia errada;

- Dose incorreta, como a modificação da dose na ficha e não observada durante o processo de verificação;

- Unidade monitora (UM) incorreta, como erro na leitura da ficha de tratamento;

- Campo de tratamento incorreto, prescrição incorreta na ficha do paciente;

- Energia incorreta, o tratamento é planejado para a energia de fótons de $10 \mathrm{MV}$, porém a prescrição dada é para energia de fótons de $6 \mathrm{MV}$;

- Dose da fração de tratamento incorreta, ocorrendo erro de cálculo;

- Fração de tratamento incorreta, números de frações a mais ou a menos sendo aplicada no tratamento.

E. Erros relacionados à imagem como:

- Imagem de CT incorreta, como a transferência de imagens de outro paciente;

- DRR (Radiografia Reconstruída Digitalmente) incorreta, como transferência incorreta;

- Filme de verificação incorreto, como o filme etiquetado do lado reverso;

- Verificação incorreta da imagem, erro no posicionamento;

- DRR não criada, falha processual na criação das imagens;

- Falha no sistema de verificação do ISO - campo, o campo ordinário é exposto com 1 UM somente para verificação e depois abortado, a seqüência não foi interrompida após o plano de verificação da posição do isocentro (PVI) como era suposto; 
- Direção do "Beam's eye view" (BEV) incorreta;

- Faltando a imagem de Tomografia Computadorizada.

F. Erros relacionados a bloco de proteção/colimador de múltiplas lâminas como:

- Bloco de proteção incorreto, por exemplo, o código incorreto para o chumbo colocado no sistema de verificação, e não verificado até o tratamento;

- Faltando o bloco de proteção, o bloco de chumbo foi prescrito, mas não posicionado durante o tratamento;

- Forma do colimador de múltiplas lâminas incorreta, como posicionamento no quadrante incorreto;

- Faltando o colimador de múltiplas lâminas;

- Suporte incorreto do bloco de proteção, utilização das bandejas de blocos do curso de tratamento anterior.

G. Erros técnicos como:

- Dimensões incorretas do campo, como por exemplo, um campo ajustado com dimensões invertidas de $18 \mathrm{~cm}$ por $20 \mathrm{~cm}$ em vez de $20 \mathrm{~cm}$ por $18 \mathrm{~cm}$;

- Ângulo do colimador incorreto, a rotação do colimador não foi realizada quando o bloco foi preparado;

- Ângulo do cabeçote incorreto, como um tratamento utilizando a técnica de 3 campos em que foram prescritos três ângulos do cabeçote, mas somente um ângulo foi utilizado;

- Acessório inadequado, como a utilização do aplicador de elétrons de outra máquina de tratamento;

- Procedimento com o plano incorreto, como exemplo o plano não foi emitido a tempo do escritório da radioterapia;

- Delineação do volume alvo incorreta;

H. Erros relacionados ao paciente/documentação como: 
- Erro de identificação e registro do paciente, como nomes semelhantes de dois pacientes que foram trocados;

- Data do tratamento incorreta, os tratamentos deveriam ocorrer em datas alternadas;

- Conflito entre a quimioterapia e a radioterapia, a quimioterapia dada em seguida à radioterapia;

- Campo tratado e não registrado, como erro na documentação;

- Faltando o campo de tratamento;

- Marca-passo não notificado, falta de informação na ficha de tratamento.

A partir dos dados disponíveis foram realizadas análises de freqüência da ocorrência dos acidentes/incidentes com o mesmo tipo de erro, a freqüência para o grau de severidade ocorrida, a freqüência para cada forma do processo de detecção e a freqüência do número de pacientes expostos. 


\section{CAPÍTULO 3}

\subsection{Resultados e Discussões}

\subsubsection{Banco de Dados}

Na FIGURA 3.1 é apresentado um exemplo da janela do formulário referente à TABELA 3.1 construída contendo as características do evento ocorrido disponibilizado no Banco de Dados do ROSIS ${ }^{8}$. Para cada evento cadastrado foi acrescentada a característica "tipo de erro".

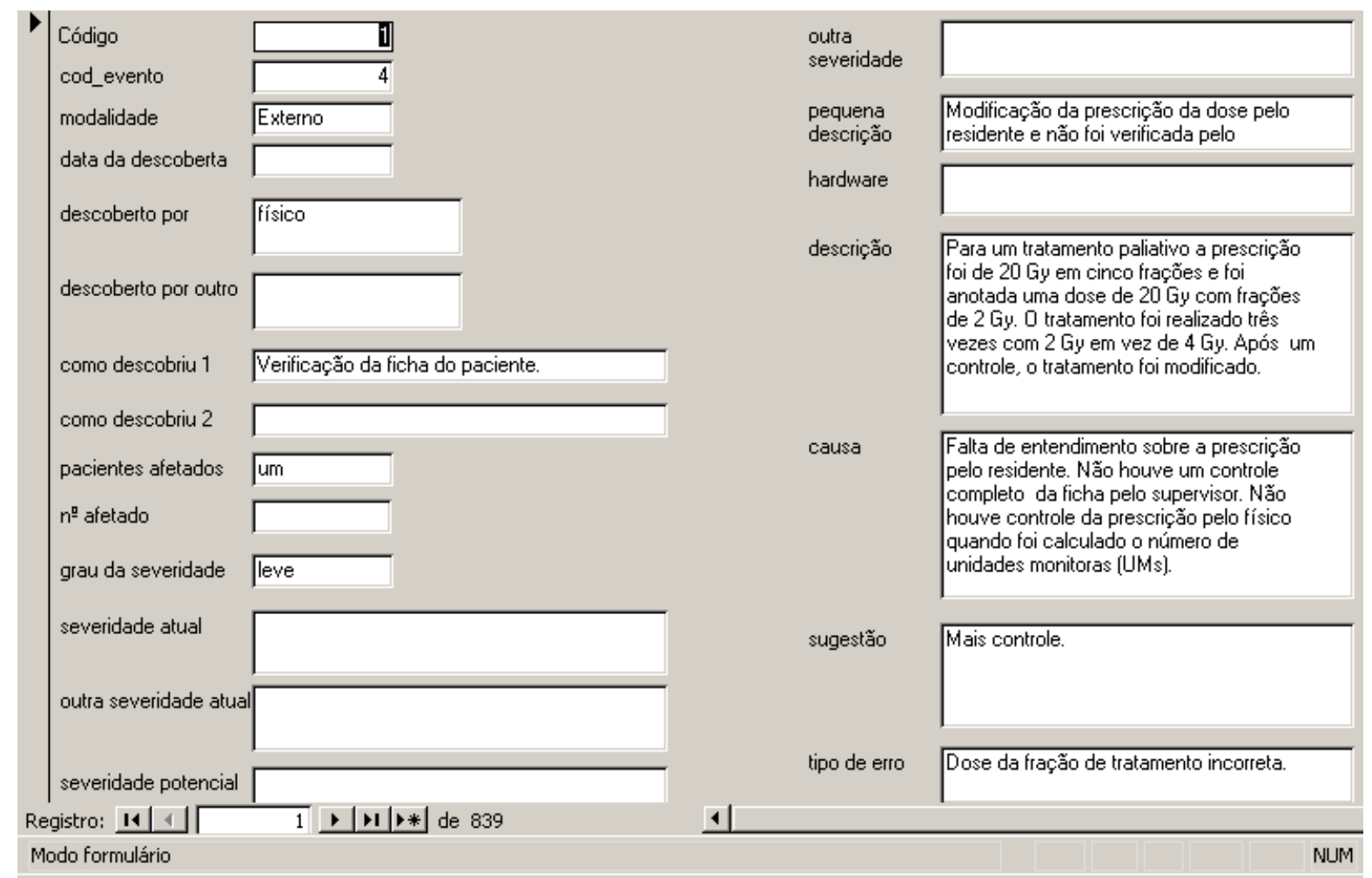

FIGURA 3.1. Formulário do Banco de Dados referente ao primeiro evento cadastrado. 
Na FIGURA 3.2. é apresentado um exemplo da janela do formulário referente à tabela contendo as características de um acidente recente ocorrido e acrescentado ao banco de dados.

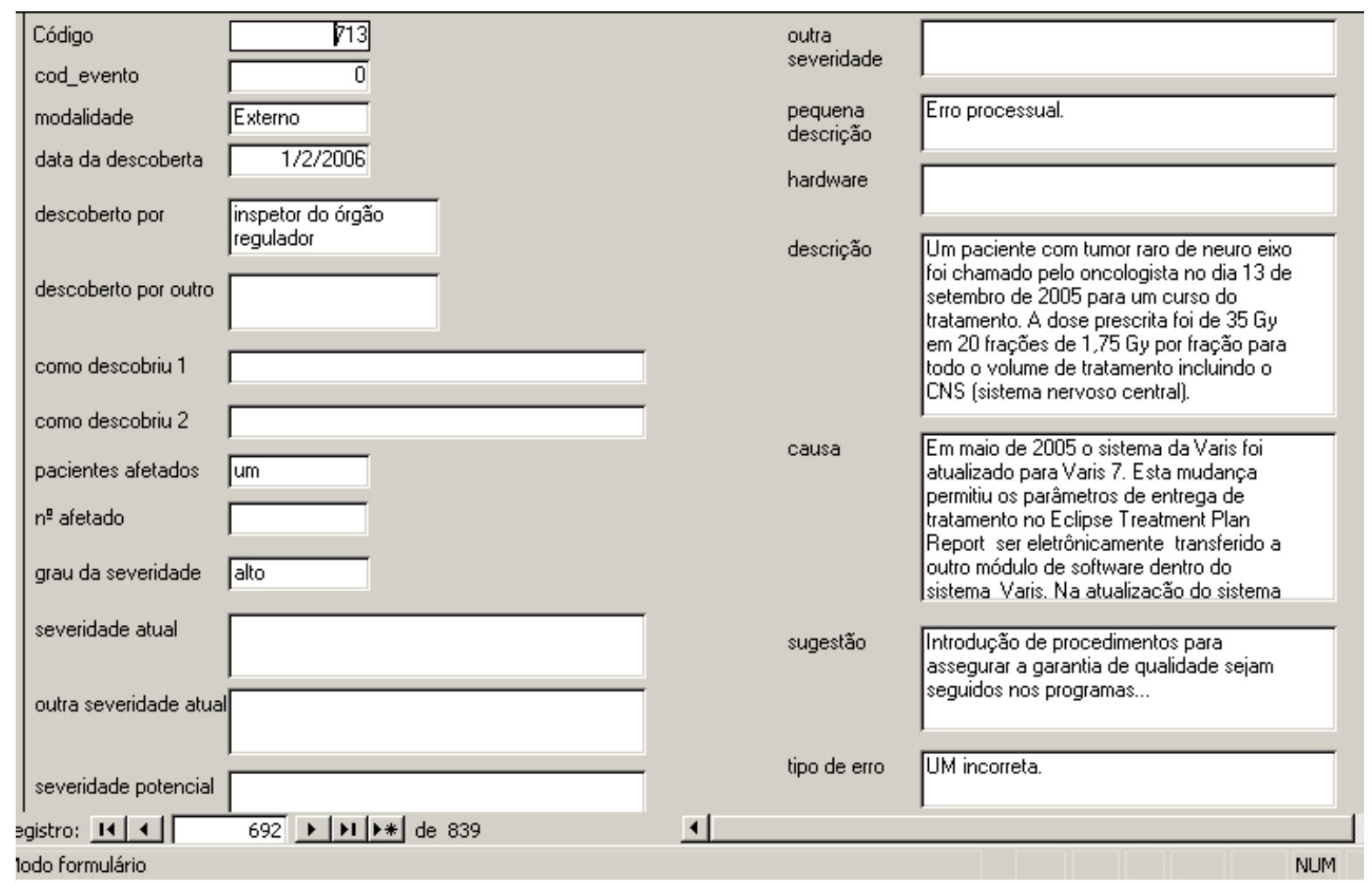

FIGURA 3.2 Formulário do Banco de Dados referente ao evento cadastrado de um acidente recente.

Como verificado nos registros (canto inferior esquerdo), ao todo são 839 eventos cadastrados. Todos os dados são inseridos em tabelas, e a partir destas tabelas são criados os formulários visualizados nas janelas.

Nos registros do banco de dados, analisando todos os incidentes foram identificados 50 tipos de erros mostrados na TABELA 3.1. O banco de dados fornece ainda informações sobre o processo de detecção do evento relacionado ao tipo de erro e a freqüência ocorrida. Do total dos 839 eventos, 29 eventos não trazem nenhuma informação sobre o processo de detecção, assim a TABELA 3.1 foi construída relacionando o tipo de erro, a freqüência dos eventos ocorridos e o processo de detecção dispostos em ordem decrescente de acordo a incidência do tipo de erro. 
TABELA 3.1. Freqüência dos eventos cadastrados no Banco de Dados relacionados ao tipo de erro e processo de detecção como o $\mathrm{CQ}$ (Controle de Qualidade) do equipamento.

\begin{tabular}{|c|c|c|c|c|c|c|}
\hline \multicolumn{2}{|c|}{ Tipo de Erro } & \multicolumn{5}{|c|}{ Processo de Detecção (\%) } \\
\hline & $\begin{array}{c}\text { No. de }^{\circ} \\
\text { Eventos } \\
(\%)\end{array}$ & $\begin{array}{c}\text { CQ } \\
\text { do } \\
\text { equip. }\end{array}$ & $\begin{array}{c}\text { Descoberto } \\
\text { no } \\
\text { momento } \\
\text { do } \\
\text { tratamento. }\end{array}$ & $\begin{array}{l}\text { Dosimetria } \\
\text { ou } \\
\text { Dosimetria } \\
\text { in vivo. }\end{array}$ & $\begin{array}{c}\text { Imagem } \\
\text { portal } \\
\text { por } \\
\text { filme } \\
\text { ou } \\
\text { EPID. }\end{array}$ & $\begin{array}{c}\text { Verificação } \\
\text { da ficha } \\
\text { ou } \\
\text { Revisão } \\
\text { clínica do } \\
\text { paciente. }\end{array}$ \\
\hline $\begin{array}{l}1 \text { - } \\
\text { Coordenada } \\
\text { de tratamento } \\
\text { incorreta. }^{*}\end{array}$ & $\begin{array}{c}243 \\
(28,96 \%)\end{array}$ & $\begin{array}{c}1 \\
(0,12 \%)\end{array}$ & $\begin{array}{c}95 \\
(11,73 \%)\end{array}$ & $\begin{array}{c}2 \\
(0,25 \%)\end{array}$ & $\begin{array}{c}31 \\
(3,83 \%)\end{array}$ & $\begin{array}{c}99 \\
(12,22 \%)\end{array}$ \\
\hline $\begin{array}{l}2 \text { - Dimensão } \\
\text { do campo } \\
\text { incorreta. * }\end{array}$ & $\begin{array}{c}49 \\
(5,84 \%)\end{array}$ & $\begin{array}{c}2 \\
(0,25 \%)\end{array}$ & $\begin{array}{c}24 \\
(2,96 \%)\end{array}$ & 0 & $\begin{array}{c}3 \\
(0,37 \%)\end{array}$ & $\begin{array}{c}20 \\
(2,47 \%)\end{array}$ \\
\hline $\begin{array}{l}3 \text { - Cálculo } \\
\text { incorreto. * }\end{array}$ & $\begin{array}{c}43 \\
(5,13 \%) \\
\end{array}$ & 0 & $\begin{array}{c}10 \\
(1,23 \%) \\
\end{array}$ & 0 & 0 & $\begin{array}{c}31 \\
(3,83 \%) \\
\end{array}$ \\
\hline $\begin{array}{l}4 \text { - Dose } \\
\text { incorreta. }\end{array}$ & $\begin{array}{c}43 \\
(5,13 \%) \\
\end{array}$ & $\begin{array}{c}3 \\
(0,37 \%) \\
\end{array}$ & $\begin{array}{c}8 \\
(0,99 \%) \\
\end{array}$ & $\begin{array}{c}1 \\
(0,12 \%) \\
\end{array}$ & 0 & $\begin{array}{c}32 \\
(3,95 \%) \\
\end{array}$ \\
\hline $\begin{array}{l}5 \text { - Ângulo do } \\
\text { colimador } \\
\text { incorreto. * }\end{array}$ & $\begin{array}{c}36 \\
(4,29 \%)\end{array}$ & 0 & $\begin{array}{c}12 \\
(1,48 \%)\end{array}$ & 0 & $\begin{array}{c}9 \\
(1,11 \%)\end{array}$ & $\begin{array}{c}18 \\
(2,22 \%)\end{array}$ \\
\hline $\begin{array}{l}6 \text { - Bloco de } \\
\text { proteção } \\
\text { incorreto. * }\end{array}$ & $\begin{array}{c}33 \\
(3,93 \%)\end{array}$ & $\begin{array}{c}1 \\
(0,12 \%)\end{array}$ & $\begin{array}{c}14 \\
(1,73 \%)\end{array}$ & 0 & $\begin{array}{c}12 \\
(1,48 \%)\end{array}$ & $\begin{array}{c}4 \\
(0,49 \%)\end{array}$ \\
\hline $\begin{array}{l}7 \text { - Bólus } \\
\text { incorreto. }\end{array}$ & $\begin{array}{c}33 \\
(3,93 \%) \\
\end{array}$ & 0 & $\begin{array}{c}24 \\
(2,96 \%) \\
\end{array}$ & 0 & 0 & $\begin{array}{c}4 \\
(0,49 \%) \\
\end{array}$ \\
\hline TOTAL & $\begin{array}{c}839 \\
(100 \%)\end{array}$ & $\begin{array}{c}16 \\
(1,98 \%)\end{array}$ & $\begin{array}{c}360 \\
(44,44 \%)\end{array}$ & $\begin{array}{c}6 \\
(0,74 \%)\end{array}$ & $\begin{array}{c}77 \\
(9,51 \%)\end{array}$ & $\begin{array}{c}351 \\
(43,33 \%)\end{array}$ \\
\hline
\end{tabular}

* Tipos de erros encontrados no trabalho de pesquisa de Klein et al ${ }^{59}$. 


\begin{tabular}{|c|c|c|c|c|c|c|}
\hline \multicolumn{2}{|c|}{ Tipo de Erro } & \multicolumn{5}{|c|}{ Processo de Detecção (\%) } \\
\hline & $\begin{array}{c}\mathrm{N}^{\circ} \text {. de } \\
\text { Eventos } \\
(\%)\end{array}$ & $\begin{array}{c}C Q \\
\text { do } \\
\text { equip. }\end{array}$ & $\begin{array}{c}\text { Descoberto } \\
\text { no } \\
\text { momento } \\
\text { do } \\
\text { tratamento. }\end{array}$ & $\begin{array}{l}\text { Dosimetria } \\
\text { ou } \\
\text { Dosimetria } \\
\text { in vivo. }\end{array}$ & $\begin{array}{c}\text { Imagem } \\
\text { portal } \\
\text { por } \\
\text { filme } \\
\text { ou } \\
\text { EPID. }\end{array}$ & $\begin{array}{c}\text { Verificação } \\
\text { da ficha } \\
\text { ou } \\
\text { Revisão } \\
\text { clínica do } \\
\text { paciente. }\end{array}$ \\
\hline $\begin{array}{l}8 \text { - Unidade } \\
\text { Monitora } \\
\text { incorreta. * }\end{array}$ & $\begin{array}{c}33 \\
(3,93 \%)\end{array}$ & 0 & $\begin{array}{c}12 \\
(1,48 \%)\end{array}$ & $\begin{array}{c}2 \\
(0,25 \%)\end{array}$ & 0 & $\begin{array}{c}16 \\
(1,98 \%)\end{array}$ \\
\hline $\begin{array}{l}9 \text { - Campo de } \\
\text { tratamento } \\
\text { incorreto. }\end{array}$ & $\begin{array}{c}31 \\
(3,69 \%)\end{array}$ & 0 & $\begin{array}{c}13 \\
(1,60 \%)\end{array}$ & 0 & $\begin{array}{c}5 \\
(0,62 \%)\end{array}$ & $\begin{array}{c}7 \\
(0,86 \%)\end{array}$ \\
\hline $\begin{array}{l}10 \text { - Erro de } \\
\text { identificação e } \\
\text { registro do } \\
\text { paciente. }\end{array}$ & $\begin{array}{c}30 \\
(3,58 \%)\end{array}$ & 0 & $\begin{array}{c}13 \\
(1,60 \%)\end{array}$ & 0 & 0 & $\begin{array}{c}15 \\
(1,85 \%)\end{array}$ \\
\hline $\begin{array}{l}11 \text { - Energia } \\
\text { incorreta. }\end{array}$ & $\begin{array}{c}25 \\
(2,98 \%)\end{array}$ & $\begin{array}{c}4 \\
(0,49 \%)\end{array}$ & $\begin{array}{c}14 \\
(1,73 \%)\end{array}$ & 0 & 0 & $\begin{array}{c}10 \\
(1,23 \%)\end{array}$ \\
\hline $\begin{array}{l}12 \text { - } \\
\text { Procedimento } \\
\text { com o plano } \\
\text { incorreto. }\end{array}$ & $\begin{array}{c}25 \\
(2,98 \%)\end{array}$ & 0 & $\begin{array}{c}9 \\
(1,11 \%)\end{array}$ & 0 & $\begin{array}{c}3 \\
(0,37 \%)\end{array}$ & $\begin{array}{c}10 \\
(1,23 \%)\end{array}$ \\
\hline $\begin{array}{l}13 \text { - Fração de } \\
\text { tratamento } \\
\text { incorreta. * }\end{array}$ & $\begin{array}{c}17 \\
(2,03 \%)\end{array}$ & 0 & $\begin{array}{c}4 \\
(0,49 \%)\end{array}$ & 0 & 0 & $\begin{array}{c}13 \\
(1,60 \%)\end{array}$ \\
\hline $\begin{array}{l}14 \text { - Dose da } \\
\text { fração de } \\
\text { tratamento } \\
\text { incorreta. }\end{array}$ & $\begin{array}{c}17 \\
(2,03 \%)\end{array}$ & 0 & 0 & 0 & 0 & $\begin{array}{c}14 \\
(1,73 \%)\end{array}$ \\
\hline $\begin{array}{l}15 \text { - Faltando } \\
\text { o bloco de } \\
\text { proteção. }\end{array}$ & $\begin{array}{c}17 \\
(2,03 \%)\end{array}$ & 0 & $\begin{array}{c}12 \\
(1,48 \%)\end{array}$ & 0 & $\begin{array}{c}1 \\
(0,12 \%)\end{array}$ & $\begin{array}{c}2 \\
(0,25 \%)\end{array}$ \\
\hline TOTAL & $\begin{array}{c}839 \\
(100 \%)\end{array}$ & $\begin{array}{c}16 \\
(1,98 \%)\end{array}$ & $\begin{array}{c}360 \\
(44,44 \%)\end{array}$ & $\begin{array}{c}6 \\
(0,74 \%)\end{array}$ & $\begin{array}{c}77 \\
(9,51 \%)\end{array}$ & $\begin{array}{c}351 \\
(43,33 \%)\end{array}$ \\
\hline
\end{tabular}




\begin{tabular}{|c|c|c|c|c|c|c|}
\hline \multicolumn{2}{|c|}{ Tipo de Erro } & \multicolumn{5}{|c|}{ Processo de Detecção (\%) } \\
\hline & $\begin{array}{c}\text { No. de }^{\circ} \\
\text { Eventos } \\
(\%)\end{array}$ & $\begin{array}{c}C Q \\
\text { do } \\
\text { equip. }\end{array}$ & $\begin{array}{c}\text { Descoberto } \\
\text { no } \\
\text { momento } \\
\text { do } \\
\text { tratamento. }\end{array}$ & $\begin{array}{c}\text { Dosimetria } \\
\text { ou } \\
\text { Dosimetria } \\
\text { in vivo. }\end{array}$ & $\begin{array}{c}\text { Imagem } \\
\text { portal } \\
\text { por } \\
\text { filme } \\
\text { ou } \\
\text { EPID. }\end{array}$ & $\begin{array}{c}\text { Verificação } \\
\text { da ficha } \\
\text { ou } \\
\text { Revisão } \\
\text { clínica do } \\
\text { paciente. }\end{array}$ \\
\hline $\begin{array}{l}16 \text { - } \\
\text { Procedimento } \\
\text { com o suporte } \\
\text { de tratamento } \\
\text { incorreto. }\end{array}$ & $\begin{array}{c}17 \\
(2,03 \%)\end{array}$ & 0 & $\begin{array}{c}9 \\
(1,11 \%)\end{array}$ & 0 & $\begin{array}{c}1 \\
(0,12 \%)\end{array}$ & $\begin{array}{c}6 \\
(0,74 \%)\end{array}$ \\
\hline $\begin{array}{l}17 \text { - Forma do } \\
\text { MLC incorreta. } \\
*\end{array}$ & $\begin{array}{c}16 \\
(1,91 \%)\end{array}$ & 0 & $\begin{array}{c}7 \\
(0,86 \%)\end{array}$ & 0 & $\begin{array}{c}2 \\
(0,25 \%)\end{array}$ & $\begin{array}{c}4 \\
(0,49 \%)\end{array}$ \\
\hline $\begin{array}{l}18 \text { - Ângulo do } \\
\text { cabeçote } \\
\text { incorreto. * }\end{array}$ & $\begin{array}{c}13 \\
(1,55 \%)\end{array}$ & 0 & $\begin{array}{c}10 \\
(1,23 \%)\end{array}$ & 0 & 0 & $\begin{array}{c}3 \\
(0,37 \%)\end{array}$ \\
\hline $\begin{array}{l}19 \text { - Campo } \\
\text { não tratado. }\end{array}$ & $\begin{array}{c}11 \\
(1,31 \%) \\
\end{array}$ & $\begin{array}{c}1 \\
(0,12 \%) \\
\end{array}$ & $\begin{array}{c}6 \\
(0,74 \%) \\
\end{array}$ & 0 & 0 & $\begin{array}{c}4 \\
(0,49 \%) \\
\end{array}$ \\
\hline $\begin{array}{l}20 \text { - Faltando } \\
\text { a cunha. }\end{array}$ & $\begin{array}{c}10 \\
(1,19 \%) \\
\end{array}$ & $\begin{array}{c}1 \\
(0,12 \%) \\
\end{array}$ & $\begin{array}{c}5 \\
(0,62 \%) \\
\end{array}$ & 0 & 0 & $\begin{array}{c}4 \\
(0,49 \%) \\
\end{array}$ \\
\hline $\begin{array}{l}21 \text { - Faltando } \\
\text { o MLC. * }\end{array}$ & $\begin{array}{c}9 \\
(1,07 \%) \\
\end{array}$ & 0 & $\begin{array}{c}1 \\
(0,12 \%) \\
\end{array}$ & 0 & $\begin{array}{c}4 \\
(0,49 \%) \\
\end{array}$ & $\begin{array}{c}2 \\
(0,25 \%) \\
\end{array}$ \\
\hline $\begin{array}{l}22 \text { - Imagem } \\
\text { de CT } \\
\text { incorreta. }\end{array}$ & $\begin{array}{c}7 \\
(0,83 \%)\end{array}$ & 0 & $\begin{array}{c}1 \\
(0,12 \%)\end{array}$ & 0 & 0 & $\begin{array}{c}2 \\
(0,25 \%)\end{array}$ \\
\hline $\begin{array}{l}23 \text { - Data do } \\
\text { tratamento } \\
\text { incorreta. }\end{array}$ & $\begin{array}{c}6 \\
(0,72 \%)\end{array}$ & 0 & $\begin{array}{c}4 \\
(0,49 \%)\end{array}$ & 0 & 0 & $\begin{array}{c}2 \\
(0,25 \%)\end{array}$ \\
\hline $\begin{array}{l}24 \text { - Direção } \\
\text { da cunha } \\
\text { incorreta. * }\end{array}$ & $\begin{array}{c}5 \\
(0,60 \%)\end{array}$ & 0 & $\begin{array}{c}2 \\
(0,25 \%)\end{array}$ & 0 & 0 & $\begin{array}{c}3 \\
(0,37 \%)\end{array}$ \\
\hline TOTAL & $\begin{array}{c}839 \\
(100 \%)\end{array}$ & $\begin{array}{c}16 \\
(1,98 \%)\end{array}$ & $\begin{array}{c}360 \\
(44,44 \%)\end{array}$ & $\begin{array}{c}6 \\
(0,74 \%)\end{array}$ & $\begin{array}{c}77 \\
(9,51 \%)\end{array}$ & $\begin{array}{c}351 \\
(43,33 \%)\end{array}$ \\
\hline
\end{tabular}




\begin{tabular}{|c|c|c|c|c|c|c|}
\hline \multicolumn{2}{|c|}{ Tipo de Erro } & \multicolumn{5}{|c|}{ Processo de Detecção (\%) } \\
\hline & $\begin{array}{c}\mathrm{N}^{\circ} \text {. de } \\
\text { Eventos } \\
(\%)\end{array}$ & $\begin{array}{c}C Q \\
\text { do } \\
\text { equip. }\end{array}$ & $\begin{array}{c}\text { Descoberto } \\
\text { no } \\
\text { momento } \\
\text { do } \\
\text { tratamento. }\end{array}$ & $\begin{array}{l}\text { Dosimetria } \\
\text { ou } \\
\text { Dosimetria } \\
\text { in vivo. }\end{array}$ & $\begin{array}{c}\text { Imagem } \\
\text { portal } \\
\text { por } \\
\text { filme } \\
\text { ou } \\
\text { EPID. }\end{array}$ & $\begin{array}{c}\text { Verificação } \\
\text { da ficha } \\
\text { ou } \\
\text { Revisão } \\
\text { clínica do } \\
\text { paciente. }\end{array}$ \\
\hline $\begin{array}{l}25 \text { - DRR } \\
\text { incorreta. }\end{array}$ & $\begin{array}{c}5 \\
(0,60 \%) \\
\end{array}$ & 0 & 0 & 0 & $\begin{array}{c}2 \\
(0,25 \%) \\
\end{array}$ & $\begin{array}{c}2 \\
(0,25 \%) \\
\end{array}$ \\
\hline $\begin{array}{l}26 \text { - Falha no } \\
\text { equipamento. }\end{array}$ & $\begin{array}{c}5 \\
(0,60 \%)\end{array}$ & 0 & $\begin{array}{c}1 \\
(0,12 \%)\end{array}$ & $\begin{array}{c}1 \\
(0,12 \%)\end{array}$ & 0 & 0 \\
\hline $\begin{array}{l}27 \text { - Posição } \\
\text { do paciente } \\
\text { incorreta. }\end{array}$ & $\begin{array}{c}5 \\
(0,60 \%)\end{array}$ & 0 & $\begin{array}{c}3 \\
(0,37 \%)\end{array}$ & 0 & 0 & $\begin{array}{c}1 \\
(0,12 \%)\end{array}$ \\
\hline $\begin{array}{l}28 \text { - } \\
\text { Imobilização } \\
\text { inadequada. }\end{array}$ & $\begin{array}{c}5 \\
(0,60 \%)\end{array}$ & 0 & $\begin{array}{c}3 \\
(0,37 \%)\end{array}$ & 0 & 0 & 0 \\
\hline $\begin{array}{l}29 \text { - Suporte } \\
\text { incorreto do } \\
\text { bloco de } \\
\text { proteção. }\end{array}$ & $\begin{array}{c}4 \\
(0,48 \%)\end{array}$ & 0 & $\begin{array}{c}3 \\
(0,37 \%)\end{array}$ & 0 & 0 & 0 \\
\hline $\begin{array}{l}30 \text { - Conflito } \\
\text { entre a } \\
\text { quimioterapia } \\
\text { e radioterapia. }\end{array}$ & $\begin{array}{c}4 \\
(0,48 \%)\end{array}$ & 0 & $\begin{array}{c}3 \\
(0,37 \%)\end{array}$ & 0 & 0 & 0 \\
\hline $\begin{array}{l}31 \text { - Campo } \\
\text { tratado e não } \\
\text { registrado. }\end{array}$ & $\begin{array}{c}4 \\
(0,48 \%)\end{array}$ & $\begin{array}{c}2 \\
(0,25 \%)\end{array}$ & $\begin{array}{c}1 \\
(0,12 \%)\end{array}$ & 0 & 0 & $\begin{array}{c}2 \\
(0,25 \%)\end{array}$ \\
\hline $\begin{array}{l}32 \text { - Faltando } \\
\text { o filtro } \\
\text { compensador. } \\
*\end{array}$ & $\begin{array}{c}4 \\
(0,48 \%)\end{array}$ & 0 & $\begin{array}{c}2 \\
(0,25 \%)\end{array}$ & 0 & 0 & 0 \\
\hline TOTAL & $\begin{array}{c}839 \\
(100 \%)\end{array}$ & $\begin{array}{c}16 \\
(1,98 \%)\end{array}$ & $\begin{array}{c}360 \\
(44,44 \%)\end{array}$ & $\begin{array}{c}6 \\
(0,74 \%)\end{array}$ & $\begin{array}{c}77 \\
(9,51 \%)\end{array}$ & $\begin{array}{c}351 \\
(43,33 \%)\end{array}$ \\
\hline
\end{tabular}




\begin{tabular}{|c|c|c|c|c|c|c|}
\hline \multicolumn{2}{|c|}{ Tipo de Erro } & \multicolumn{5}{|c|}{ Processo de Detecção (\%) } \\
\hline & $\begin{array}{c}\mathrm{N}^{\circ} \text {. de } \\
\text { Eventos } \\
(\%)\end{array}$ & $\begin{array}{c}\text { CQ } \\
\text { do } \\
\text { equip. }\end{array}$ & $\begin{array}{c}\text { Descoberto } \\
\text { no } \\
\text { momento } \\
\text { do } \\
\text { tratamento. }\end{array}$ & $\begin{array}{c}\text { Dosimetria } \\
\text { ou } \\
\text { Dosimetria } \\
\text { in vivo. }\end{array}$ & $\begin{array}{c}\text { Imagem } \\
\text { portal } \\
\text { por } \\
\text { filme } \\
\text { ou } \\
\text { EPID. }\end{array}$ & $\begin{array}{c}\text { Verificação } \\
\text { da ficha } \\
\text { ou } \\
\text { Revisão } \\
\text { clínica do } \\
\text { paciente. }\end{array}$ \\
\hline $\begin{array}{l}33 \text { - Filtro } \\
\text { compensador } \\
\text { incorreto. * }\end{array}$ & $\begin{array}{c}4 \\
(0,48 \%)\end{array}$ & 0 & 0 & 0 & 0 & $\begin{array}{c}2 \\
(0,25 \%)\end{array}$ \\
\hline $\begin{array}{l}34 \text { - Fixação } \\
\text { inadequada do } \\
\text { acessório de } \\
\text { tratamento. }\end{array}$ & $\begin{array}{c}3 \\
(0,36 \%)\end{array}$ & 0 & $\begin{array}{c}2 \\
(0,25 \%)\end{array}$ & 0 & 0 & 0 \\
\hline $\begin{array}{l}35 \text { - DRR não } \\
\text { criada. }\end{array}$ & $\begin{array}{c}3 \\
(0,36 \%) \\
\end{array}$ & 0 & 0 & 0 & 0 & $\begin{array}{c}3 \\
(0,37 \%) \\
\end{array}$ \\
\hline $\begin{array}{l}36 \text { - Cunha } \\
\text { dinâmica } \\
\text { incorreta. }\end{array}$ & $\begin{array}{c}3 \\
(0,36 \%)\end{array}$ & 0 & $\begin{array}{c}1 \\
(0,12 \%)\end{array}$ & 0 & 0 & $\begin{array}{c}2 \\
(0,25 \%)\end{array}$ \\
\hline $\begin{array}{l}37 \text { - Filme de } \\
\text { verificação } \\
\text { incorreto. }\end{array}$ & $\begin{array}{c}3 \\
(0,36 \%)\end{array}$ & 0 & $\begin{array}{c}1 \\
(0,12 \%)\end{array}$ & 0 & $\begin{array}{c}1 \\
(0,12 \%)\end{array}$ & 0 \\
\hline $\begin{array}{l}38 \text { - } \\
\text { Verificação } \\
\text { incorreta da } \\
\text { imagem. }\end{array}$ & $\begin{array}{c}3 \\
(0,36 \%)\end{array}$ & 0 & 0 & 0 & $\begin{array}{c}3 \\
(0,37 \%)\end{array}$ & 0 \\
\hline $\begin{array}{l}39 \text { - Faltando } \\
\text { o campo de } \\
\text { tratamento. }\end{array}$ & $\begin{array}{c}2 \\
(0,24 \%)\end{array}$ & 0 & 0 & 0 & 0 & $\begin{array}{c}2 \\
(0,25 \%)\end{array}$ \\
\hline $\begin{array}{l}40 \text { - Marca- } \\
\text { passo não } \\
\text { notificado. }\end{array}$ & $\begin{array}{c}2 \\
(0,24 \%)\end{array}$ & 0 & $\begin{array}{c}1 \\
(0,12 \%)\end{array}$ & 0 & 0 & 0 \\
\hline TOTAL & $\begin{array}{c}839 \\
(100 \%)\end{array}$ & $\begin{array}{c}16 \\
(1,98 \%)\end{array}$ & $\begin{array}{c}360 \\
(44,44 \%)\end{array}$ & $\begin{array}{c}6 \\
(0,74 \%)\end{array}$ & $\begin{array}{c}77 \\
(9,51 \%)\end{array}$ & $\begin{array}{c}351 \\
(43,33 \%)\end{array}$ \\
\hline
\end{tabular}




\begin{tabular}{|c|c|c|c|c|c|c|}
\hline \multicolumn{2}{|c|}{ Tipo de Erro } & \multicolumn{5}{|c|}{ Processo de Detecção (\%) } \\
\hline & $\begin{array}{c}\mathrm{N}^{\circ} \text {. de } \\
\text { Eventos } \\
(\%)\end{array}$ & $\begin{array}{c}C Q \\
\text { do } \\
\text { equip. }\end{array}$ & $\begin{array}{c}\text { Descoberto } \\
\text { no } \\
\text { momento } \\
\text { do } \\
\text { tratamento. }\end{array}$ & $\begin{array}{c}\text { Dosimetria } \\
\text { ou } \\
\text { Dosimetria } \\
\text { in vivo. }\end{array}$ & $\begin{array}{c}\text { Imagem } \\
\text { portal } \\
\text { por } \\
\text { filme } \\
\text { ou } \\
\text { EPID. }\end{array}$ & $\begin{array}{c}\text { Verificação } \\
\text { da ficha } \\
\text { ou } \\
\text { Revisão } \\
\text { clínica do } \\
\text { paciente. }\end{array}$ \\
\hline $\begin{array}{l}41 \text { - Falha no } \\
\text { sistema de } \\
\text { verificação do } \\
\text { ISO- campo. }\end{array}$ & $\begin{array}{c}2 \\
(0,24 \%)\end{array}$ & 0 & 0 & 0 & 0 & $\begin{array}{c}1 \\
(0,12 \%)\end{array}$ \\
\hline $\begin{array}{l}42 \text { - Acessório } \\
\text { inadequado. }\end{array}$ & $\begin{array}{c}1 \\
(0,12 \%)\end{array}$ & 0 & $\begin{array}{c}1 \\
(0,12 \%)\end{array}$ & 0 & 0 & 0 \\
\hline $\begin{array}{l}43 \text { - } \\
\text { Delineação do } \\
\text { volume alvo } \\
\text { incorreta. }\end{array}$ & $\begin{array}{c}1 \\
(0,12 \%)\end{array}$ & 0 & 0 & 0 & 0 & 0 \\
\hline $\begin{array}{l}44 \text { - Sistema } \\
\text { de fixação do } \\
\text { paciente } \\
\text { inadequado. }\end{array}$ & $\begin{array}{c}1 \\
(0,12 \%)\end{array}$ & 0 & $\begin{array}{c}1 \\
(0,12 \%)\end{array}$ & 0 & 0 & 0 \\
\hline $\begin{array}{l}45 \text { - Faltando } \\
\text { o filtro } \\
\text { dinâmico. }\end{array}$ & $\begin{array}{c}1 \\
(0,12 \%)\end{array}$ & 0 & 0 & 0 & 0 & $\begin{array}{c}1 \\
(0,12 \%)\end{array}$ \\
\hline $\begin{array}{l}46 \text { - Fator de } \\
\text { rendimento da } \\
\text { máquina } \\
\text { incorreto. }\end{array}$ & $\begin{array}{c}1 \\
(0,12 \%)\end{array}$ & 0 & 0 & 0 & 0 & $\begin{array}{c}1 \\
(0,12 \%)\end{array}$ \\
\hline $\begin{array}{l}47 \text { - Direção } \\
\text { do BEV } \\
\text { incorreta. }\end{array}$ & $\begin{array}{c}1 \\
(0,12 \%)\end{array}$ & 0 & 0 & 0 & 0 & 0 \\
\hline TOTAL & $\begin{array}{c}839 \\
(100 \%)\end{array}$ & $\begin{array}{c}16 \\
(1,98 \%)\end{array}$ & $\begin{array}{c}360 \\
(44,44 \%)\end{array}$ & $\begin{array}{c}6 \\
(0,74 \%)\end{array}$ & $\begin{array}{c}77 \\
(9,51 \%)\end{array}$ & $\begin{array}{c}351 \\
(43,33 \%)\end{array}$ \\
\hline
\end{tabular}




\begin{tabular}{|c|c|c|c|c|c|c|}
\hline \multicolumn{2}{|c|}{ Tipo de Erro } & \multicolumn{5}{|c|}{ Processo de Detecção (\%) } \\
\hline & $\begin{array}{c}\text { №. de } \\
\text { Eventos } \\
(\%)\end{array}$ & $\begin{array}{c}C Q \\
\text { do } \\
\text { equip. }\end{array}$ & $\begin{array}{c}\text { Descoberto } \\
\text { no } \\
\text { momento } \\
\text { do } \\
\text { tratamento. }\end{array}$ & $\begin{array}{l}\text { Dosimetria } \\
\text { ou } \\
\text { Dosimetria } \\
\text { in vivo. }\end{array}$ & $\begin{array}{c}\text { Imagem } \\
\text { portal } \\
\text { por } \\
\text { filme } \\
\text { ou } \\
\text { EPID. }\end{array}$ & $\begin{array}{c}\text { Verificação } \\
\text { da ficha } \\
\text { ou } \\
\text { Revisão } \\
\text { clínica do } \\
\text { paciente. }\end{array}$ \\
\hline $\begin{array}{l}48 \text { - Faltando } \\
\text { a imagem de } \\
\text { CT. }\end{array}$ & $\begin{array}{c}1 \\
(0,12 \%)\end{array}$ & 0 & 0 & 0 & 0 & 0 \\
\hline $\begin{array}{l}49 \text { - Faltando } \\
\text { a imobilização. }\end{array}$ & $\begin{array}{c}1 \\
(0,12 \%) \\
\end{array}$ & 0 & $\begin{array}{c}1 \\
(0,12 \%) \\
\end{array}$ & 0 & 0 & 0 \\
\hline $\begin{array}{l}50 \text { - Cunha } \\
\text { incorreta. }\end{array}$ & $\begin{array}{c}1 \\
(0,12 \%)\end{array}$ & $\begin{array}{c}1 \\
(0,12 \%)\end{array}$ & $\begin{array}{c}5 \\
(0,62 \%)\end{array}$ & 0 & 0 & $\begin{array}{c}4 \\
(0,49 \%)\end{array}$ \\
\hline TOTAL & $\begin{array}{c}839 \\
(100 \%)\end{array}$ & $\begin{array}{c}16 \\
(1,98 \%)\end{array}$ & $\begin{array}{c}360 \\
(44,44 \%)\end{array}$ & $\begin{array}{c}6 \\
(0,74 \%)\end{array}$ & $\begin{array}{c}77 \\
(9,51 \%)\end{array}$ & $\begin{array}{c}351 \\
(43,33 \%)\end{array}$ \\
\hline
\end{tabular}

* Tipos de erros encontrados no trabalho de pesquisa de Klein et $\mathrm{al}^{59}$.

A maior incidência de erros nos eventos ocorre para o tipo de erro classificado como "Coordenada de Tratamento Incorreta", como mostra a FIGURA 3.3 do gráfico da freqüência dos eventos cadastrados.

O gráfico ilustrado na FIGURA 3.3 mostra os principais tipos de erros, dos 50 encontrados, com suas respectivas freqüências e disponibilizados em ordem decrescente. Embora os erros geométricos, ou seja, o tipo de erro "Coordenada de Tratamento Incorreta" seja de aproximadamente $29 \%$, outros erros como "Dimensão do campo incorreta" e "Cálculo incorreto" também apresentam índices significativos. 


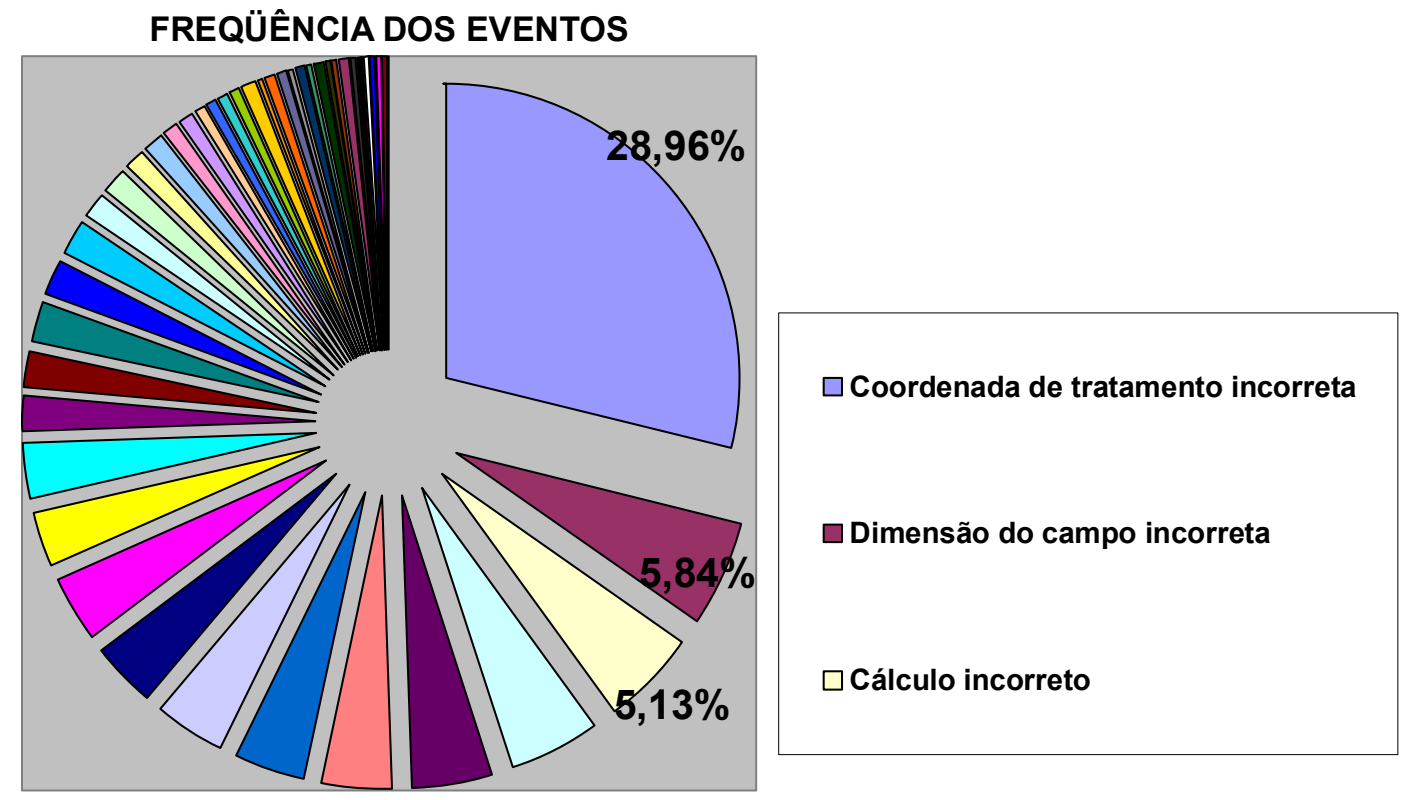

FIGURA 3.3. Gráfico da freqüência dos eventos cadastrados no Banco de Dados para os 50 tipos de erros identificados.

O gráfico apresentado na FIGURA 3.4 mostra a relevância da verificação da ficha de tratamento ou a revisão clínica do paciente no processo de deteç̧ão para o tipo de erro ocorrido em maior freqüência "Coordenada de Tratamento Incorreta". Em termos relativos, isto representa dos 243 casos ocorridos aproximadamente $41 \%$. Os erros geométricos são de vida curta, ou seja, descobertos no início do tratamento, são detectados mais freqüentemente na primeira fração de tratamento concordando com os resultados obtidos por Klein et al $^{59}$. Representam quase $39 \%$ em termos de valor relativo. O processo de detecção através da realização da imagem portal revelou ser um método importante para se descobrir o erro, representando quase $13 \%$ dos 243 eventos cadastrados com este tipo de erro. 


\section{PROCESSO DE DETECÇÃO DO ERRO}
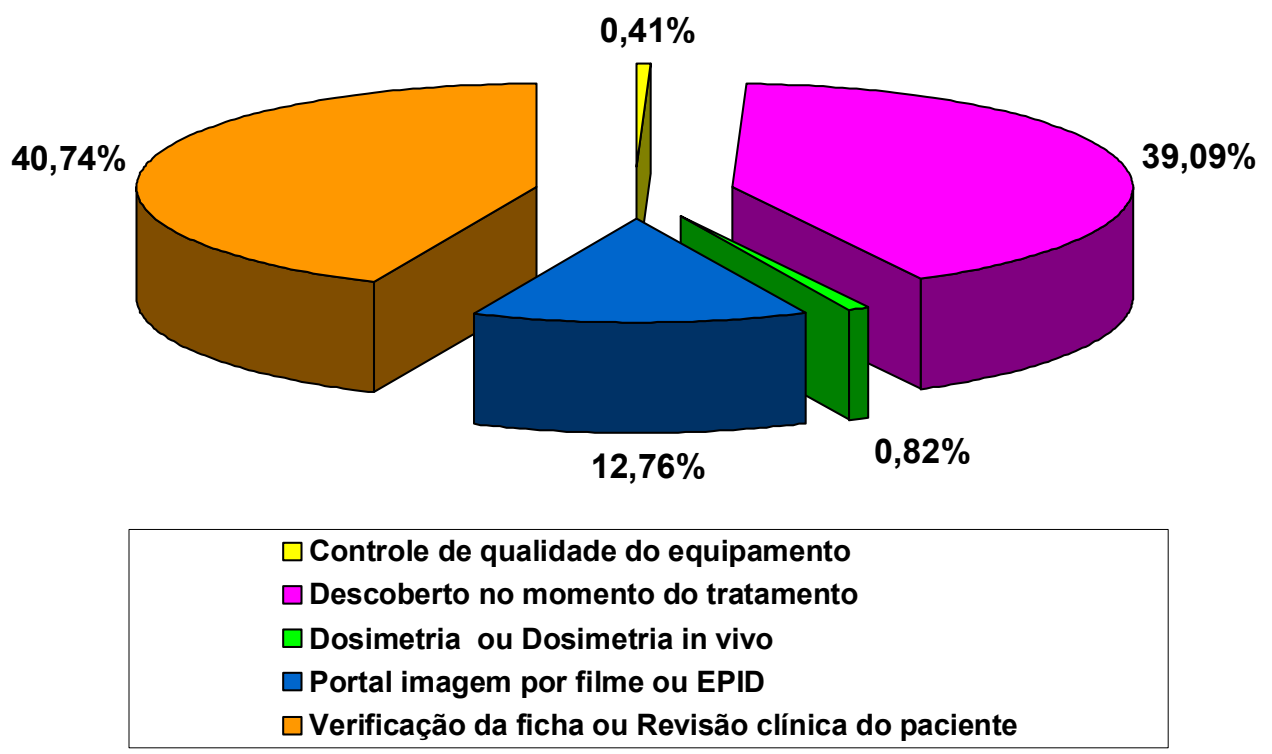

FIGURA 3.4. Gráfico da freqüência do processo de detecção para o tipo de erro "Coordenada de Tratamento Incorreta".

A seguir serão apresentados os gráficos contendo dois tipos de erros que ilustram a freqüência do processo de detecção (controle de qualidade do equipamento, descoberto no momento do tratamento, dosimetria ou dosimetria in vivo, imagem portal por filme ou dispositivos eletrônicos de imagem (EPID), verificação da ficha ou revisão clínica do paciente) para os tipos de erros ocorridos mais significativos.

Na FIGURA 3.5, pode-se observar que, embora a freqüência para os dois tipos de erros apresentados: "Coordenada de Tratamento Incorreta" e "Dimensão do Campo incorreta" apresenta índices bem diferentes; em ambos os casos, a verificação da ficha ou revisão clínica do paciente foi um processo significativo empregado na detecção do erro, aproximadamente $41 \%$ em termos relativos e que os incidentes/acidentes são em sua maioria de vida curta, detectados logo no início do tratamento, aproximadamente $49 \%$. 


\section{PROCESSO DE DETECÇÃO DO ERRO}

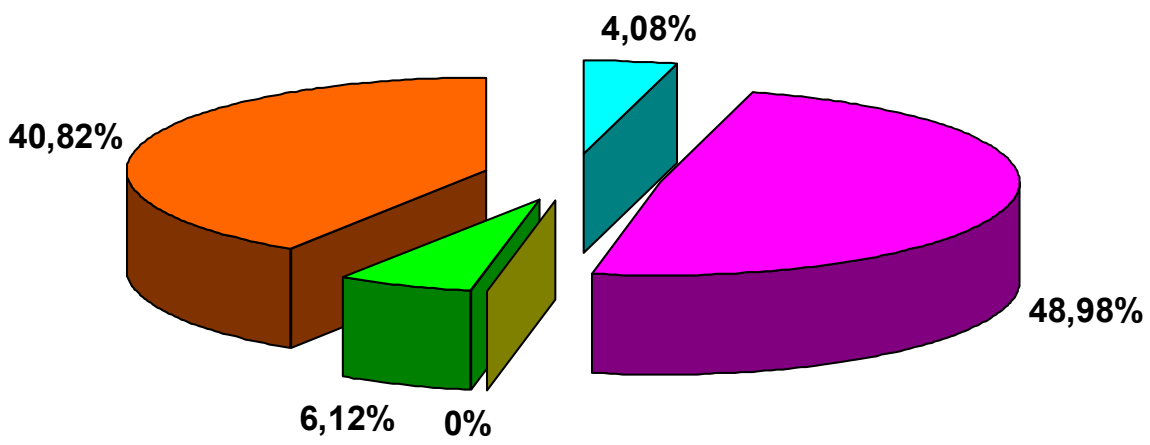

\begin{tabular}{|l|}
$\square$ Controle de qualidade do equipamento \\
$\square$ Descoberto no momento do tratamento \\
$\square$ Dosimetria ou Dosimetria in vivo \\
$\square$ Portal imagem por filme ou EPID \\
$\square$ Verificação da ficha ou Revisão clínica do paciente
\end{tabular}

FIGURA 3.5. Gráfico da freqüência do processo de detecção para o tipo de erro "Dimensão do Campo Incorreta".

O gráfico da freqüência do processo de detecção para os tipos de erros "Cálculo Incorreto" e "Dose Incorreta" ilustrados na FIGURA 3.6, representando o terceiro e quarto erro ocorrido em maior freqüência respectivamente indica que o processo de detecção através da verificação da ficha ou revisão clínica do paciente é também muito significativo. São detectados no início do tratamento, representando aproximadamente $23 \%$ dos 43 incidentes para o tipo de erro "Cálculo Incorreto" e 19\% dos 43 incidentes para "Dose Incorreta". No entanto para "Dose Incorreta" o controle de qualidade do equipamento revelou ser um importante modo de detecção do erro, significando aproximadamente $7 \%$ em termos de valor relativo, considerando as freqüências apresentadas na TABELA 3.1. 


\section{PROCESSO DE DETECÇÃO DO ERRO}
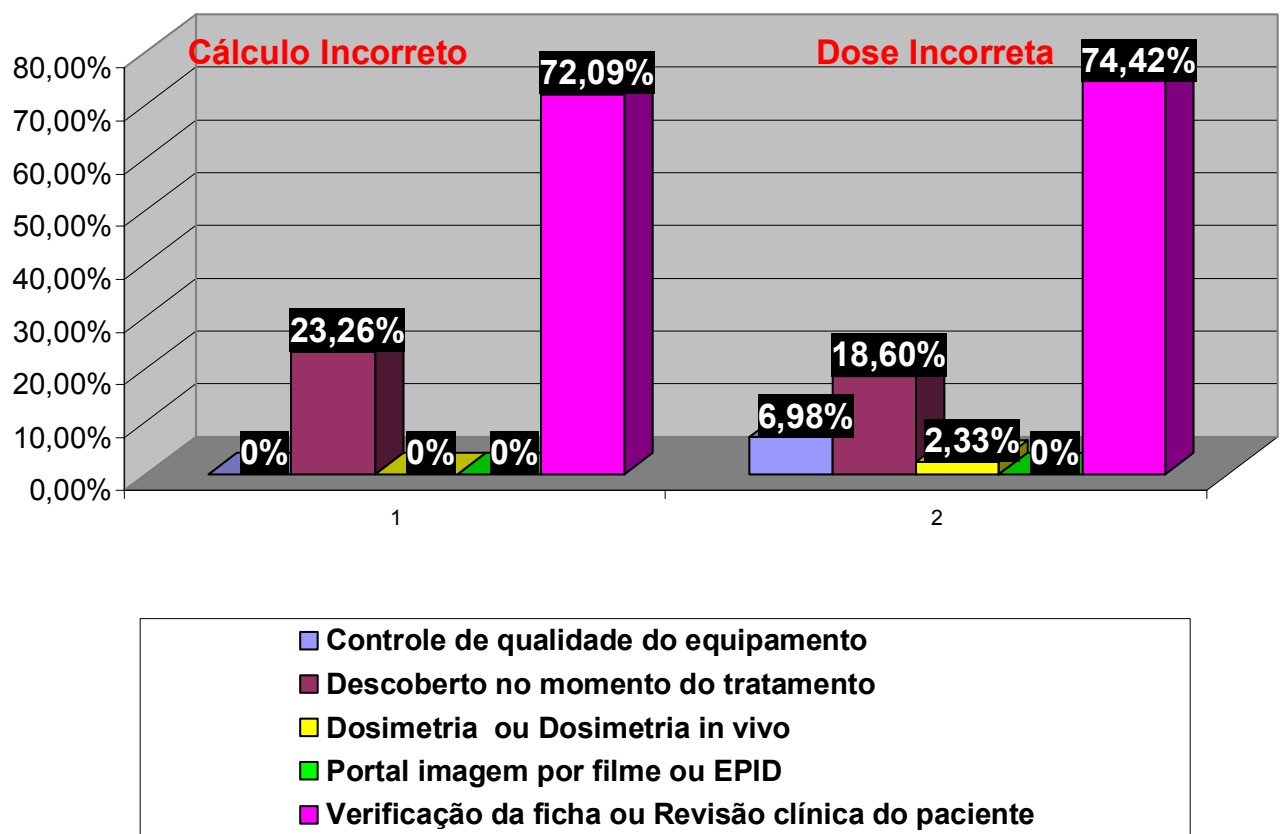

FIGURA 3.6. Gráfico da freqüência do processo de detecção para os tipos de erros "Cálculo Incorreto" e "Dose Incorreta".

O modo de detecção mais relevante considerando todos os acidentes/incidentes cadastrados no banco de dados é através da verificação da ficha ou revisão clínica do paciente como mostra a FIGURA 3.7. Os resultados mostram que o processo de verificação da ficha ou revisão clínica é uma checagem mais segura e que detectou mais de $40 \%$ do número total dos eventos pesquisados, tendo uma contribuição relevante para a descoberta do erro. O gráfico indica também que para aproximadamente $44 \%$ dos eventos os erros são descobertos logo no início do tratamento, apresentando uma vida curta e a imagem portal realizado durante o tratamento tem uma contribuição relevante no processo de detecção do erro. Medidas simples tomadas durante o processo de planejamento e tratamento do paciente são de grande importância e muito eficazes na prevenção de incidentes. Para os outros tipos de erros pesquisados os resultados mostram um grau de incidência diferente da encontrada na literatura. No trabalho de pesquisa realizado por Klein et al. ${ }^{59}$ não há registro de todos os tipos de erros identificados neste trabalho, sendo assim não há possibilidade de se comparar todos os resultados. 
PROCESSO DE DETECÇÃO DO ERRO PARA TODOS OS EVENTOS CADASTRADOS

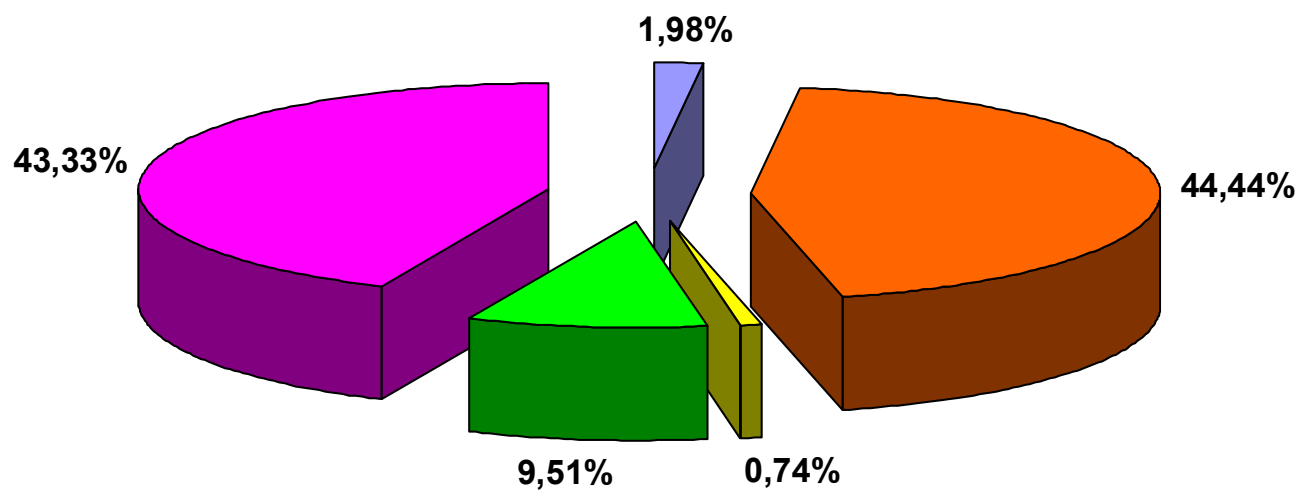

$$
\begin{aligned}
& \square \text { Controle de qualidade do equipamento } \\
& \square \text { Descoberto no momento do tratamento } \\
& \square \text { Dosimetria ou Dosimetria in vivo } \\
& \square \text { Portal imagem por filme ou EPID } \\
& \square \text { Verificação da ficha ou Revisão clínica do paciente }
\end{aligned}
$$

FIGURA 3.7. Gráfico da freqüência do processo de detecção para todos os tipos de erros de todos os eventos cadastrados no Banco de Dados.

Na TABELA 3.2 são apresentados a freqüência dos eventos ocorridos para um determinado grau de severidade específico e o número de pacientes afetados para cada tipo de erro. Do total dos 839 eventos, 11 incidentes não trouxeram as informações sobre o grau de severidade, apenas um evento não traz a informação sobre o número de pacientes afetados e um evento traz a informação "nenhum paciente afetado ou a equipe afetada". Os cálculos de porcentagem foram realizados sem contabilizar estes eventos. 
TABELA 3.2. Freqüência dos eventos correspondentes ao grau de severidade e No. de pacientes afetados para cada tipo de erro.

\begin{tabular}{|c|c|c|c|c|c|c|c|}
\hline \multirow{2}{*}{$\begin{array}{c}\text { Tipo } \\
\text { de } \\
\text { Erro }\end{array}$} & \multicolumn{4}{|c|}{$\begin{array}{c}\text { Grau de Severidade } \\
\text { (\% de 828) }\end{array}$} & \multicolumn{3}{|c|}{$\begin{array}{c}N^{\circ} . \text { de Pacientes Afetados } \\
\text { (\% de 828) }\end{array}$} \\
\hline & Nenhum & Leve & Moderado & Alto & nenhum & um & vários \\
\hline 1 & $\begin{array}{c}133 \\
(16,06 \%)\end{array}$ & $\begin{array}{c}88 \\
(10,63 \%)\end{array}$ & $\begin{array}{c}16 \\
(1,93 \%)\end{array}$ & $\begin{array}{c}2 \\
(0,24 \%)\end{array}$ & $\begin{array}{c}92 \\
(11,11 \%)\end{array}$ & $\begin{array}{c}150 \\
(18,12 \%)\end{array}$ & $\begin{array}{c}1 \\
(0,12 \%)\end{array}$ \\
\hline 2 & $\begin{array}{c}31 \\
(3,74 \%) \\
\end{array}$ & $\begin{array}{c}12 \\
(1,45 \%) \\
\end{array}$ & $\begin{array}{c}6 \\
(0,72 \%) \\
\end{array}$ & 0 & $\begin{array}{c}21 \\
(2,54 \%) \\
\end{array}$ & $\begin{array}{c}28 \\
(3,38 \%) \\
\end{array}$ & 0 \\
\hline 3 & $\begin{array}{c}19 \\
(2,29 \%) \\
\end{array}$ & $\begin{array}{c}20 \\
(2,42 \%) \\
\end{array}$ & $\begin{array}{c}1 \\
(0,12 \%) \\
\end{array}$ & $\begin{array}{c}3 \\
(0,36 \%) \\
\end{array}$ & $\begin{array}{c}13 \\
(1,57 \%) \\
\end{array}$ & $\begin{array}{c}27 \\
(3,26 \%) \\
\end{array}$ & $\begin{array}{c}2 \\
(0,24 \%) \\
\end{array}$ \\
\hline 4 & $\begin{array}{c}18 \\
(2,17 \%)\end{array}$ & $\begin{array}{c}11 \\
(1,33 \%)\end{array}$ & $\begin{array}{c}10 \\
(1,21 \%)\end{array}$ & $\begin{array}{c}3 \\
(0,36 \%)\end{array}$ & $\begin{array}{c}15 \\
(1,81 \%)\end{array}$ & $\begin{array}{c}27 \\
(3,26 \%)\end{array}$ & $\begin{array}{c}1 \\
(0,12 \%)\end{array}$ \\
\hline 5 & $\begin{array}{c}28 \\
(3,38 \%) \\
\end{array}$ & $\begin{array}{c}4 \\
(0,48 \%) \\
\end{array}$ & $\begin{array}{c}4 \\
(0,48 \%) \\
\end{array}$ & 0 & $\begin{array}{c}17 \\
(2,05 \%) \\
\end{array}$ & $\begin{array}{c}18 \\
(2,17 \%) \\
\end{array}$ & $\begin{array}{c}1 \\
(0,12 \%) \\
\end{array}$ \\
\hline 6 & $\begin{array}{c}17 \\
(2,05 \%) \\
\end{array}$ & $\begin{array}{c}13 \\
(1,57 \%) \\
\end{array}$ & $\begin{array}{c}1 \\
(0,12 \%) \\
\end{array}$ & 0 & $\begin{array}{c}11 \\
(1,33 \%) \\
\end{array}$ & $\begin{array}{c}20 \\
(2,42 \%) \\
\end{array}$ & $\begin{array}{c}2 \\
(0,24 \%) \\
\end{array}$ \\
\hline 7 & $\begin{array}{c}17 \\
(2,05 \%) \\
\end{array}$ & $\begin{array}{c}14 \\
(1,69 \%) \\
\end{array}$ & $\begin{array}{c}2 \\
(0,24 \%) \\
\end{array}$ & 0 & $\begin{array}{c}5 \\
(0,60 \%) \\
\end{array}$ & $\begin{array}{c}28 \\
(3,38 \%) \\
\end{array}$ & 0 \\
\hline 8 & $\begin{array}{c}18 \\
(2,17 \%) \\
\end{array}$ & $\begin{array}{c}13 \\
(1,57 \%) \\
\end{array}$ & 0 & $\begin{array}{c}2 \\
(0,24 \%) \\
\end{array}$ & $\begin{array}{c}8 \\
(0,97 \%) \\
\end{array}$ & $\begin{array}{c}25 \\
(3,02 \%) \\
\end{array}$ & 0 \\
\hline 9 & $\begin{array}{c}11 \\
(1,33 \%)\end{array}$ & $\begin{array}{c}12 \\
(1,45 \%)\end{array}$ & $\begin{array}{c}5 \\
(0,60 \%)\end{array}$ & $\begin{array}{c}1 \\
(0,12 \%)\end{array}$ & $\begin{array}{c}11 \\
(1,33 \%)\end{array}$ & $\begin{array}{c}19 \\
(2,29 \%)\end{array}$ & $\begin{array}{c}1 \\
(0,12 \%)\end{array}$ \\
\hline 10 & $\begin{array}{c}19 \\
(2,29 \%)\end{array}$ & $\begin{array}{c}5 \\
(0,60 \%) \\
\end{array}$ & $\begin{array}{c}6 \\
(0,72 \%) \\
\end{array}$ & $\begin{array}{c}1 \\
(0,12 \%) \\
\end{array}$ & $\begin{array}{c}21 \\
(2,54 \%) \\
\end{array}$ & $\begin{array}{c}8 \\
(0,97 \%) \\
\end{array}$ & $\begin{array}{c}1 \\
(0,12 \%) \\
\end{array}$ \\
\hline 11 & $\begin{array}{c}9 \\
(1,09 \%) \\
\end{array}$ & $\begin{array}{c}10 \\
(1,21 \%) \\
\end{array}$ & $\begin{array}{c}6 \\
(0,72 \%) \\
\end{array}$ & 0 & $\begin{array}{c}4 \\
(0,48 \%) \\
\end{array}$ & $\begin{array}{c}21 \\
(2,54 \%) \\
\end{array}$ & 0 \\
\hline 12 & $\begin{array}{c}12 \\
(1,45 \%) \\
\end{array}$ & $\begin{array}{c}7 \\
(0,85 \%) \\
\end{array}$ & $\begin{array}{c}5 \\
(0,60 \%)\end{array}$ & $\begin{array}{c}1 \\
(0,12 \%)\end{array}$ & $\begin{array}{c}10 \\
(1,21 \%)\end{array}$ & $\begin{array}{c}12 \\
(1,45 \%)\end{array}$ & $\begin{array}{c}3 \\
(0,36 \%)\end{array}$ \\
\hline 13 & $\begin{array}{c}6 \\
(0,72 \%) \\
\end{array}$ & $\begin{array}{c}7 \\
(0,85 \%) \\
\end{array}$ & $\begin{array}{c}4 \\
(0,48 \%) \\
\end{array}$ & 0 & $\begin{array}{c}6 \\
(0,72 \%) \\
\end{array}$ & $\begin{array}{c}11 \\
(1,33 \%) \\
\end{array}$ & 0 \\
\hline TOTAL & $\begin{array}{c}449 \\
(54,23 \%)\end{array}$ & $\begin{array}{c}289 \\
(34,90 \%)\end{array}$ & $\begin{array}{c}76 \\
(9,18 \%)\end{array}$ & $\begin{array}{c}14 \\
(1,69 \%)\end{array}$ & $\begin{array}{c}302 \\
(36,47 \%)\end{array}$ & $\begin{array}{c}518 \\
(62,56 \%)\end{array}$ & $\begin{array}{c}17 \\
(2,05 \%)\end{array}$ \\
\hline
\end{tabular}




\begin{tabular}{|c|c|c|c|c|c|c|c|}
\hline \multirow{2}{*}{$\begin{array}{c}\text { Tipo } \\
\text { de } \\
\text { Erro }\end{array}$} & \multicolumn{4}{|c|}{$\begin{array}{c}\text { Grau de Severidade } \\
\qquad(\% \text { de } 828)\end{array}$} & \multicolumn{3}{|c|}{$\begin{array}{c}N^{\circ} \text {. de Pacientes Afetados } \\
\text { (\% de 828) }\end{array}$} \\
\hline & Nenhum & Leve & Moderado & Alto & nenhum & um & vários \\
\hline 14 & $\begin{array}{c}5 \\
(0,60 \%) \\
\end{array}$ & $\begin{array}{c}10 \\
(1,21 \%) \\
\end{array}$ & $\begin{array}{c}1 \\
(0,12 \%) \\
\end{array}$ & $\begin{array}{c}1 \\
(0,12 \%) \\
\end{array}$ & $\begin{array}{c}6 \\
(0,72 \%) \\
\end{array}$ & $\begin{array}{c}11 \\
(1,33 \%) \\
\end{array}$ & 0 \\
\hline 15 & $\begin{array}{c}3 \\
(0,36 \%) \\
\end{array}$ & $\begin{array}{c}11 \\
(1,33 \%) \\
\end{array}$ & $\begin{array}{c}2 \\
(0,24 \%) \\
\end{array}$ & 0 & $\begin{array}{c}2 \\
(0,24 \%) \\
\end{array}$ & $\begin{array}{c}15 \\
(1,81 \%) \\
\end{array}$ & 0 \\
\hline 16 & $\begin{array}{c}11 \\
(1,33 \%)\end{array}$ & $\begin{array}{c}6 \\
(0,72 \%)\end{array}$ & 0 & 0 & $\begin{array}{c}6 \\
(0,72 \%)\end{array}$ & $\begin{array}{c}11 \\
(1,33 \%)\end{array}$ & 0 \\
\hline 17 & $\begin{array}{c}9 \\
(1,09 \%)\end{array}$ & $\begin{array}{c}7 \\
(0,85 \%)\end{array}$ & 0 & 0 & $\begin{array}{c}7 \\
(0,85 \%)\end{array}$ & $\begin{array}{c}9 \\
(1,09 \%)\end{array}$ & 0 \\
\hline 18 & $\begin{array}{c}9 \\
(1,09 \%) \\
\end{array}$ & $\begin{array}{c}3 \\
(0,36 \%) \\
\end{array}$ & $\begin{array}{c}1 \\
(0,12 \%) \\
\end{array}$ & 0 & $\begin{array}{c}7 \\
(0,85 \%) \\
\end{array}$ & $\begin{array}{c}6 \\
(0,72 \%) \\
\end{array}$ & 0 \\
\hline 19 & $\begin{array}{c}5 \\
(0,60 \%) \\
\end{array}$ & $\begin{array}{c}6 \\
(0,72 \%) \\
\end{array}$ & 0 & 0 & $\begin{array}{c}2 \\
(0,24 \%) \\
\end{array}$ & $\begin{array}{c}8 \\
(0,97 \%) \\
\end{array}$ & $\begin{array}{c}1 \\
(0,12 \%) \\
\end{array}$ \\
\hline 20 & $\begin{array}{c}6 \\
(0,72 \%)\end{array}$ & $\begin{array}{c}4 \\
(0,48 \%)\end{array}$ & 0 & 0 & $\begin{array}{c}1 \\
(0,12 \%)\end{array}$ & $\begin{array}{c}9 \\
(1,09 \%)\end{array}$ & 0 \\
\hline 21 & $\begin{array}{c}8 \\
(0,97 \%) \\
\end{array}$ & $\begin{array}{c}1 \\
(0,12 \%) \\
\end{array}$ & 0 & 0 & $\begin{array}{c}2 \\
(0,24 \%) \\
\end{array}$ & $\begin{array}{c}7 \\
(0,85 \%) \\
\end{array}$ & 0 \\
\hline 22 & $\begin{array}{c}3 \\
(0,36 \%)\end{array}$ & $\begin{array}{c}4 \\
(0,48 \%)\end{array}$ & 0 & 0 & $\begin{array}{c}3 \\
(0,36 \%)\end{array}$ & $\begin{array}{c}4 \\
(0,48 \%)\end{array}$ & 0 \\
\hline 23 & $\begin{array}{c}3 \\
(0,36 \%) \\
\end{array}$ & $\begin{array}{c}2 \\
(0,24 \%) \\
\end{array}$ & $\begin{array}{c}1 \\
(0,12 \%) \\
\end{array}$ & 0 & $\begin{array}{c}2 \\
(0,24 \%) \\
\end{array}$ & $\begin{array}{c}4 \\
(0,48 \%) \\
\end{array}$ & 0 \\
\hline 24 & $\begin{array}{c}3 \\
(0,36 \%) \\
\end{array}$ & $\begin{array}{c}1 \\
(0,12 \%) \\
\end{array}$ & $\begin{array}{c}1 \\
(0,12 \%) \\
\end{array}$ & 0 & $\begin{array}{c}3 \\
(0,36 \%) \\
\end{array}$ & $\begin{array}{c}2 \\
(0,24 \%) \\
\end{array}$ & 0 \\
\hline 25 & $\begin{array}{c}5 \\
(0,60 \%)\end{array}$ & 0 & 0 & 0 & $\begin{array}{c}5 \\
(0,60 \%)\end{array}$ & 0 & 0 \\
\hline 26 & $\begin{array}{c}1 \\
(0,12 \%) \\
\end{array}$ & $\begin{array}{c}3 \\
(0,36 \%) \\
\end{array}$ & 0 & $\begin{array}{c}1 \\
(0,12 \%) \\
\end{array}$ & $\begin{array}{c}1 \\
(0,12 \%)\end{array}$ & $\begin{array}{c}3 \\
(0,36 \%) \\
\end{array}$ & $\begin{array}{c}1 \\
(0,12 \%) \\
\end{array}$ \\
\hline 27 & $\begin{array}{c}2 \\
(0,24 \%) \\
\end{array}$ & $\begin{array}{c}3 \\
(0,36 \%) \\
\end{array}$ & 0 & 0 & $\begin{array}{c}1 \\
(0,12 \%) \\
\end{array}$ & $\begin{array}{c}4 \\
(0,48 \%) \\
\end{array}$ & 0 \\
\hline TOTAL & $\begin{array}{c}449 \\
(54,23 \%)\end{array}$ & $\begin{array}{c}289 \\
(34,90 \%)\end{array}$ & $\begin{array}{c}76 \\
(9,18 \%)\end{array}$ & $\begin{array}{c}14 \\
(1,69 \%)\end{array}$ & $\begin{array}{c}302 \\
(36,47 \%)\end{array}$ & $\begin{array}{c}518 \\
(62,56 \%)\end{array}$ & $\begin{array}{c}17 \\
(2,05 \%)\end{array}$ \\
\hline
\end{tabular}




\begin{tabular}{|c|c|c|c|c|c|c|c|}
\hline \multirow{2}{*}{$\begin{array}{c}\text { Tipo } \\
\text { de } \\
\text { Erro }\end{array}$} & \multicolumn{4}{|c|}{$\begin{array}{c}\text { Grau de Severidade } \\
\text { (\% de } 828)\end{array}$} & \multicolumn{3}{|c|}{$\begin{array}{c}N^{\circ} \text {. de Pacientes Afetados } \\
\text { (\% de 828) }\end{array}$} \\
\hline & Nenhum & Leve & Moderado & Alto & nenhum & um & vários \\
\hline 28 & $\begin{array}{c}5 \\
(0,60 \%) \\
\end{array}$ & 0 & 0 & 0 & $\begin{array}{c}1 \\
(0,12 \%) \\
\end{array}$ & $\begin{array}{c}4 \\
(0,48 \%) \\
\end{array}$ & 0 \\
\hline 29 & $\begin{array}{c}2 \\
(0,24 \%) \\
\end{array}$ & $\begin{array}{c}2 \\
(0,24 \%) \\
\end{array}$ & 0 & 0 & $\begin{array}{c}2 \\
(0,24 \%) \\
\end{array}$ & $\begin{array}{c}2 \\
(0,24 \%) \\
\end{array}$ & 0 \\
\hline 30 & $\begin{array}{c}1 \\
(0,12 \%)\end{array}$ & $\begin{array}{c}1 \\
(0,12 \%)\end{array}$ & $\begin{array}{c}2 \\
(0,24 \%)\end{array}$ & 0 & 0 & $\begin{array}{c}4 \\
(0,48 \%)\end{array}$ & 0 \\
\hline 31 & $\begin{array}{c}2 \\
(0,24 \%)\end{array}$ & $\begin{array}{c}1 \\
(0,12 \%)\end{array}$ & 0 & 0 & $\begin{array}{c}3 \\
(0,36 \%)\end{array}$ & 0 & $\begin{array}{c}1 \\
(0,12 \%)\end{array}$ \\
\hline 32 & $\begin{array}{c}4 \\
(0,48 \%) \\
\end{array}$ & 0 & 0 & 0 & $\begin{array}{c}1 \\
(0,12 \%) \\
\end{array}$ & $\begin{array}{c}3 \\
(0,36 \%) \\
\end{array}$ & 0 \\
\hline 33 & $\begin{array}{c}2 \\
(0,24 \%) \\
\end{array}$ & $\begin{array}{c}1 \\
(0,12 \%) \\
\end{array}$ & $\begin{array}{c}1 \\
(0,12 \%) \\
\end{array}$ & 0 & $\begin{array}{c}3 \\
(0,36 \%) \\
\end{array}$ & $\begin{array}{c}1 \\
(0,12 \%) \\
\end{array}$ & 0 \\
\hline 34 & $\begin{array}{c}2 \\
(0,24 \%)\end{array}$ & $\begin{array}{c}1 \\
(0,12 \%)\end{array}$ & 0 & 0 & $\begin{array}{c}1 \\
(0,12 \%)\end{array}$ & $\begin{array}{c}1 \\
(0,12 \%)\end{array}$ & $\begin{array}{c}1 \\
(0,12 \%)\end{array}$ \\
\hline 35 & $\begin{array}{c}3 \\
(0,36 \%) \\
\end{array}$ & 0 & 0 & 0 & $\begin{array}{c}3 \\
(0,36 \%) \\
\end{array}$ & 0 & 0 \\
\hline 36 & $\begin{array}{c}3 \\
(0,36 \%)\end{array}$ & 0 & 0 & 0 & 0 & $\begin{array}{c}3 \\
(0,36 \%)\end{array}$ & 0 \\
\hline 37 & $\begin{array}{c}1 \\
(0,12 \%) \\
\end{array}$ & $\begin{array}{c}2 \\
(0,24 \%) \\
\end{array}$ & 0 & 0 & $\begin{array}{c}2 \\
(0,24 \%) \\
\end{array}$ & $\begin{array}{c}1 \\
(0,12 \%) \\
\end{array}$ & 0 \\
\hline 38 & $\begin{array}{c}1 \\
(0,12 \%) \\
\end{array}$ & $\begin{array}{c}2 \\
(0,24 \%) \\
\end{array}$ & 0 & 0 & $\begin{array}{c}1 \\
(0,12 \%) \\
\end{array}$ & $\begin{array}{c}2 \\
(0,24 \%) \\
\end{array}$ & 0 \\
\hline 39 & $\begin{array}{c}2 \\
(0,24 \%)\end{array}$ & 0 & 0 & 0 & $\begin{array}{c}2 \\
(0,24 \%)\end{array}$ & 0 & 0 \\
\hline 40 & $\begin{array}{c}2 \\
(0,24 \%) \\
\end{array}$ & 0 & 0 & 0 & 0 & $\begin{array}{c}2 \\
(0,24 \%) \\
\end{array}$ & 0 \\
\hline 41 & $\begin{array}{c}2 \\
(0,24 \%) \\
\end{array}$ & 0 & 0 & 0 & 0 & $\begin{array}{c}1 \\
(0,12 \%) \\
\end{array}$ & $\begin{array}{c}1 \\
(0,12 \%) \\
\end{array}$ \\
\hline TOTAL & $\begin{array}{c}449 \\
(54,23 \%)\end{array}$ & $\begin{array}{c}289 \\
(34,90 \%)\end{array}$ & $\begin{array}{c}76 \\
(9,18 \%)\end{array}$ & $\begin{array}{c}14 \\
(1,69 \%)\end{array}$ & $\begin{array}{c}302 \\
(36,47 \%)\end{array}$ & $\begin{array}{c}518 \\
(62,56 \%)\end{array}$ & $\begin{array}{c}17 \\
(2,05 \%)\end{array}$ \\
\hline
\end{tabular}




\begin{tabular}{|c|c|c|c|c|c|c|c|}
\hline \multirow{2}{*}{$\begin{array}{c}\text { Tipo } \\
\text { de } \\
\text { Erro }\end{array}$} & \multicolumn{4}{|c|}{$\begin{array}{c}\text { Grau de Severidade } \\
\text { (\% de } 828)\end{array}$} & \multicolumn{3}{|c|}{$\begin{array}{c}N^{\circ} \text {. de Pacientes Afetados } \\
\text { (\% de 828) }\end{array}$} \\
\hline & Nenhum & Leve & Moderado & Alto & nenhum & um & vários \\
\hline 42 & $\begin{array}{c}1 \\
(0,12 \%)\end{array}$ & 0 & 0 & 0 & - & - & - \\
\hline 43 & $\begin{array}{c}1 \\
(0,12 \%) \\
\end{array}$ & 0 & 0 & 0 & 0 & $\begin{array}{c}1 \\
(0,12 \%) \\
\end{array}$ & 0 \\
\hline 44 & 0 & 0 & $\begin{array}{c}1 \\
(0,12 \%)\end{array}$ & 0 & 0 & $\begin{array}{c}1 \\
(0,12 \%)\end{array}$ & 0 \\
\hline 45 & $\begin{array}{c}1 \\
(0,12 \%)\end{array}$ & 0 & 0 & 0 & 0 & $\begin{array}{c}1 \\
(0,12 \%)\end{array}$ & 0 \\
\hline 46 & 0 & $\begin{array}{c}1 \\
(0,12 \%) \\
\end{array}$ & 0 & 0 & 0 & $\begin{array}{c}1 \\
(0,12 \%) \\
\end{array}$ & 0 \\
\hline 47 & $\begin{array}{c}1 \\
(0,12 \%) \\
\end{array}$ & 0 & 0 & 0 & 0 & $\begin{array}{c}1 \\
(0,12 \%) \\
\end{array}$ & 0 \\
\hline 48 & $\begin{array}{c}1 \\
(0,12 \%)\end{array}$ & 0 & 0 & 0 & $\begin{array}{c}1 \\
(0,12 \%)\end{array}$ & 0 & 0 \\
\hline 49 & $\begin{array}{c}1 \\
(0,12 \%)\end{array}$ & 0 & 0 & 0 & 0 & $\begin{array}{c}1 \\
(0,12 \%)\end{array}$ & 0 \\
\hline 50 & 0 & $1(0,12 \%)$ & 0 & 0 & 0 & $\begin{array}{c}1 \\
(0,12 \%) \\
\end{array}$ & 0 \\
\hline TOTAL & $\begin{array}{c}449 \\
(54,23 \%)\end{array}$ & $\begin{array}{c}289 \\
(34,90 \%)\end{array}$ & $\begin{array}{c}76 \\
(9,18 \%)\end{array}$ & $\begin{array}{c}14 \\
(1,69 \%)\end{array}$ & $\begin{array}{c}302 \\
(36,47 \%)\end{array}$ & $\begin{array}{c}518 \\
(62,56 \%)\end{array}$ & $\begin{array}{c}17 \\
(2,05 \%)\end{array}$ \\
\hline
\end{tabular}

Os valores obtidos para o grau de severidade mostraram que mais de $50 \%$ dos eventos ocorridos o grau de severidade é nulo concordando com os dados da literatura. Quanto aos valores encontrados para o número de pacientes afetados evidenciaram que para mais de $60 \%$ dos eventos ocorridos um paciente é afetado relacionado ao impacto do acidente.

A seguir serão apresentados os gráficos que ilustram a freqüência do grau de severidade e número de pacientes afetados para os tipos de erros mais significativos dos incidentes. 
O Gráfico da freqüência do Grau de Severidade e No. de Pacientes Afetados para o tipo de erro "Coordenada de Tratamento Incorreta".apresentado na FIGURA 3.8 mostra que para a maioria dos eventos classificados para este tipo de erro apresentam grau de severidade nulo. Em termos de valor relativo do total dos 243 incidentes, aproximadamente 55\% dos eventos cadastrados no banco de dados não apresentaram nenhum grau de severidade e 36\% apresentaram o grau leve. De acordo com a literatura ${ }^{59}$ o grau de severidade está relacionado à porção do volume alvo tratado inadequadamente e para o grau de severidade alto é esperado em menor freqüência. Do total de 243 eventos classificados com esse tipo de erro, o gráfico apresentou em termos de valor relativo, aproximadamente $62 \%$ dos eventos cadastrados em que um paciente foi afetado e o número de casos onde nenhum paciente é afetado também apresenta um índice significativo de aproximadamente $38 \%$.

\section{Coordenada de Tratamento Incorreta}

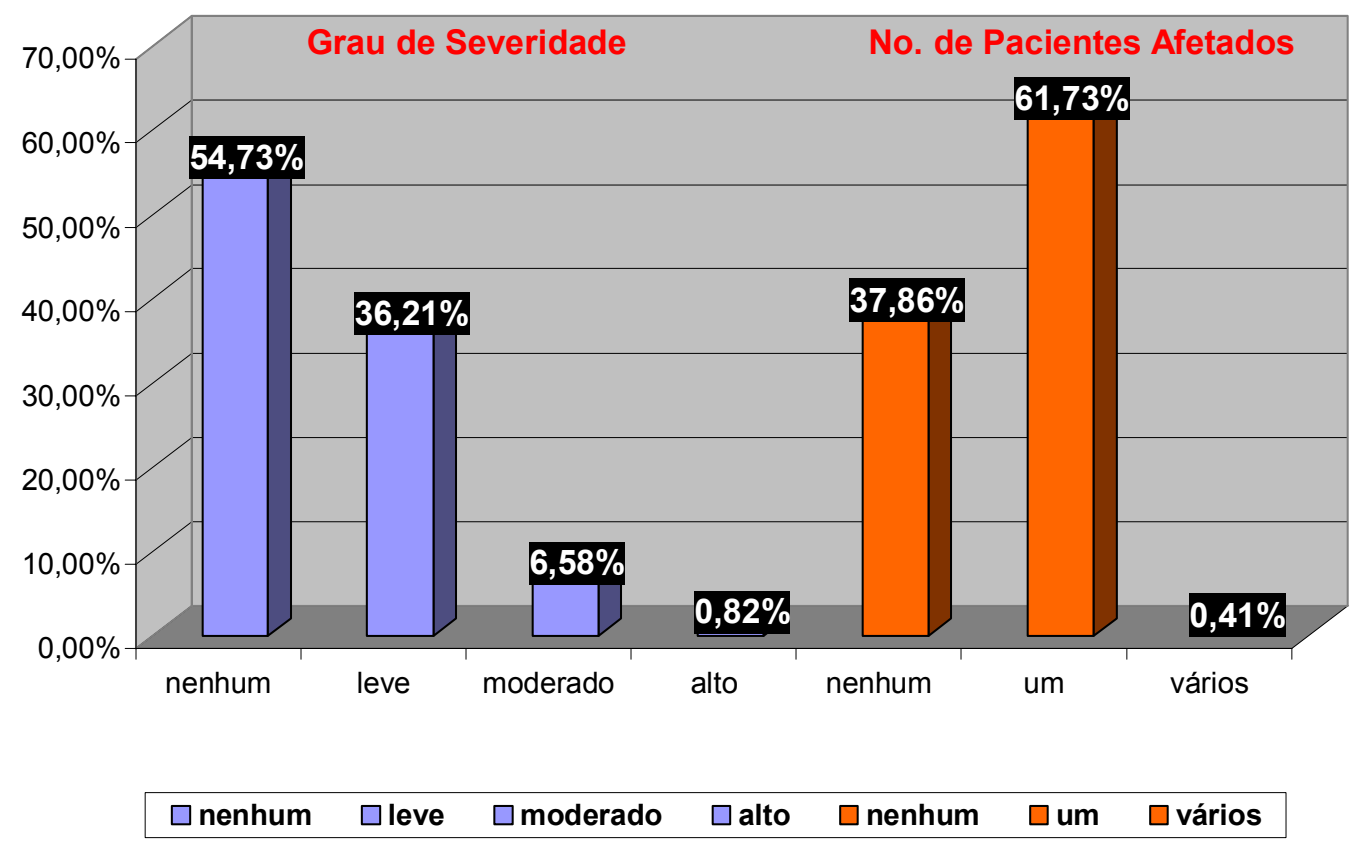

FIGURA 3.8. Gráfico da freqüência do Grau de Severidade e No. de Pacientes Afetados para o tipo de erro "Coordenada de Tratamento Incorreta". 
Para o quarto tipo de erro mais freqüente "Dose incorreta" o gráfico da freqüência do Grau de Severidade ilustrado na FIGURA 3.9 mostra que embora o número de incidentes que apresentam o grau de severidade nulo seja maior, a freqüência de incidentes que apresentam os graus leve, moderado e alto é significativa. Dos 43 eventos classificados para esse tipo de erro aproximadamente $23 \%$ em termos de valor relativo apresentaram grau moderado e quase $7 \%$ grau alto. Quanto à freqüência de eventos em que um paciente é afetado $(3,22 \%)$ foi aproximadamente o dobro de eventos em que nenhum paciente foi afetado. Foram encontrados $2,33 \%$, em termos de valor relativo, incidentes em que mais de um paciente foi afetado.

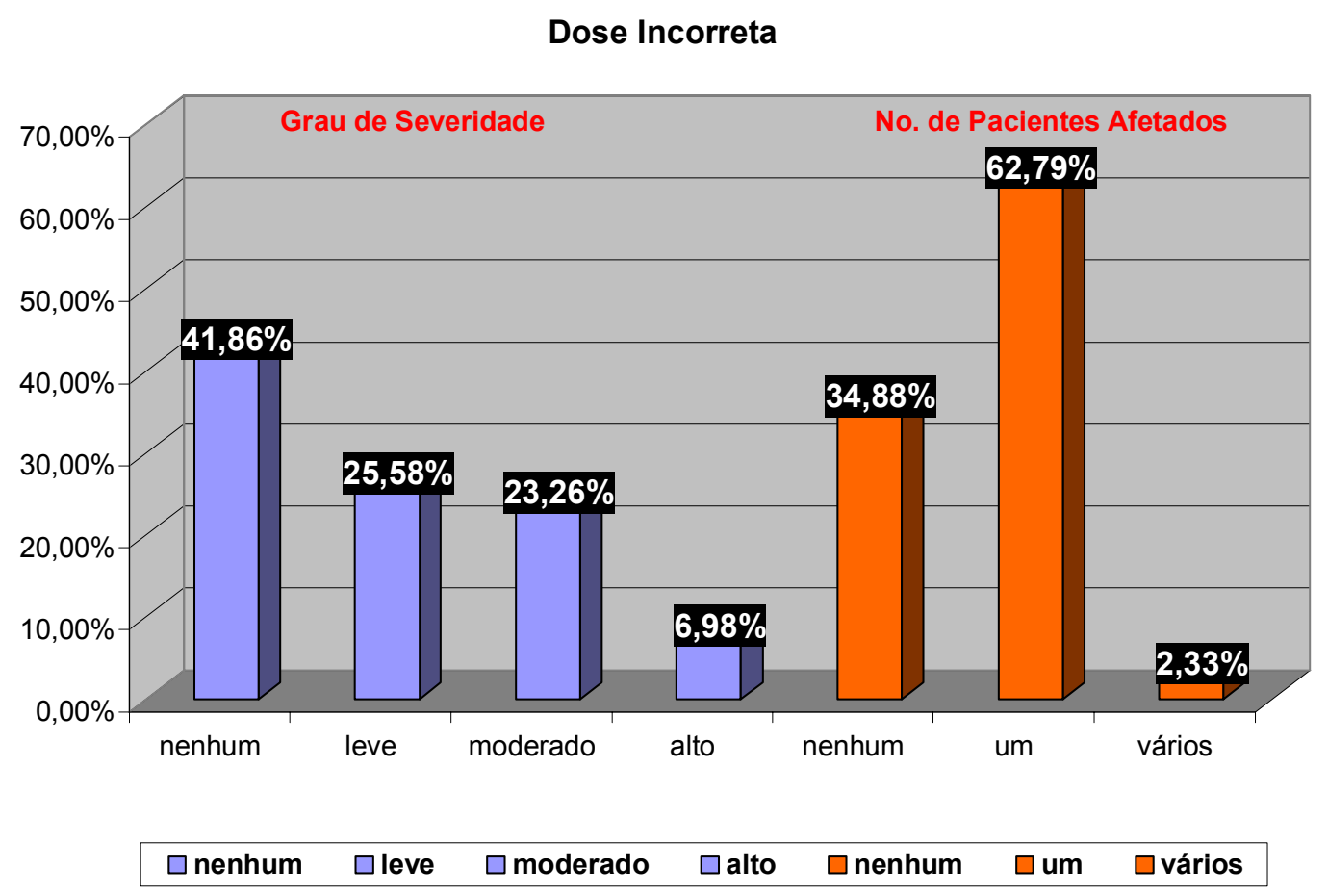

FIGURA 3.9 Gráfico da freqüência do Grau de Severidade e No. de Pacientes Afetados para o tipo de erro "Dose incorreta". 
O gráfico apresentado na FIGURA 3.10 mostra que, para o décimo quarto tipo de erro mais freqüente "Dose da Fração de Tratamento Incorreta", a freqüência de eventos cujo grau de severidade é nulo representa em termos de valor relativo aproximadamente $29 \%$ dos 17 incidentes cadastrados no banco de dados. Para o grau leve representa em termos de valor relativo aproximadamente $59 \%$ e para o grau moderado e alto 6\%. Quanto ao número de pacientes afetados a freqüência de incidentes apresentando nenhum paciente afetado é de aproximadamente $35 \%$ e incidentes em que um paciente é afetado representa um valor relativo de $65 \%$.

\section{Dose da Fração de Tratamento Incorreta}

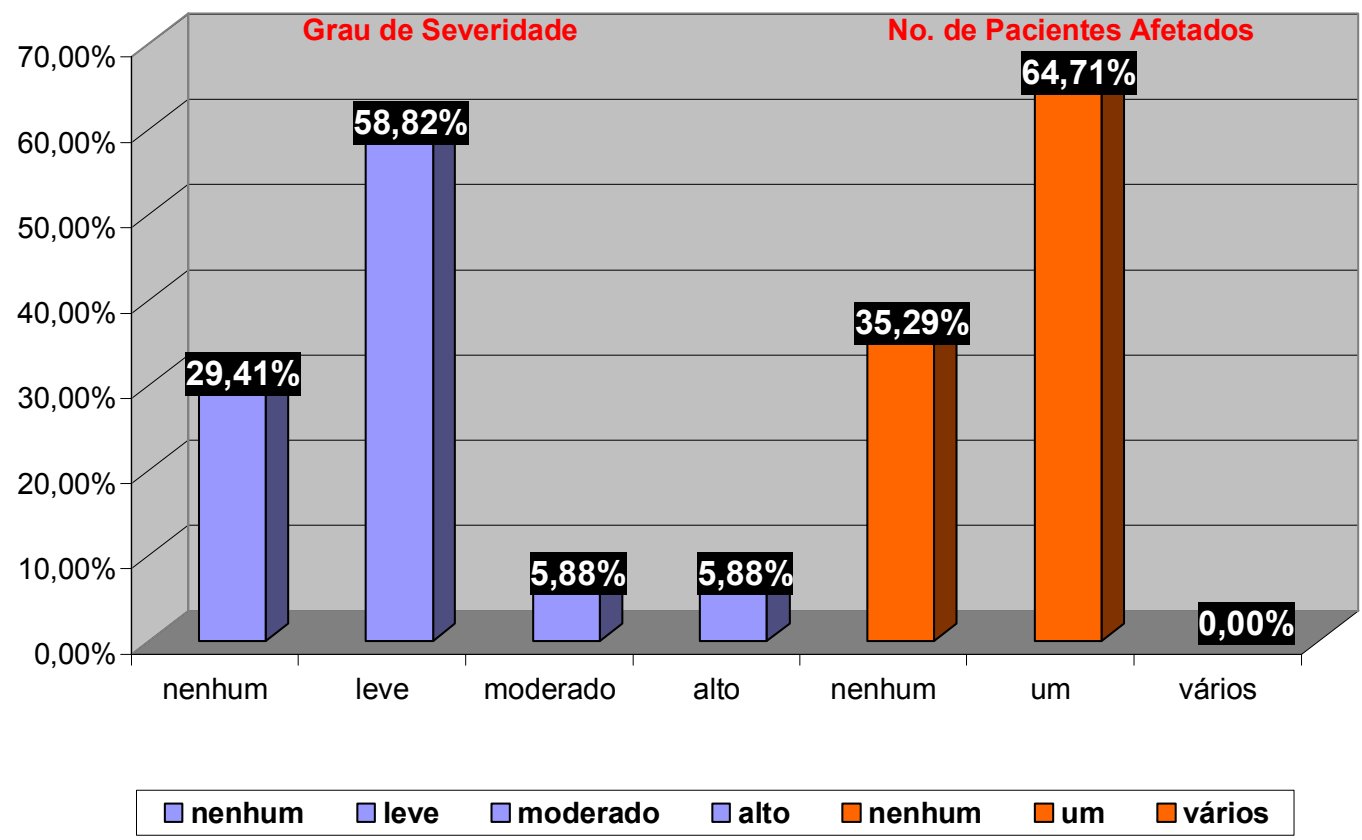

FIGURA 3.10. Gráfico da freqüência do Grau de Severidade e No. de Pacientes Afetados para o tipo de erro "Dose da Fração de Tratamento Incorreta".

O gráfico apresentado na FIGURA 3.11 mostra que, para o vigésimo tipo de erro mais freqüente "Faltando a Cunha", a freqüência de eventos cujo grau de severidade é nulo representa em termos de valor relativo representa $60 \%$ dos 10 incidentes cadastrados no banco de dados. Para o grau leve representa em termos de valor relativo $40 \%$.Quanto ao número de pacientes afetados a freqüência de incidentes apresentando um paciente afetado é $90 \%$ e incidentes em que nenhum paciente é afetado representa um valor relativo de $10 \%$. 
Faltando a Cunha

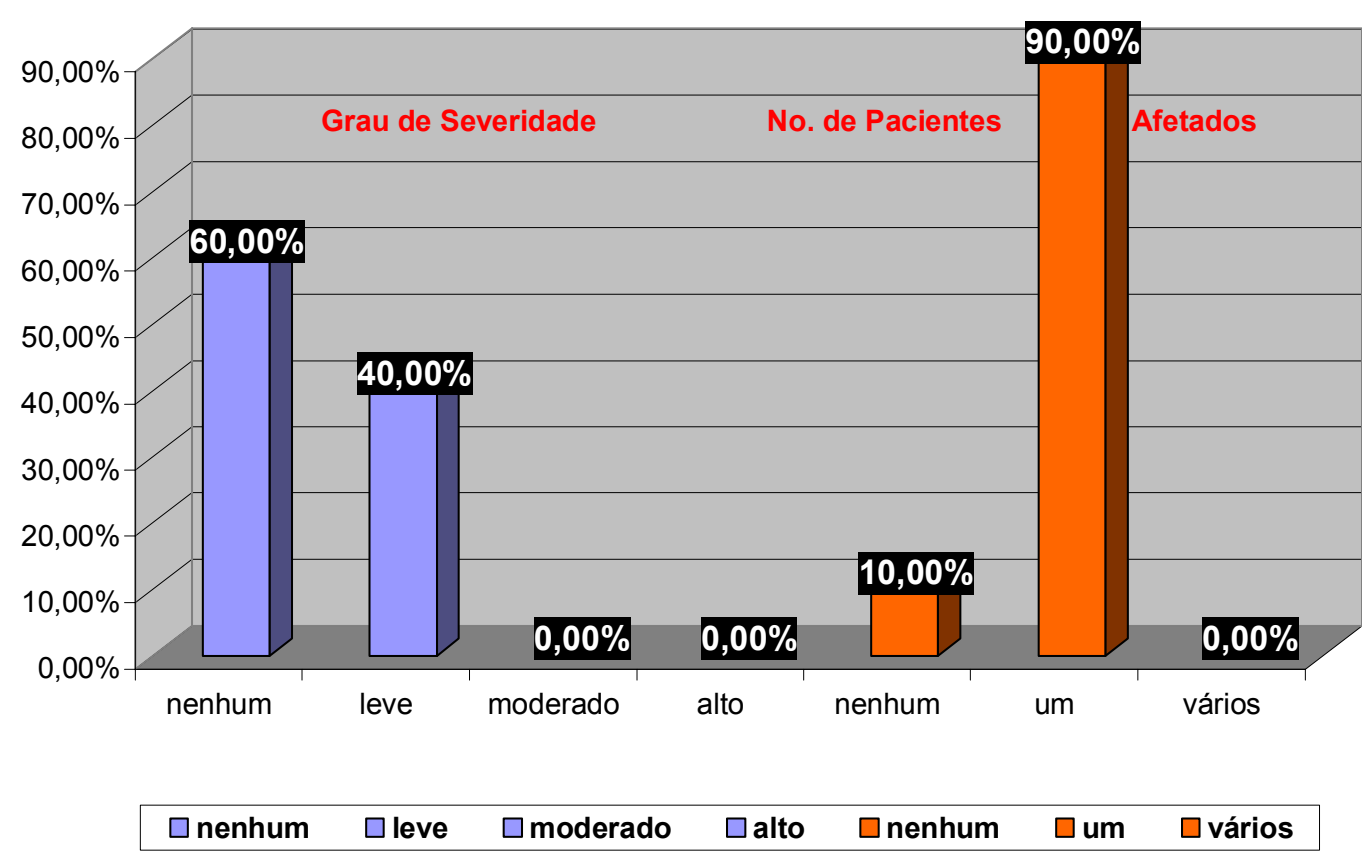

FIGURA 3.11. Gráfico da freqüência do Grau de Severidade e No. de Pacientes Afetados para o tipo de erro "Faltando a Cunha".

O gráfico da freqüência do Grau de Severidade para os erros classificados no banco de dados de todos os eventos cadastrados ilustrados na FIGURA 3.12 indica que, em mais de $50 \%$ dos incidentes o grau de severidade é nulo. De acordo com a literatura, nos acidentes ocorridos em radioterapia, os efeitos colaterais relacionados à proporção dos volumes alvos tratados inadequadamente, são geralmente menores em termos de severidade e transientes; enquanto que complicações mais severas e de longo tempo, ou seja, injúrias causadas ao paciente, são esperadas em menor freqüência. 


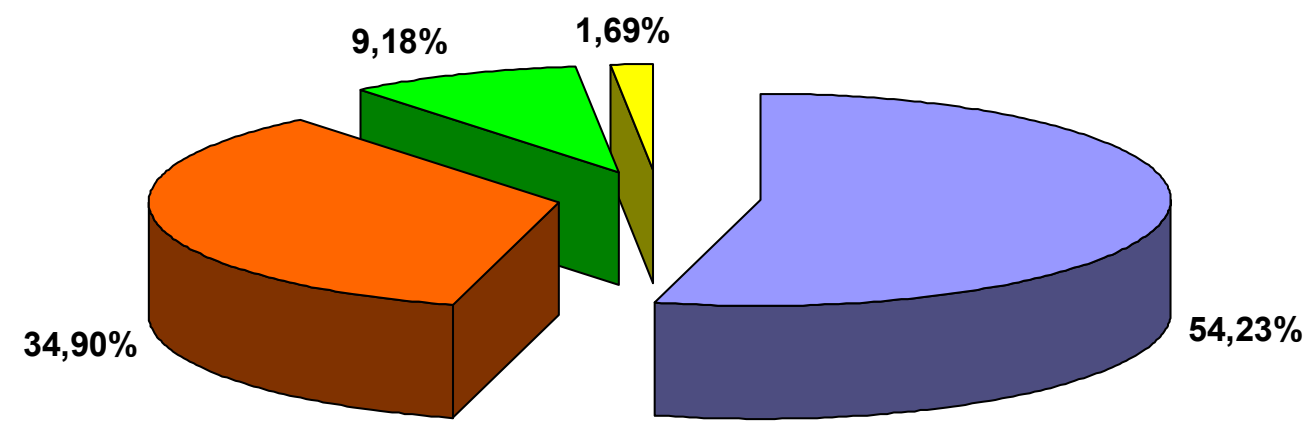

$\square$ nenhum $\quad \square$ leve $\quad \square$ moderado $\quad \square$ alto

FIGURA 3.12. Gráfico da freqüência do Grau de Severidade para os erros classificados no banco de dados de todos os eventos cadastrados.

Segundo o gráfico da freqüência do No. de Pacientes Afetados para os erros classificados no banco de dados de todos os eventos cadastrados apresentado na FIGURA 3.13, em aproximadamente $62 \%$ dos incidentes ocorridos um paciente é afetado durante a realização do tratamento de radioterapia. Já para os incidentes em que nenhum paciente é afetado representa $36 \%$. Pode-se observar que os incidentes ocorridos com mais de um paciente afetado aparecem em menor freqüência, o que está de acordo com a literatura. 


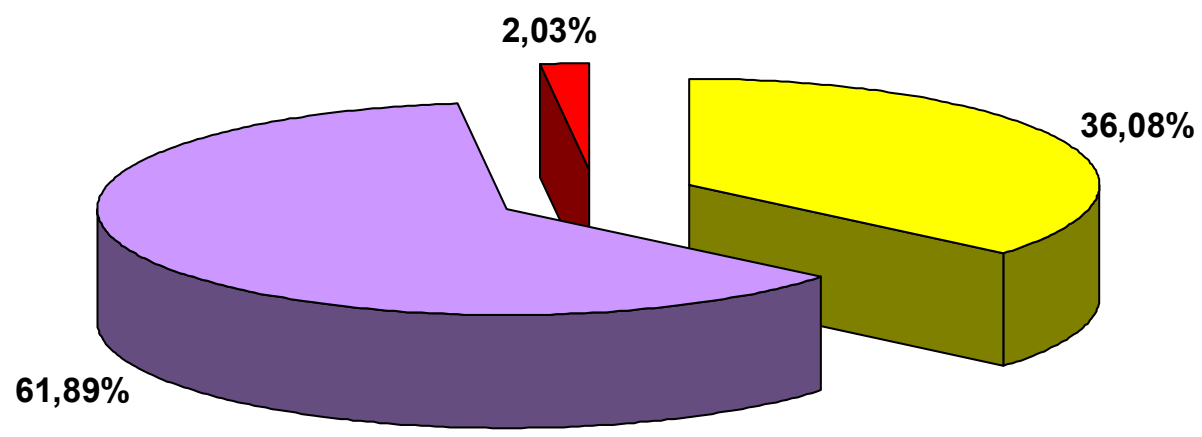

FIGURA 3.13. Gráfico da freqüência do No. de Pacientes Afetados para os erros classificados no banco de dados de todos os eventos cadastrados.

\subsubsection{Análise das Metodologias}

A metodologia proposta por Klein et al. ${ }^{59}$ utilizada para identificar a freqüência, a longevidade e o impacto dosimétrico dos incidentes para os tipos de erros mostrados na TABELA 1.1 não é uma metodologia tão abrangente e adequada para ser utilizada no banco de dados do ROSIS ${ }^{8}$, uma vez que não há todas as informações necessárias para fazer as mesmas análises realizadas por Klein et al. Segundo klein et. al. sua análise para longevidade utiliza como um dos critérios para a classificação do tipo de erro o número de frações do tratamento.e para a análise do impacto dosimétrico realiza a classificação do tipo de erro de acordo com o erro da dose e/ou volume.

Outra metodologia proposta para realizar uma análise dos dados do Banco de Dados segundo ROSIS é a metodologia desenvolvida por Reason ${ }^{61}$. De acordo com Reason o problema do erro humano pode ser visto de duas formas: uma 
aproximação pessoal, focalizado em atos inseguros (erros e violação dos procedimentos); e uma aproximação do sistema, cada qual possuindo um modelo próprio de causa dos erros, e conseqüentemente cada um apresenta uma filosofia diferente de gerenciamento do erro. Compreender essas diferenças tem implicações práticas importantes para lidar com o risco sempre atual dos infortúnios na prática clínica. Do ponto de vista da aproximação pessoal, os atos inseguros surgem de processos mentais tais como: esquecimento, falta de atenção, baixa motivação, negligência, imprudência, e assim, as medidas preventivas estão dirigidas no sentido de se restringir a variabilidade indesejável do comportamento humano. Os seguidores dessa teoria tratam o erro como um papel moral, assumindo que coisas ruins acontecem com pessoas ruins. Já na aproximação do sistema considera-se que os humanos falham e os erros são esperados, mesmo nas melhores organizações. Os erros são considerados mais como conseqüências do que como causas, tendo suas origens nem tanto na natureza perversa do ser humano, mas em fatores sistêmicos que estão acima deste. As medidas de segurança baseiam-se no fato de que não podemos mudar a natureza humana, mas $\operatorname{sim}$ as condições sob as quais os seres humanos trabalham. A idéia central é a dos sistemas de defesa, ou seja, toda tecnologia "perigosa" possui barreiras e proteções. Quando um evento adverso ocorre o importante não é quem cometeu o erro, mas sim como e porque as defesas falharam.

O modelo "Queijo Suíço", apresentado por Reason ${ }^{61}$ ilustrado na FIGURA 3.14, mostra como as barreiras, defesas e proteções, tratadas como camadas defensivas, podem ser penetradas na trajetória do acidente. A função de todos eles é a de proteger vítimas potenciais e o patrimônio dos perigos do ambiente. A maioria das camadas de defesa, barreiras e proteções funcionam bem, mas sempre existem fraquezas. Em um mundo ideal cada camada defensiva seria intacta. Na realidade, entretanto, são mais como "fatias" do queijo suíço, tendo muitos orifícios, embora ao contrário do queijo, esses orifícios estão continuamente abrindo, fechando, e deslocando sua posição. A trajetória de um erro pode passar por todas as camadas defensivas levando ao acidente. Os buracos nas camadas defensivas são levantados por duas razões: descobrir a falha ativa (atos inseguros cometidos pelas pessoas) e circunstâncias latentes (decisões tomadas pelos projetistas, construtores, escritores dos procedimentos e pela gerência de nível 
superior). Quase todos os eventos adversos envolvem uma combinação destes dois fatores.

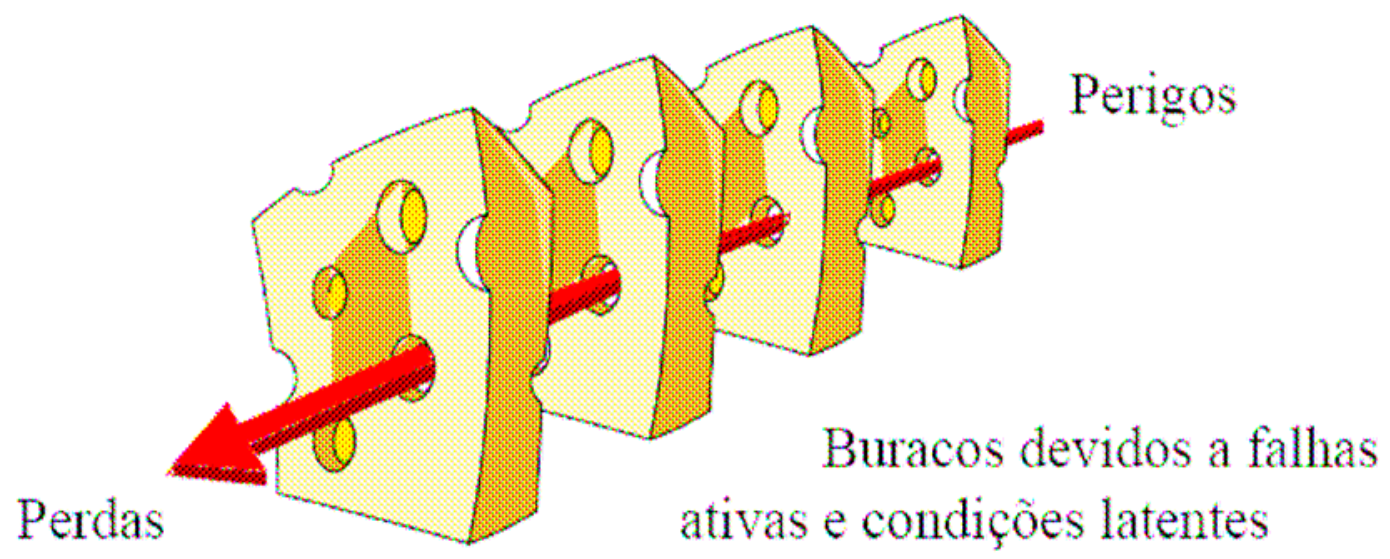

FIGURA 3.14. Modelo "Queijo Suíço” aplicado por Reason ilustrando as diversas camadas (barreiras, defesas e proteções) indicando a trajetória do erro e conduzindo ao incidente.

Como estamos pensando em camadas, esses buracos em uma camada são inofensivos, mas quando ocorre um alinhamento desses buracos nas diferentes camadas do sistema de defesas, barreiras ou proteções, ocorre a possibilidade de ocorrência de um evento perigoso, conforme ilustrado na FIGURA 3.14. Os buracos nas defesas surgem por duas razões: falhas ativas e condições latentes. As falhas ativas são representadas pelos atos inseguros cometidos pelas pessoas que estão em contato direto com o sistema, podendo assumir diferentes formas: deslizes, lapsos, perdas, erros e violações de procedimentos. As falhas ativas geralmente têm um impacto de curta duração sobre as defesas. As condições latentes são representadas pelas patologias intrínsecas do sistema, e surgem a partir de decisões dos projetistas, construtores, elaboradores de procedimentos e do nível gerencial mais alto. Tais decisões podem se constituir de erros ou não. As condições latentes têm dois tipos de efeitos adversos: podem contribuir para o erro no local de trabalho (como, por exemplo, pressão de tempo, sobrecarga de trabalho, equipamentos inadequados, fadiga e inexperiência) e podem criar buracos ou fraquezas duradouras nas defesas (alarmes e indicadores não confiáveis, procedimentos não exeqüíveis, dentre outros). As condições 
latentes, como o nome sugere, podem permanecer latentes no sistema por anos antes que se combine com as falhas ativas provocando acidentes. As falhas ativas não podem ser previstas facilmente, mas as condições latentes podem ser identificadas e corrigidas antes de um evento adverso. A compreensão desse fato leva ao gerenciamento proativo ao invés do reativo

As organizações de alta confiabilidade reconhecem que a variabilidade humana é uma força para ser aproveitada na prevenção de erros. Não é possível mudar a condição humana, mas é possível mudar as condições em que os seres humanos trabalham. A administração do risco efetivo depende crucialmente da cultura de segurança estabelecida. Sem uma análise detalhada dos erros, incidentes e "lições livres" não há um modo de "perceber" o erro descoberto. Projetar uma cultura justa é uma etapa adiantada essencial para criar uma cultura de segurança. Analisar cada incidente do banco de dados ROSIS ${ }^{8}$ através do conhecimento da trajetória percorrida do erro e da época que foi detectada seria uma abordagem mais complexa que pode ser realizada em trabalhos futuros

Segundo Dunscombe et al. $^{62}$ é importante obter um método para quantificar as conseqüências aplicáveis a todos os incidentes clínicos em tratamentos com radiação. Uma das metodologias proposta Dunscombe ${ }^{63}$, a taxonomia, um sistema definido de classificação, é uma maneira estruturada de se entender o caminho que o erro percorre dentro do sistema em "cadeia" do tratamento, podendo ser aplicado na análise de incidentes em radioterapia. $\mathrm{Na}$ FIGURA 3.15 ilustra um exemplo esquemático da taxonomia aplicada à radioterapia, apresentando quatro níveis. Pode-ocorrer erro de dose ou volume durante o processo de preparação do tratamento, conduzindo a erros esporádicos ou sistemáticos. 


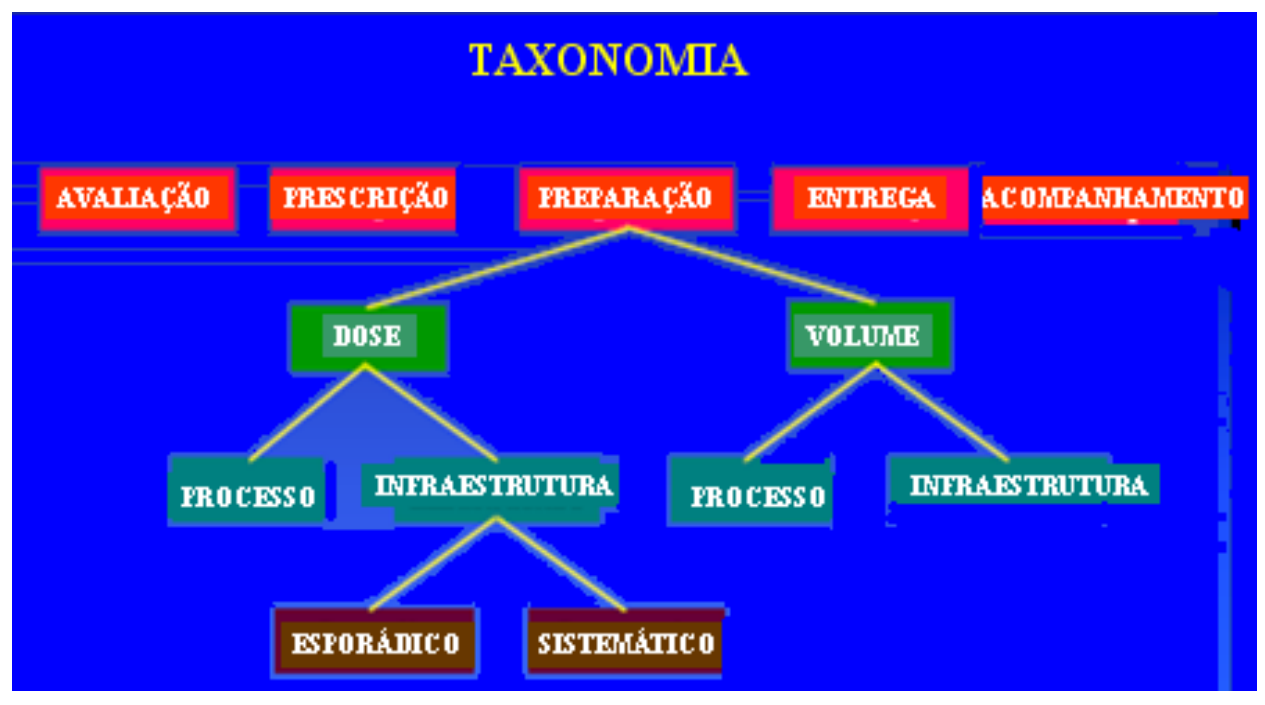

FIGURA 3.15. Forma esquemática da taxonomia segundo Dunscombe et al. aplicada na análise dos incidentes em radioterapia ${ }^{63}$.

Outra metodologia proposta por Dunscombe et $\mathrm{al}^{62}$ aplica o sistema métrico Equivalent Uniform Dose (EUD) expresso em Gy representando a dose equivalente uniforme. O EUD tem propriedades desejáveis e é relativamente fácil de calcular e depende da fração do volume alvo e a dose naquele volume. Nos estudos realizados por Dunscombe et al. foram simulados incidentes típicos de tratamento com radiação sobre o planejamento de tratamento por computador, para uma única fração e um curso completo de tratamento. Um estudo quantitativo do impacto desses acidentes foi realizado sobre o EUD dos volumes alvo e órgãos de risco (OAR) para quatro sítios anatômicos: mama, pulmão, próstata e cabeça. $O$ sistema métrico EUD é empregado se há a intenção de conhecer o grau de severidade na preparação e entrega do tratamento definido.

A maioria dos protocolos de controle de qualidade recomenda a recalibração, ou ao menos a monitoração cuidadosa, quando o rendimento do acelerador linear apresentar desvios que excedem $2 \%$ do valor nominal. O desvio no valor nominal do EUD de $2 \%$, ou menor, em escalas de dose, no volume alvo ou órgão de risco não seria considerado clinicamente significativo. As conclusões obtidas por Dunscombe et al. ${ }^{62}$ mostraram que o método EUD é um sistema métrico potencialmente útil para descrever a severidade dos incidentes no tratamento com radiação, se os incidentes afetarem a dose ou o volume ou ambos. Os resultados mostraram que quase todos os incidentes que são propagados 
através de todo o tratamento indicaram desvios que excedem normalmente a variabilidade clínica, freqüentemente por uma margem considerável. Então, um incidente que ocorre durante a preparação do tratamento e que não é detectado de imediato pode levar as conseqüências graves. No entanto, essa metodologia utilizada para quantificar o impacto métrico empregando o sistema métrico EUD não é adequada para ser aplicável ao banco de dados segundo ROSIS ${ }^{8}$; uma vez que nos casos relatados dos incidentes, não se dispõe de todas as informações necessárias sobre a fração do volume alvo e a dose naquele volume para realizar o mesmo estudo e comparar os resultados.

\subsubsection{Medidas de Prevenção do Erro}

Como já comentado no texto, segundo Dunscombe ${ }^{18}$, considera-se a prevenção de erros na radioterapia como uma componente da gestão de qualidade. A International Organization for Standardization (ISO) criou um conjunto de padrões internacionais para qualidade, conhecida como ISO $9000^{11}$. Elementos do ISO incluem modernas técnicas de qualidade, como a responsabilidade da gerência "sênior" e requerimentos de aperfeiçoamento contínuo, que pode ser implantado utilizando um amplo programa de qualidade. Tem sido proposta a sua utilização na radioterapia. Os físicos e os radioterapeutas utilizaram prontamente tecnologias novas e deram muitas contribuições significativas à radioterapia nesses anos. Assim como a medicina, a qualidade é também uma arte e há uma necessidade de investigação. O treinamento científico conduz físicos e oncologistas a esperar a evidência convencendo para a eficácia de técnicas novas antes de incorporar alguma mudança dos procedimentos aos pacientes. Entretanto, não se devem ignorar as aproximações à qualidade que têm origem na probabilidade e nas estatísticas com muitos anos de experiência prática e o benefício demonstrado em outros campos ${ }^{64}$.

A construção do banco de dados facilitou o acesso aos dados referentes dos eventos de exposições acidentais. Esse histórico permite avaliar a consistência da freqüência dos tipos de erros ocorridos, além de permitir levar à prática algumas medidas com a finalidade de se obter um maior controle de qualidade. O Banco de Dados $\mathrm{ROSIS}^{8}$ foi construído para caracterizar os incidentes, relatados de forma 
voluntária, com o objetivo de fornecer dados úteis e compreensão para minimizar os ricos de incidentes, mas, no entanto, faltam algumas informações para realizar análises mais profundas dos eventos cadastrados. Este trabalho mostrou que, para a aplicação das metodologias segundo Klein et al $^{59}$ e Dunscombe et al. ${ }^{62,63}$ é interessante inserir características mais detalhadas dos acidentes no Banco de Dados do ROSIS tais como: o número de frações por paciente afetado, número de campos de tratamento por fração que foi afetado, desvio da dose prescrita e desvio do volume prescrito em todos os eventos cadastrados o número de frações do tratamento ocorridas até a descoberta do erro e a proporção do volume tratado inadequadamente.

Segundo Reason ${ }^{61}$ todas as tecnologias "perigosas" possuem barreiras e proteções. Gerenciar os fatores de risco humanos nunca será $100 \%$ efetivo. As falhas humanas podem ser controladas, mas nunca eliminadas. O sistema de análise e classificação dos incidentes na metodologia proposta por Reason representa uma abordagem interessante sobre a aplicação do modelo "Queijo Suiço" a ser empregada no Banco de Dados ROSIS ${ }^{8}$, que enfatiza a busca incessante das causas latentes dos acidentes na organização. No entanto, o grande desafio que se lança é criar um modelo aplicável à radioterapia com aplicações práticas deste modelo a ser utilizado no Banco de Dados ROSIS.

É possível observar uma ampla variedade de tipos de erros. Todas as instituições são susceptíveis a erros. É necessário desenvolver um mecanismo nacional para investigação e distribuição de experiência aprendida para análise de erros. Uma questão crucial para qualquer progresso significativo para fabricantes, organizações nacionais e governamentais. Pode-se então desenvolver uma análise formal do risco, uma abordagem estruturada tal como sugerida por Dunscombe et al, possibilitando revelar e refinar as análises do risco refletindo as circunstâncias locais, sendo assim, a criação de um banco de dados mais completo, com dados que possibilite a análise dos incidentes de acordo com as diferentes metodologias propostas.

A partir da análise realizada dos incidentes do banco de dados pode-se constatar que procedimentos simples como a verificação da ficha ou revisão clínica do paciente são responsáveis pela descoberta de uma parcela considerável de incidentes e também são descobertos logo início do tratamento, totalizando 
aproximadamente $88 \%$ do total de incidentes no processo de detecção. Em mais de $89 \%$ dos incidentes o grau de severidade é nulo ou leve, como também incidentes em que um paciente é afetado ocorre em quase $62 \%$.

A partir de toda a análise realizada dos eventos cadastrados no banco de dados nesse trabalho propõe-se que todas essas informações sejam disponibilizadas em nível nacional. Desta forma, órgãos competentes, tais como, INCa (Instituto Nacional de Câncer) e CNEN (Comissão Nacional de Energia Nuclear) possa empregar estas informações para fins de medidas regulatórias, seja no aspecto do controle e combate ao câncer, seja no aspecto da proteção ao paciente, enfatizando a cultura de segurança. Apoiar os organismos nacionais interessados em prevenir e minimizar o impacto de acidentes. Colaborar com centros nacionais de apoio a acidentes, tais como o Centro de Apoio em Acidentes com Radiação (LCR/UERJ), composto por uma equipe multidisciplinar. 


\section{CAPÍTULO 4}

\subsection{Conclusões}

Existem várias causas que podem conduzir a erros quando pacientes são submetidos à irradiação em radioterapia. Tais erros devem ser minimizados ao máximo, mediante controle da qualidade rígido dos planejamentos dos pacientes. Algumas medidas podem ser tomadas para que esses erros não ocorram como:

- Realizar dosimetria in vivo "off-axis" com diodo para reduzir o uso da direção incorreta da cunha;

- Utilizar valores da distância vertical com indicador de distância óptica (SSD) para evitar erro de distância de tratamento;

- Empregar o sistema de transferência de dados DICOM-RT entre as estações de trabalho do planejamento de tratamento e a simulação, aumentando a eficiência e acurácia no tratamento;

- Considerar a redundância nas verificações dos cálculos realizados por computador ou manualmente;

- Empregar um sistema computadorizado de registro e verificação do tratamento; evitando-se erros nos tratamentos diários devidos à seleção incorreta dos parâmetros de tratamento;

- Implantar um cartão magnético de identificação do paciente com foto, número de identificação, nome da instituição, nome do departamento, a data da primeira emissão e médico responsável para se evitar erros de identificação e registro e poderá ser utilizado em todo o processo do tratamento.

Desta forma, esses procedimentos podem evitar mais incidentes em radioterapia e aumentar a segurança dos pacientes. 


\section{Sugestões para trabalhos futuros}

Como indicação para trabalhos futuros propõe-se a criação de um banco de dados "on-line" de incidentes em nível nacional, pois há a necessidade de avaliar os incidentes e acidentes ocorridos no contexto do país. Como a complexidade dos tratamentos vem aumentando o potencial para a ocorrência de incidentes também aumenta ${ }^{59}$. É importante conhecer a natureza dos erros ocorridos em centros de radioterapia no Brasil com a finalidade de conhecer os problemas específicos nacionais, deficiências e erros em potencial, possibilitando assim tomar medidas direcionadas para a nossa realidade local. 


\section{REFERÊNCIAS BIBLIOGRÁFICAS}

1. MEDICAL PHYSICS PUBLISHING, ACRONYMS, 20 th Year Anniversary Edition With a Foreword by John R. Cameron, Jan. 2005.

2. SHRIMPTON, P.C. The Current Uses of Radiation in Medicine. Proceedings of the International Conference Held in Malaga, Radiological Protection of Patients in Diagnostic and Interventional Radiology, Nuclear Medicine and Radiotherapy, Vienna: IAEA, 2001. p. 109-118.

3. INTERNATIONAL COMMISSION ON RADIATION UNITS AND MEASUREMENTS. Determination of Absorbed Dose in a Patient Irradiated by Beams of X or Gamma Rays in Radiotherapy Procedures. ICRU, Report 24, 1976.

4. INTERNATIONAL ATOMIC ENERGY AGENCY. Lessons Learned From Accidental Exposures in Radiotherapy. IAEA, Vienna, 2000 (Safety Reports Series No. 17).

5. INTERNATIONAL COMMISSION ON RADIOLOGICAL PROTECTION. Prevention of Accidental Exposures to Patients Undergoing Radiation Therapy. ICRP, Publication No. 86, 2000 (Annals of the ICRP 30: 1-70).

6. HOLMBERG, O.; MCCLEAN, B. Preventing treatment errors in radiotherapy by identifying and evaluating near misses and actual incidents. J. Radiother. Pract., v.3, p. 13-25, 2002.

7. VATNITSKY*, S.; LOPEZ, P.O.; IZEWSKA, J.; MEGHZIFENE, A.; LEVIN, V. Commentary - The radiation overexposure of radiotherapy patients in Panama 15 June 2001. Radiother. Oncol., v. 60, p. 237-238, 2001.

8. ROSIS (Radiation Oncology Safety Information System): banco de dados. Disponível em: <http://www.clin.radfys.lu.se/queries.asp>. Acesso em: 9 março 2007.

9. INTERNATIONAL ATOMIC ENERGY AGENCY. Aspectos físicos de la garantía de calidad: Protocolo de control de calidad, IAEA, Tec Doc 1151, Viena, 2000.

10. WORLD HEALTH ORGANIZATION. Quality assurance in radiotherapy. Geneva: WHO, 1988

11. INTERNATIONAL ORGANIZATION FOR STANDARDIZATION. Quality management and quality assurance standards-part I, guidelines for selection and use. ISO 9000, Geneva, 1994.

12. EUROPEAN SOCIETY FOR THERAPEUTIC RADIOLOGY AND ONCOLOGY. Practical guidelines for the implementation of a quality system in radiotherapy. ESTRO, Physics for Clinical Radiotherapy booklet no. 4, Brussels, 1998. 
13. INSTITUTE OF PHYSICS AND ENGINEERING IN MEDICINE. Physics aspects of quality control in radiotherapy", IPEM Report 81, edited by Mayles, W.P.M.; Lake, R.; McKenzie, A.; Macaulay, E.M. et al., IPEM Report 81, York, 2000.

14. TAUHATA, L.; SALATI, I. P. A.;PRINZIO, R. Di; PRINZIO, A. R. Di. Radioproteção e Dosimetria: Fundamentos $-5^{\mathrm{a}}$ revisão agosto, 2003. IRD/CNEN.

15. ANNO, G. H.; WILSON, D. B.; BAUM, S. J. Severity levels and symptoms complexes for acute radiation sickness - Description and Quantification. 30 nov. 1985. Disponível em: <http://handle.dtic.mil/100.2/ADA175840>. Acesso em: 18 nov. 2007.

16. TURAI, I.; VERESS, K.; GÜNALP, B.; SOUCHKEVITCH, G. Medical response to radiation incidents and radionuclear threats. BMJ, v. 328, p. 568-572, 2004. Disponível em: <http://www.bmj.com/cgi/content/full/328/7439/568>. Acesso em: 20 nov. 2007.

17. INTERNATIONAL ATOMIC ENERGY AGENCY. Review of Radiation Oncology Physics: A Handbook for Teachers and Students, IAEA, Vienna, May, 2003 (Educational Reports Series).

18. DUNSCOMBE, P.B. Working Group on the Prevention of Errors in Radiation Oncology. AAPM NEWSLETTER, Nov./Dez., 2006.

19. INTERNATIONAL ATOMIC ENERGY AGENCY. Design and Implementation of a Radiotherapy Programmer: Clinical, Medical Physics, Radiation Protection and Safety Aspects. IAEA, Tec Doc 1040, Vienna, 1998.

20. LÓPEZ, P. O.; WRIXON, A.D.; MEGHZIFENE, A.; IZEWSKA, J. Role of the IAEA in the Radiological Protection of Patients. Proceedings of the International Conference Held in Malaga, Radiological Protection of Patients in Diagnostic and Interventional Radiology, Nuclear Medicine and Radiotherapy, Vienna: IAEA, 2001. p. 35-46.

21. METTLER, F.A. Radiological Risks Associated with the Various Uses of Radiation in Medicine within the Context of Their Associated Benefits. Proceedings of the International Conference Held in Malaga, Radiological Protection of Patients in Diagnostic and Interventional Radiology, Nuclear Medicine and Radiotherapy, Vienna: IAEA, 2001, p.119-127.

22. INTERNATIONAL ATOMIC ENERGY AGENCY. The Radiological Accident at the Irradiation Facility in Nesvizh. IAEA, Vienna, 1996.

23. INTERNATIONAL ATOMIC ENERGY AGENCY. The International Chernobyl Project: An Overview, IAEA, Vienna, 1993. 
24. INTERNNATIONAL ATOMIC ENERGY AGENCY The Radiological Accident in Soreq, IAEA, Vienna, 1993.

25. INTERNNATIONAL ATOMIC ENERGY AGENCY The International Chernobyl Project: An Overview (Russian edition), IAEA, Vienna, 1991.

26. INTERNATIONAL ATOMIC ENERGY AGENCY. The International Chernobyl Project: Technical Report, IAEA, Vienna, 1991.

27. INTERNNATIONAL ATOMIC ENERGY AGENCY. The International Chernobyl Project Assessment of Radiological Consequences and Evaluation of Protective Measures Summary Brochure, IAEA, Vienna, 1991.

28. INTERNATIONAL ATOMIC ENERGY AGENCY. The Radiological Accident in San Salvador, IAEA, Vienna, 1990.

29. INTERNNATIONAL ATOMIC ENERGY AGENCY. The Radiological Accident in Goiânia, AIEA, Vienna, 1988.

30. INTERNATIONAL ATOMIC ENERGY AGENCY. The Radiological Accident in Cochabamba, IAEA, Vienna, 2004.

31. INTERNATIONAL ATOMIC ENERGY AGENCY. The Radiological Accident in Gilan, IAEA, Vienna, 2002.

32. INTERNATIONAL ATOMIC ENERGY AGENCY. The Radiological Accident in Samut Prakarn, IAEA, Vienna, 2002.

33. INTERNATIONAL ATOMIC ENERGY AGENCY. The Criticality Accident in Sarov, IAEA, Vienna, 2001.

34. INTERNATIONAL ATOMIC ENERGY AGENCY. The Radiological Accident in Lilo, IAEA, Vienna, 2000.

35. INTERNATIONAL ATOMIC ENERGY AGENCY. The Radiological Accident in Istanbul, IAEA, Vienna, 2000.

36. INTERNATIONAL ATOMIC ENERGY AGENCY. The Radiological Accident in Yanango, IAEA, Vienna, 2000.

37. INTERNATIONAL ATOMIC ENERGY AGENCY. Report on the Preliminary Fact Finding Mission Following the Accident at the Nuclear Fuel Processing Facility in Tokaimura, Japan, IAEA, Vienna, 1999.

38. INTERNATIONAL ATOMIC ENERGY AGENCY. The Radiological Accident in Tammiku, IAEA, Vienna, 1998.

39. INTERNATIONAL ATOMIC ENERGY AGENCY. The Radiological Accident in the Reprocessing Plant at Tomsk, AIEA, Vienna, 1998. 
40. INTERNNATIONAL ATOMIC ENERGY AGENCY An Electron Accelerator Accident in Hanoi, Viet Nam, AIEA, Vienna, 1996.

41. INTERNATIONAL ATOMIC ENERGY AGENCY. International Basic Safety Standards for Protection against lonizing Radiation and for the Safety of Radiation Sources. IAEA, Vienna, 1996 (Safety Reports Series No. 115).

42. INTERNATIONAL ATOMIC ENERGY AGENCY. Accidental Overexposure of Radiotherapy Patients in San José, Costa Rica. IAEA, Vienna, 1998.

43. INTERNATIONAL ATOMIC ENERGY AGENCY. Investigation of an Accidental Exposure of Radiotherapy Patients in Panama, IAEA, Vienna, 2001.

44. INTERNATIONAL ATOMIC ENERGY AGENCY. Accidental Overexposure of Radiotherapy Patients in Białystok, IAEA, Vienna, 2004.

45. WACK, G.; LALANDE, F. Inspection générale des affaires sociales. Résume du rapport ASN nº 2006 ENSTR 019 - IGAS n. RM 2007-015P sur l'accident de radiothérapie d'Epinal.

46. BACHELOT, R. Accident de radiothérapie d'Epinal: 300 nouveaux cas identifiés.TV5 Monde, set. 2007. Disponível em: <http://www.tv5.org/TV5Site/info/afp article.php?idrub=15\&xml=070907174527 .amce05j5.xml> Acesso em: 10 set. 2007.

47. SCOTTISH EXECUTIVE PUBLICATIONS. Report of an investigation by the Inspector appointed by Scottish Ministers for The Ionizing Radiation (Medical Exposures) Regulations, 2000. Unintended overexposure of patient Lisa Norris during radiotherapy treatment at the Beatson Oncology Centre, Glasgow in January 2006. Disponível em: <http://www.scotland.gov.uk/Publications/2006/10/27084909/0>. Acesso em: 12 abr. 2007.

48. PEREIRA,C.; CASTELLÓN,L. Quando o médico diz "Me desculpe". Isto é, 22 Fev. $2006 . \quad$ Disponível em: <http://www.terra.com.br/istoe/1896/medicina/1896_quando_o_medico_diz_me _desculpe.htm > Acesso em: 28 julho 2007.

49. INTERNATIONAL ATOMIC ENERGY AGENCY. Applying Radiation Safety Standards in Radiotherapy. IAEA, Vienna, 2006 (Safety Reports Series No. 38).

50. SOUZA, C. N.; MONTI, C. R.; SIBATA, C. H.. Recomendações para se evitar grandes erros de dose em tratamentos radioterapêuticos. Radiol. Bras., v. 34, n. 1, p. 29-37, 2001.

51. COZZI, L.; COZZI, F. A. Quality assurance in radiation oncology. A study of feasibility and impact on action levels of an in vivo dosimetry program during breast cancer irradiation. Radiother. Oncol., v. 47, n. 1, p. 29-36, 1998. 
52. KLEIN, E. E.; DRZYMALA, R. E.; et al. A change in treatment process with a modern record and verify system. Int. J. Radiat. Oncol. Biol. Phys., v. 42, n. 5, p. 1163-1168, 1998.

53. MACKLIS, R.M.; MEIER, T.; WEINHOUS, M.S. Error rates in clinical radiotherapy. J. Clin. Oncol., v. 16, n. 2, p. 551-556, 1998.

54. PATTON, G.A.; GAFFNEY, D.K.; MOELLER, J.H. Facilitation of radiotherapeutic error by computerized record and verify systems. Int. J. Radiat. Oncol. Biol. Phys., v. 56, n. 1, p. 50-57, 2003.

55. VALLI, M.C.; PRINA, M.; BOSSI, A., et al. Evaluation of most frequent errors in daily compilation and use of a radiation treatment chart. Radiother. Oncol., v. 32, n. 1, p. 87-89, 1994.

56. BRUNDAGE, M.D.; DIXON, P.F.; MACKILLOP, W.J.; et al. A real-time audit of radiation therapy in a regional cancer center. Int. J. Radiat. Oncol. Biol. Phys., v. 43, n. 1, p. 115-124(10), 1999.

57. OSTROM, L.T.; RATHIBUN, P.; CUMBERLIN, R.; et al. Lessons learned from investigations of therapy misadministration events. Int. J. Radiat. Oncol. Biol. Phys., v. 34, n. 1, p. 227-234(8), 1996.

58. PHILLIPS, B.L.; JIROUTEK, M.R.; TRACTON, G.; et al. Thresholds for human detection of patient setup errors in digitally reconstructed portal images of prostate fields. Int. J. Radiat. Oncol. Biol., v. 54, n. 1, p. 270-277, 2002.

59. KLEIN, E. E.; DRZYMALA, R. E.; JAMES, A. P.; MICHALSKI, J. Errors in radiation oncology: A study in pathways and dosimetric impact. J. Appl. Clin. Med. Phys., v. 6, n. 3, p. 81-94, 2005.

60. HALVORSEN, H.; Das, I. J.; Fraser, M.; et al. AAPM Task Group 103 report on peer review in clinical radiation oncology physics. J. Appl. Clin. Med. Phys., v. 6, n. 4, 2005.

61. REASON, J. Human error: models and management. BMJ, v. 320, p.768-770, 2000. Disponível em: <http://www.bmj.com/cgi/content/full/320/7237/768>. Acesso em: $1^{\circ}$ de ago. 2007.

62. DUNSCOMBE, P.B.; IFTODY, S.; PLOQUIN, N.; et al. The Equivalent Uniform Dose as a severity metric for radiation treatment incidents. Radiother. Oncol., v. 84, p. 64-66, 2007.

63. DUNSCOMBE, P.B.;EKAETTE, E.U.; LEE, R.C.; et al. Risk Analysis in radiation treatment: Application of a new taxonomic structure. Radiother. Oncol, v. 80, n. 3, p. 282-287, 2006.

64. PAWLICKI, T.; MUNDT, A.J. Quality in radiation oncology. Med. Phys., v. 34, n. 5, may. 2007. 